\title{
CDSMS
}

MICHEL BAUWENS,

VASILIS KOSTAKIS \& ALEX PAZAITIS

\section{PEER TO PEER \\ The Commons Manifesto}

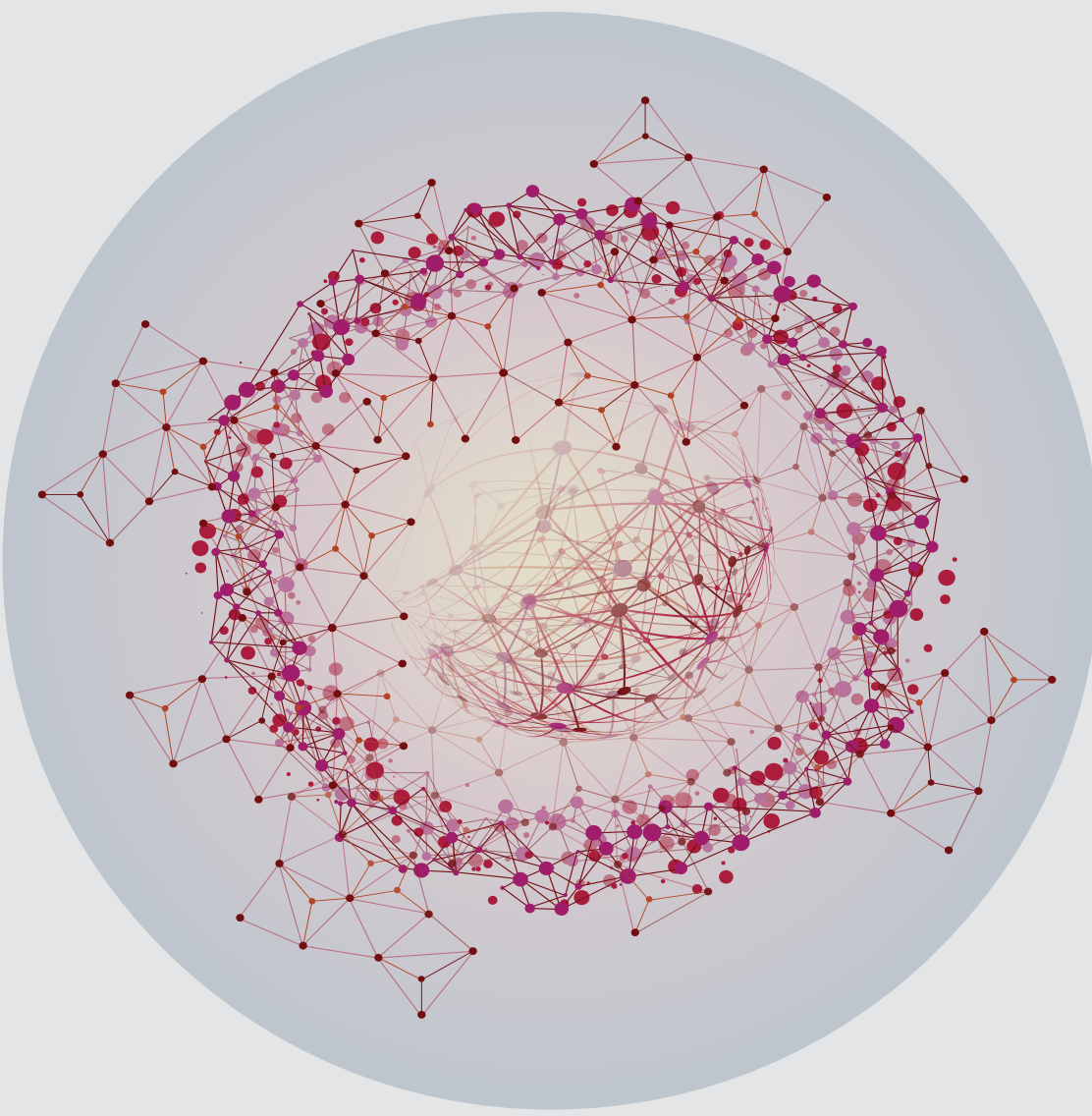




\section{Peer to Peer: \\ The Commons Manifesto}

Michel Bauwens, Vasilis Kostakis, and

Alex Pazaitis 


\section{Critical, Digital and Social Media Studies}

\section{Series Editor: Christian Fuchs}

The peer-reviewed book series edited by Christian Fuchs publishes books that critically study the role of the internet and digital and social media in society. Titles analyse how power structures, digital capitalism, ideology and social struggles shape and are shaped by digital and social media. They use and develop critical theory discussing the political relevance and implications of studied topics. The series is a theoretical forum for internet and social media research for books using methods and theories that challenge digital positivism; it also seeks to explore digital media ethics grounded in critical social theories and philosophy.

\section{Editorial Board}

Thomas Allmer, Mark Andrejevic, Miriyam Aouragh, Charles Brown, Eran Fisher, Peter Goodwin, Jonathan Hardy, Kylie Jarrett, Anastasia Kavada, Maria Michalis, Stefania Milan, Vincent Mosco, Jack Qiu, Jernej Amon Prodnik, Marisol Sandoval, Sebastian Sevignani, Pieter Verdegem

\section{Published}

Critical Theory of Communication: New Readings of Lukács, Adorno, Marcuse, Honneth and Habermas in the Age of the Internet

Christian Fuchs

https://doi.org/10.16997/book1

Knowledge in the Age of Digital Capitalism: An Introduction to Cognitive Materialism Mariano Zukerfeld

https://doi.org/10.16997/book3

Politicizing Digital Space: Theory, the Internet, and Renewing Democracy

Trevor Garrison Smith

https://doi.org/10.16997/book5

Capital, State, Empire: The New American Way of Digital Warfare

Scott Timcke

https://doi.org/10.16997/book6

The Spectacle 2.0: Reading Debord in the Context of Digital Capitalism

Edited by Marco Briziarelli and Emiliana Armano

https://doi.org/10.16997/book11

The Big Data Agenda: Data Ethics and Critical Data Studies

Annika Richterich

https://doi.org/10.16997/book14

Social Capital Online: Alienation and Accumulation

Kane X. Faucher

https://doi.org/10.16997/book16

The Propaganda Model Today: Filtering Perception and Awareness

Edited by Joan Pedro-Carañana, Daniel Broudy and Jeffery Klaehn

https://doi.org/10.16997/book27

Critical Theory and Authoritarian Populism

Edited by Jeremiah Morelock

https://doi.org/10.16997/book30

FORTHCOMING

Bubbles and Machines: Gender, Information and Financial Crises

Micky Lee 


\section{Peer to Peer: \\ The Commons Manifesto}

Michel Bauwens, Vasilis Kostakis, and

Alex Pazaitis

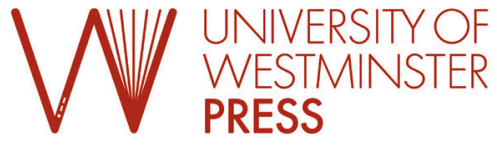

University of Westminster Press www.uwestminsterpress.co.uk 


\author{
Published by \\ University of Westminster Press \\ 115 New Cavendish Street \\ London W1W 6UW \\ www.uwestminsterpress.co.uk
}

Text @ Michel Bauwens, Vasilis Kostakis, and Alex Pazaitis 2019

First published 2019

Cover design: www.ketchup-productions.co.uk

Series cover concept: Mina Bach (minabach.co.uk)

Print and digital versions typeset by Siliconchips Services Ltd.

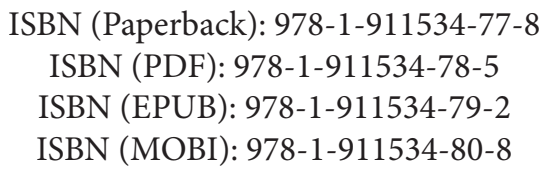

DOI: https://doi.org/10.16997/book33

This work is licensed under the Creative Commons Attribution-NonCommercialNoDerivatives 4.0 International License. To view a copy of this license, visit http://creativecommons.org/licenses/by-nc-nd/4.0/ or send a letter to Creative Commons, 444 Castro Street, Suite 900, Mountain View, California, 94041, USA. This license allows for copying and distributing the work, providing author attribution is clearly stated, that you are not using the material for commercial purposes, and that modified versions are not distributed.

The full text of this book has been peer-reviewed to ensure high academic standards. For full review policies, see: http://www.uwestminsterpress. co.uk/site/publish. Competing interests: The authors have no competing interests to declare.

Suggested citation:

Bauwens, M., Kostakis, V. and Pazaitis, A. 2019 Peer to Peer: The Commons Manifesto London: University of Westminster Press.

DOI: https://doi.org/10.16997/book33 License: CC-BY-NC-ND 4.0

To read the free, open access version of this book online, visit https://doi.org/10.16997/ book33 or scan this QR code with your mobile device:

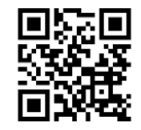


This work is dedicated to Jean Lievens, who passed away in 2016 after a lifetime of engagement for social justice and the commons. 



\section{Contents}

1 Introduction 1

1.1 What is $\mathrm{P} 2 \mathrm{P}$ and How is it Related to the Commons? 2

1.2 Are P2P Technologies Good or Bad? 3

1.3 How Does P2P Relate to Capitalism? 4

1.4 How is P2P to be Implemented in Practice? 6

1.5 Towards a Commons-centric Society?

2 P2P and a New Ecosystem of Value Creation 11

2.1 Diverse Skills and Motivations 11

2.2 Transparent Heterarchy 12

2.3 A New Ecosystem of Value Creation $\quad 12$

$\begin{array}{lll}2.4 & \text { Four Short Case Studies } & 19\end{array}$

2.5 From Contradictions to an Integrated Economic Reality 27

3 P2P and New Socio-technological Frameworks 33

3.1 Two Generic Models 34

3.2 The Extractive Model of Cognitive Capitalism 36

3.3 The Generative Model of Commons-based Peer Production 39

4 P2P and the Structure of World History 47

4.1 Four Modes of Exchange 47

4.2 Towards Associationism 50

5 A Commons Transition Strategy $\quad 55$

5.1 Pooling and Mutualizing Resources Wherever Possible 56

5.2 Introducing Reciprocity 56

5.3 From Redistribution to Empowerment and Predistribution 58

5.4 Subordinating the Capitalist Market 64

5.5 Organizing at the Local and Global Level 65

$\begin{array}{ll}\text { 5.6 Summary of our Proposals } & 67\end{array}$

5.7 A Last Word 68 
Acknowledgments 75

References

Endnotes 85

Index 


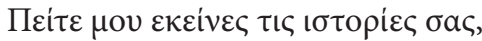

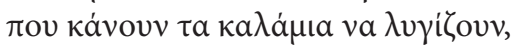

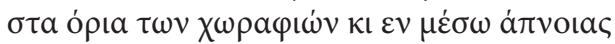

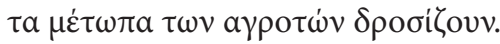

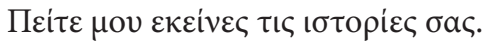

Tell me those stories of yours that make the reeds bend, at the edge of the fields, and that, amidst wind lull, cool the farmers' brow.

Tell me those stories of yours.

Thanasis Papakonstantinou, San Michele (avena un gallo) (2011) 



\section{CHAPTER ।}

\section{Introduction: Peer to Peer}

Not since Marx identified the manufacturing plants of Manchester as the blueprint for the new capitalist society has there been a more profound transformation of the fundamentals of our social life. As capitalism faces a series of structural crises, a new social, political and economic dynamic is emerging: peer to peer.

What is peer to peer (P2P)? Why is it essential for building a commons-centric future? How could this happen? These are the questions we try to answer, by tying together four of its aspects:

1. $\mathrm{P} 2 \mathrm{P}$ is a type of social relations in human networks, where participants have maximum freedom ${ }^{1}$ to connect.

2. $\mathrm{P} 2 \mathrm{P}$ is also a technological infrastructure that makes the generalization and scaling up of such relations possible.

3. $\mathrm{P} 2 \mathrm{P}$ thus enables a new mode of production and property.

4. P2P creates the potential for a transition to an economy that can be generative towards people and nature.

We believe that these four aspects will profoundly change human society. P2P ideally describes systems in which any human being can contribute to the creation and maintenance of a shared resource while benefiting from it. There is an enormous variety of such systems: from the free encyclopedia Wikipedia to free and open-source software projects, to open design and hardware communities, to relocalization initiatives and community currencies.

Our narrative is structured as follows. This chapter explains what this book is about by introducing some basic concepts. Chapter 2 describes how a new ecosystem of value creation is developed by implementing $\mathrm{P} 2 \mathrm{P}$ technologies and practices. Chapter 3 sheds light on how different interests can use P2P dynamics. Chapter 4 places P2P into the broader context of the world history.

How to cite this book chapter:

Bauwens, M., Kostakis, V. and Pazaitis, A. 2019. Peer to Peer: The Commons Manifesto. Pp. 1-10. London: University of Westminster Press. DOI: https://doi.org/10.16997/ book33.a. License: CC-BY-NC-ND 4.0 
Then, Chapter 5 proposes a generic strategy for a transition to a commonsoriented society. At the end of each chapter, the infographics visualize the central message of it.

\subsection{What is $\mathrm{P} 2 \mathrm{P}$ and How is it Related to the Commons? ${ }^{2}$}

Consensual connections between 'peers' characterize P2P computing systems. The computers in the network can interact with each other without going through a separate server computer. It is in this context that the literature started to characterize the sharing of audio and video files as $\mathrm{P} 2 \mathrm{P}$ file-sharing and that a part of the underlying infrastructure of the Internet, like its data transmission infrastructure, has been called P2P. So, in a P2P network, peers are equally privileged, equipotent participants in the application that the network performs.

Let us now assume that behind those computers are human users. A conceptual jump can be made to argue that users now have a technological affordance (a tool) that allows them to interact and engage with each other more efficiently and on a global scale. P2P is a social/relational dynamic through which peers can freely collaborate with each other and create value in the form of shared resources. It is this mutual dependence of the relational dynamic and the underlying technological infrastructure that facilitates it, which creates the linguistic confusion between P2P as a technological infrastructure and P2P as a human relational dynamic.

However, a technological infrastructure does not have to be fully P2P to facilitate P2P human relationships. For example, compare Facebook or Bitcoin with Wikipedia or free and open-source software projects. They all utilize P2P dynamics, but they do so in different ways and with different political orientations (Chapter 3 discusses this issue).

$\mathrm{P} 2 \mathrm{P}$ is therefore primarily a mode of relationship that allows human beings to be connected and organized in networks, to collaborate, produce and share. The collaboration is often permissionless, meaning that one may not need the permission of another to contribute. The P2P system is, therefore, generally open to all contributors and contributions. The quality and inclusion of the work are usually determined 'post-hoc' by a layer of maintainers and editors, as in the case of Wikipedia.

$\mathrm{P} 2 \mathrm{P}$ can also be a mode to allocate resources that do not involve any specific reciprocity between individuals but only between the individuals and the collective resource. For example, a developer is allowed to develop her software based on an existing piece of software distributed under the widely used GNU General Public License, only if her final product is available under the same kind of free and open-source license (in this case, GNU General Public License).

In the realm of information, which can be shared and copied at low marginal cost, the P2P networks of interconnected computers used by collaborating 
people can provide shared functionalities for the creation and maintenance of collective resources. However, P2P does not only refer to the digital sphere and is not solely related to high technology. P2P can generally be synonymous with 'commoning', in the sense that it describes the capacity to contribute to the creation and maintenance of any shared resource. As discussed in Chapter 4, P2P commoning has always existed, but without the scale that computing affords it.

There are multiple definitions of the 'commons.' We adhere to David Bollier's (2014a) characterization of the commons as a shared resource, co-governed by its user community according to the rules and norms of that community ${ }^{3}$. The sphere of the commons may contain either rivalrous goods and resources, which two individuals cannot both have at the same time or non-rival goods and resources, whose use does not deplete them. These types of goods or resources have been inherited, or they are human-made.

For example, a type of commons may include the gifts of nature, such as the water and land, but also shared assets or creative work such as cultural and knowledge artifacts. Our focus here is on the digital commons of knowledge, software, and design because they are the 'new commons' (Benkler, 2014). These commons represent the pooling of productive knowledge that is an integral part of the capacity for any production, including physical goods.

$\mathrm{P} 2 \mathrm{P}$ is arguably moving from the periphery of the socio-economic system to its core, thereby also transforming other types of relationships, such as market dynamics, state dynamics, and reciprocity dynamics. These dynamics become more efficient and obtain advantages by utilizing the commons. P2P relations can effectively scale up, mainly because of the emergence of Internet-enabled P2P technologies: small-group dynamics can now apply at the global level.

\subsection{Are P2P technologies Good or Bad?}

We do not claim that a particular technology may lead to one inevitable social outcome. We recognize the critical role that technologies play in social evolution and the new possibilities they create if specific human groups successfully utilize them. Different social forces invest in this potential and use it to their advantage, struggling to benefit from its use. Technology is, therefore, best understood as a focus of social struggle, and not as a predetermined 'given' that creates just one technologically determined future.

Still, when social groups appropriate a particular technology for their purposes, then social, political and economic systems can change. An example is the role that the invention of the printing press, associated with other inventions, played in transforming European society (Eisenstein, 1983/2012).

The fast-growing availability of information and communication technology enables many-to-many communication and allows an increasing number of humans to communicate in ways that were not technically possible before. This, in turn, makes possible massive self-organization up to a global scale. It 
also allows for the creation of a new mode of production and new types of social relations outside of the state-market nexus.

The Internet creates opportunities for social transformation. In the past, with pre-digital technologies, the costs of scaling regarding communication and coordination made hierarchies and markets necessary as forms of reducing these costs. Hence societies that scaled through their adoption 'outcompeted' their tribal rivals. Today, by contrast, it is also possible to scale projects through new coordination mechanisms, which can allow small group dynamics to apply at the global level. It is, thus, possible to combine 'flatter' structures and still operate efficiently on a planetary scale. This has never been the case before.

\subsection{How does P2P Relate to Capitalism?}

We are living through a historical moment in which networked and relatively horizontal forms of organization can produce complex and sophisticated products. The latter are often better than the artifacts produced through statebased or market-based mechanisms alone. Consider how the user-generated Wikipedia displaced the corporate-organized Encyclopedia Britannica, how the open-source Apache HTTP server outcompeted Microsoft server software, or how Wikileaks survived the assaults of some of the world's most powerful states.

The hybrid forms of organization within P2P projects do not primarily rely on either hierarchical decisions or market pricing signals, but on forms of mutual coordination mechanisms that are remarkably resilient. Peer production (often also 'P2P production') has been broadly portrayed as a generic form of self-organization among loosely-affiliated individuals that volunteer on equal footing to reach a common goal. When it comes to the production of information or culture, where the means of production are often more distributed, peer production presents a number of systemic advantages over managerial hierarchies and markets (Benkler, 2002). These advantages in turn entail an 'immanent', but also a 'transcendent' aspect in relation to the dominant economic system.

On one hand, these emerging mutual coordination mechanisms increasingly become an essential ingredient of capitalism. They are reinforced and enabled by capital investment to rejuvenate its circulation. This is the 'immanent' aspect of peer production that changes the current dominant forms. But on the other hand, such mechanisms can become the vehicle of new configurations of production and allocation, no longer dominated by capital and state. This is the 'transcendent' aspect of peer production, as it creates a new overall system that can subsume the other forms. In the first scenario, capital and state subsume the commons under their direction and domination, leading to a new type of commons-centric capitalism. In the second scenario, the commons, its 
communities, and institutions become dominant and, thus, may adapt state and market modalities to their interests.

As we discuss in the following chapters, peer production is a prototype of a new mode of production, rather than a full mode of production today. This means that currently peer production is in a mutually dependent relationship with capital, which uses both the processes and virtue of peer production for its own gain. Moreover, as prominent cases of $\mathrm{P} 2 \mathrm{P}$ projects have gradually delineated a winning strategy in the new economy, distorted forms of P2Penabled production have surfaced. In name, they endorse the same values of community-driven initiatives, though substantially they merely approximate a community-related narrative to form a new locus for accumulation (O'Dwyer, 2013). The key, therefore, lies in strategies that aim to keep the surplus value within the cycle of peer production itself and allow genuine $\mathrm{P} 2 \mathrm{P}$ projects to reverse this process. Elsewhere, we have expressed this as transitioning 'from the communism of capital to capital for the commons' (Bauwens and Kostakis, 2014). In Chapter 5 we discuss those strategies in more detail.

Yet, the new forms of collaborative production that rely on P2P mechanisms do have some hierarchies. Nevertheless, they generally lack a hierarchical command structure for the production process itself. Peer production has introduced the capacity to organize complex global projects through extensive mutual coordination. What market pricing is to capitalism and planning is to state-based production, mutual coordination is to peer production.

As a result, the emergence and scaling of these $\mathrm{P} 2 \mathrm{P}$ dynamics point to a potential transition in the main modality by which humanity allocates resources: from a market-state system that uses hierarchical decision-making (in firms and the state) and pricing (amongst companies and consumers), towards a system that uses various mechanisms of mutual coordination. The market and the state will not disappear, but the configuration of different modalities - and the balance between them - will be radically reconfigured.

None of this implies that the P2P transition will lead to a utopia, nor that it will be easy. Indeed, if the history of previous socio-economic transitions is any guide, the transition will most likely be messy. Just as P2P is likely to solve some problems in our current society, it will create others in the new one. Nevertheless, this remains a worthwhile social progress to strive for, and even if $\mathrm{P} 2 \mathrm{P}$ relations do not become the dominant social form, they will profoundly influence the future of humanity.

Summarizing the relationship between the relational and technological aspects, the P2P relational dynamic - strengthened by particular forms of technological capacities - may become the dominant way of allocating the necessary resources for human self-reproduction, and thus replace capitalism as the dominant form. This will require a stronger expansion of this P2P modality not just for the production of 'digital goods', but also for the production of physical goods. 


\subsection{How is P2P to be Implemented in Practice?}

While $\mathrm{P} 2 \mathrm{P}$ is emerging as a significant form of technological infrastructure for various social forces, the direction of its implementation makes all the difference. Not all P2P is equal in its effects. Different forms of P2P technological infrastructure are identified, each of which leads to different forms of social and political organization.

On the one side, for example, we can consider the capitalism of Facebook, Uber or Bitcoin. On the other, we can look at the commons-oriented models of Wikipedia, Enspiral, Farm Hack, WikiHouse or free and open-source software projects (discussed in Chapters 2 and 3). Adopting this or that form of P2P technological infrastructure is the locus of social conflict because the choice between them has consequences for what may or may not be possible.

P2P enables an emerging mode of production, named commons-based peer production, characterized by new relations of production. In commons-based peer production, contributors create shared value through open contributory systems, govern the work through participatory practices, and create shared resources that can, in turn, be used in new iterations. This cycle of open input, the participatory process, and commons-oriented output is a cycle of accumulation of the commons, which parallels the accumulation of capital.

At this stage, commons-based peer production is a prefigurative prototype of what could become an entirely new mode of production and a new form of society. It is currently a prototype since it cannot as yet fully reproduce itself outside of mutual dependence with capitalism. This emerging modality of peer production is not only productive and innovative 'within capitalism,' but also in its capacity to solve some of the structural problems that have been generated by the capitalist mode of production. In other words, it represents a potential transcendence of capitalism. That said, as long as peer producers or commoners cannot engage in their self-reproduction outside of capital accumulation, commons-based peer production remains a proto-mode of production, not a full one.

Peer production can be innovative within the context of capitalist competition because firms that can access the knowledge commons possess a competitive advantage over firms that use proprietary knowledge and can only rely on their research (Tapscott and Williams, 2005; Benkler 2006; von Hippel, 2016). For example, by mutualizing the development of software in an open network, firms obtain considerable savings in their infrastructural investments. In this context, peer production is a mutualization of productive knowledge by capitalist coalitions themselves, with IBM's investments in free and open-source software projects, a case in point (Tapscott and Williams, 2005).

This capitalist investment is not a negative thing in itself, but rather a condition that increases the societal investment needed for a P2P-based transition. Both productive and managerial classes move towards $\mathrm{P} 2 \mathrm{P}$ because it solves some structural issues of the current system. Capital flows towards P2P 
projects, and even though it distorts $\mathrm{P} 2 \mathrm{P}$ to use it to prolong the dominance of the old economic models, it simultaneously creates new ways of thinking in society that undermine that dominance.

Nevertheless, the new class of commoners cannot rely on capitalist investment and practices. They must use skillful means to render commons-based peer production more autonomous from the dominant political economy. Eventually, we may arrive at a position where the balance of power is reversed: the commons and its social forces become the dominant modality in society, which allows them to force the state and market modalities to adapt to its requirements. So we should escape the situation in which capitalists co-opt the commons, and head towards a situation in which the commons capture the capital, and make it work for its development.

This proposed strategy of reverse co-optation has been called 'transvestment' by Dmytri Kleiner and Baruch Gottlieb (Kleiner, 2010; 2016). Transvestment describes the transfer of value from one modality to another. In our case, this would be from capitalism to the commons. Thus transvestment strategies aim to help commoners become financially sustainable and independent. ${ }^{4}$ Such strategies are being developed and implemented by commons-oriented entrepreneurial coalitions such as the Enspiral network or Sensorica (see Chapter 2).

Digital commons of knowledge, software, and design are non-rival resources enriched through usage (thus they could even be considered 'anti-rival'). It is here that full sharing and the full ability for contributions must be preserved. However, we do engage with rival resources in the added value services and products built around these commons. Here the commons should be protected from capture by capital. It is in this cooperative sphere of physical and service production where reciprocity rules should be enforced. We propose to combine non-reciprocal sharing in the digital sphere, with reciprocal arrangements in the sphere of physical production. Thus, in our vision, commons-based peer production - as a full mode of production - combines commons and cooperativism (see Chapter 4).

\subsection{Towards a Commons-centric Society?}

At that point, if the move from microeconomic P2P communities to a new 'macroeconomic' dominant modality of value creation and distribution is successful, a transition phase towards a commons-centric economy and society can occur. This will be the revolution of our times, and a fundamental shift in the rules and norms that decide what value is and how it is produced and distributed in society. In short: a shift to a new post-capitalist value regime.

$\mathrm{P} 2 \mathrm{P}$ is considered to be both a social relation and a mode of allocation, as a socio-technological infrastructure and as a mode of production, and all these aspects when combined contribute to the creation of a new post-capitalist model, a new phase in the evolution of the organization of human societies. 
This will necessitate a discussion about economic and political transitions. At the microeconomic level of commons-based peer production, P2P dynamics are already creating the institutional seedlings prefiguring a new social model.

P2P could lead to a model where civil society becomes productive through the participation of citizens in the collaborative creation of value through commons. In this pluralistic commonwealth, multiple forms of value creation and distribution will co-exist, but most likely around the universal attractor that is the commons. We do not argue for a 'totalitarianism' of the commons, but to make the commons a core institution that 'guides' all other social forms including the state and the market - towards achieving the greatest common good and the maximum autonomy. 

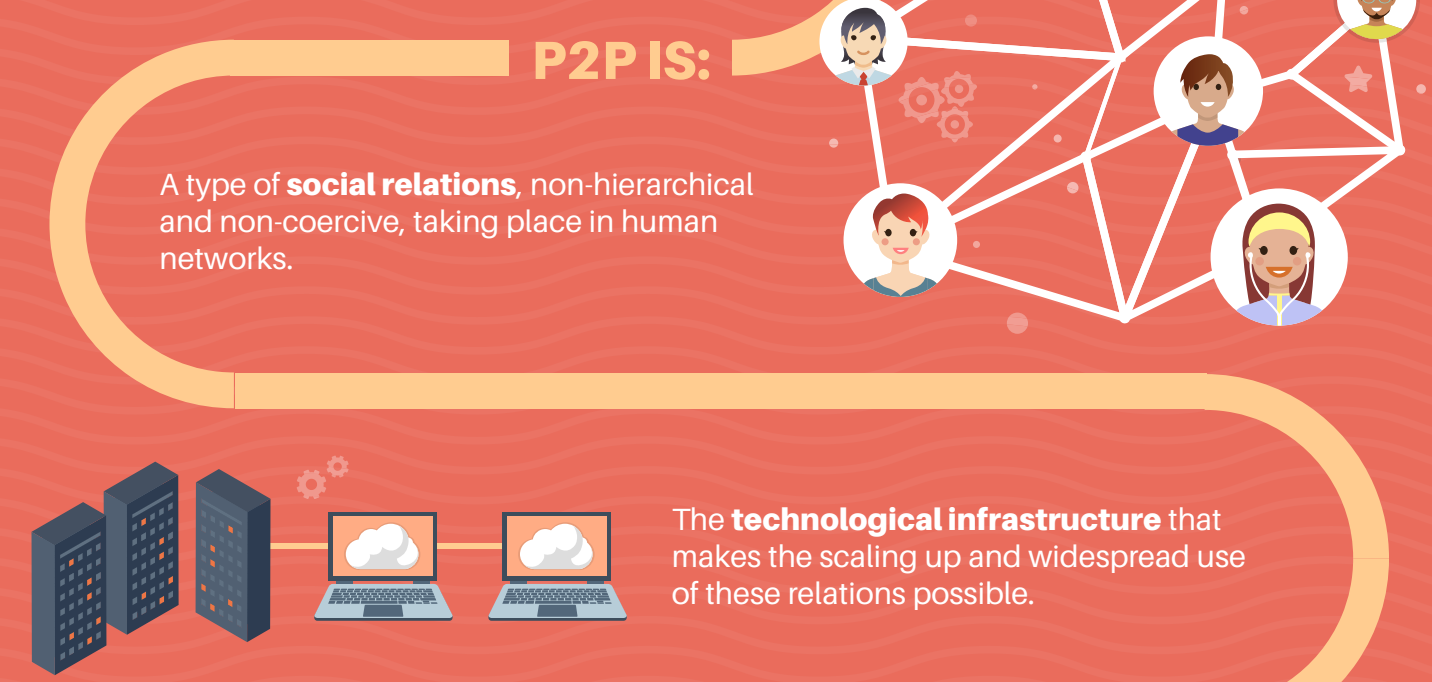

The technological infrastructure that makes the scaling up and widespread use of these relations possible.

P2P enables a new mode of production

building on the first two aspects.
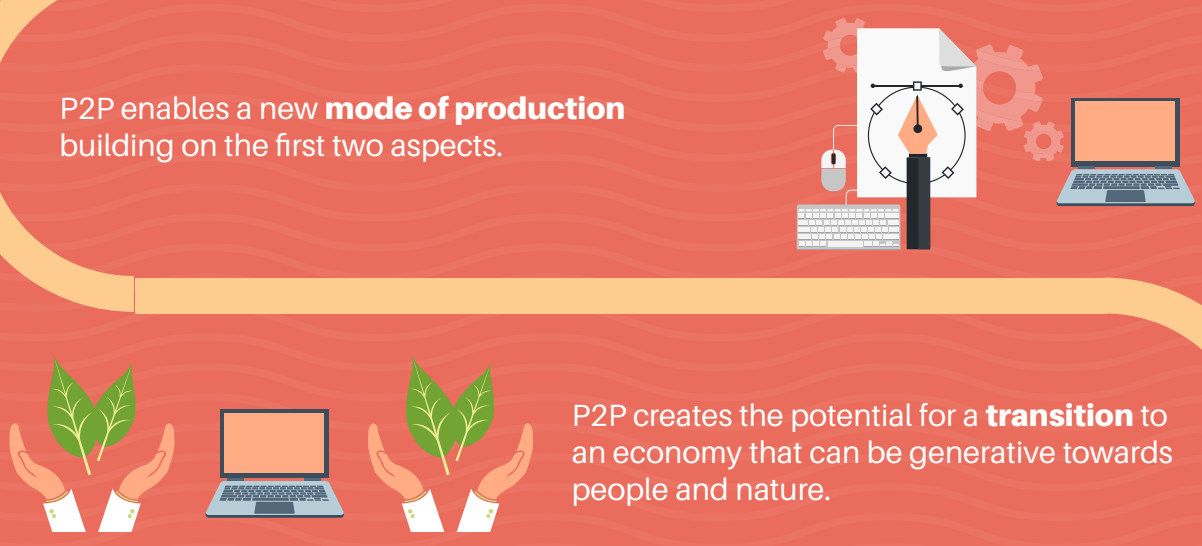

P2P creates the potential for a transition to an economy that can be generative towards people and nature.

\section{HOW DO COMMONS AND P2P WORK TOGETHER?}

The relation of P2P with the Commons is one of enabling capacities for contributive actions. P2P creates the conditions to optimize the specific what (resource), who (community) and how (rules) of commoning.

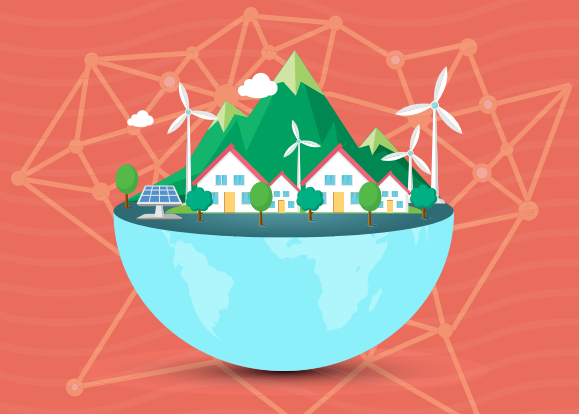




\section{CHAPTER 2}

\section{P2P and a New Ecosystem of Value Creation}

The P2P capacity to relate to each other over the Internet entails the emergence of what Yochai Benkler (2006) has called 'commons-based peer production' (СBPP). CBPP is a new pathway of value creation and distribution, through which $\mathrm{P} 2 \mathrm{P}$ infrastructures allow individuals to communicate, self-organize and, ultimately, co-create non-rivalrous use-value, in the form of digital commons of knowledge, software, and design. Think of the free encyclopedia Wikipedia, the myriad of free and open-source projects (e.g. Linux, Apache HTTP Server, Mozilla Firefox, Wordpress) or open design communities such as WikiHouse, RepRap, and Farm Hack.

\subsection{Diverse Skills and Motivations}

CBPP is fundamentally different from the incumbent models of value creation under industrial capitalism. In the latter, the owners of the means of production hire workers, direct the work process and sell products for profit maximization. Such production is organized by allocating resources through price signals, or through hierarchical command.

In contrast, CBPP is in principle open to anyone with the skills to contribute to a joint project: the knowledge of every participant is pooled. These participants may be paid, but not necessarily. Precisely because CBPP projects are open systems in which knowledge can be freely shared and distributed, anyone with the right knowledge and skills can contribute, either paid by companies, clients or not at all. In these open systems, there are many reasons to contribute beyond or besides that of receiving monetary payment.

CBPP allows contributions based on all kinds of motivations, but most importantly on the desire to create something mutually useful to those contributing. People generally contribute because they find it meaningful and useful.

How to cite this book chapter:

Bauwens, M., Kostakis, V. and Pazaitis, A. 2019. Peer to Peer: The Commons Manifesto. Pp. 11-32. London: University of Westminster Press. DOI: https://doi.org/10.16997/ book33.b. License: CC-BY-NC-ND 4.0 
For the productive communities as well as simple users, the orientation of their work is most often on use-value creation, not exchange-value.

\subsection{Transparent Heterarchy}

In CBPP some contributors may be paid/employed but all (in collaboration with groups and individuals that are not) produce commons. Hence, the work is not directed by corporate hierarchies, but through the mutual coordination mechanisms of the productive community. CBPP is based on open and transparent systems, in which everyone can see the signals of the work of others, and can, therefore, adapt to the needs of the system as a whole.

CBPP is often based on stigmergic collaboration. In its most generic formulation, stigmergy is the phenomenon of indirect communication among agents and actions (Marsh and Onof, 2007, 1). Think how the ants or the termites exchange information by laying down pheromones (traces). Through this indirect form of communication, these social insects manage to build complex structures such as trails and nests. An action leaves a trace that stimulates the performance of a next action, by the same or a different agent (ant, termite or commoner in the case of CBPP).

Stigmergy has been used to analyze forms of complex self-organization in various domains, from insects to robotics and the social web, where planning, control, communication, simultaneous presence and even mutual awareness are not required to coordinate collective action (Heylighen, 2016). In CBPP, stigmergic collaboration enables 'collective, distributed action' by mediating social negotiation via Internet-based technologies (Elliott, 2006). For example, see how free and open-source software code lines and Wikipedia entries are produced in a distributed and ad hoc manner through the contributions from large numbers of people.

Further, CBPP projects do have systems of quality control that represent a kind of benevolent hierarchy or heterarchy. These 'maintainers' or 'editors' protect the integrity of the system as a whole and can refuse contributions that endanger the integrity of the system. However, and this is crucial, they do not coerce work.

To recap, CBPP is based on the open input; a participatory process of coordinating the work; and a commons as output.

\subsection{A New Ecosystem of Value Creation}

\subsubsection{On Value}

In capitalism, value is almost exclusively perceived in the exchange of commodities. Markets are the primary institutions enabling and regulating exchange 
and, hence, the creation and distribution of value. In antiquity, Aristotle offered one of the first treatises on value in The Nicomachean Ethics (2009). He too held that value is expressed in the exchange of two goods, but claimed that it is the usability of those goods that make them desirable in an exchange. Aristotle, thus, had already evinced one of the fundamental dichotomies of economic affairs: use-value and exchange-value.

However, Aristotle's distinction of use-value and exchange-value already implied their close interrelation, whereas the former was arguably held to be a prerequisite to the latter. Value was, then, defined by the desire or need for the products of human labour (things or actions). Exchange was all but an institution crystallizing this interaction.

Similarly, in the medieval times, markets were also present. However, the value of goods, as perceived at the time by philosophers like Albert the Great and Thomas Aquinas, served a broader social necessity, bound to ethical and legal constraints (Baldwin, 1959; Sewall, 1901). For instance, the price of grain was regulated so that everyone had food in a medieval city, whereas speculative traders were put to death. This is still exchange-value, but it is not related to a 'rational' economic aim; instead, it is embedded in social constraints.

The pursuit of economic affairs before the industrial revolution was not merely some efficiency in equating the value of commodities. There was a notion of a 'just price' reflecting the true value of goods in exchange, one that provided fair compensation for all the agents involved. Subsequently, economics as a discipline subsisted as part of justice and moral philosophy. It was not until the classical political economists and under the influence of established capitalist institutions that elements like a 'natural' order (Smith, 1776), scarcity (Ricardo, 1821) and command of possession (Mill, 1848) were associated with commodity exchange. With ensuing generations of economists, theoretical discussion on value gradually abated, and the concept became almost interchangeable with the market price. An exaggerated version of this trend has developed in finance terminology, with value acquiring one superficial attribute wholly divorced from productive activities.

Since the aftermath of the 2007 crash, a reintroduction of theoretical explorations on the topic of value has surfaced. This trend is connected to the intensified contradictions between what is being 'valued' in economic affairs and what is perceived as valuable. Many of the classical debates have been revived, such as between objective and subjective perceptions of value. In this direction, a substantial body of theoretical inquiries has delved into the relevance of the labour theory of value and its Marxist interpretation, with special reference to the digital economy. Some scholars (e.g. Rigi, 2015; Fraysse, 2015) consider the disconnect of surplus value from labour processes. Other approaches (e.g. Hardt and Negri, 2011; Arvidsson and Peitersen, 2013) have focused on the breadth of 'social production' and the subsequent dismissal of labour time as a relevant measure. Lastly, a stream of critical analyses (e.g. Fuchs, 2015) contest 
the purported post-capitalist shape of the digital economy and thus reaffirmed the relevance of the labour theory of value.

From a different angle, Mazzucato (2018) touches upon some very timely issues by revisiting the dispute about productive and unproductive activities through the graphically presented colloquy between 'makers' and 'takers'. Stemming from the heterodox tradition, she attempts to debunk the financialized interpretations of value creation and re-connect it to material production. Most importantly, Mazzucato emphasizes the influence, even in their absence, of ideas on value on policymaking.

The common element in all the above insights is a general suggestion of a 'crisis of value' (Arvidsson et al., 2008), signalling a turning point in the dominant value regime and the way it recognizes new value and how it is created.

Elsewhere (Pazaitis et al., 2017a) we have observed a tentative transition of value regimes evident on three layers: (a) production of value; (b) record of value; and (c) actualization of value. The first layer refers to the mode of production that provides the basis for meaningful contributions to societal needs. The capitalist mode of production has been associated with private ownership and control of the means of production, hierarchical command of labour and the production of surplus value. In contrast, CBPP is characterized by collective ownership and management of resources, horizontal coordination, and the production of social value.

The second layer concerns a systematic assessment that provides the means to motivate and nourish such interaction, allowing the system to scale and become sustainable. In this layer, the chosen method to track and record the produced value, by and large, crystallizes the logic of the established economic system. Sombart (1902) discussed the role of double-entry bookkeeping in unleashing and stimulating the business activities of capitalism. Double-entry bookkeeping conveyed the logic of mathematical precision and abstraction to business operations and hard-wired it into the price system. Similarly, seed forms of commons-oriented coalitions have developed their systems of value representation to encapsulate the polycentricity, fluid coordination, and multiplicity of contributions found in CBPP (Bauwens and Niaros, 2017a).

The third layer includes the development of the systems of institutions that guide meaningful interaction within the logic of the dominant economic system. It is where value becomes real, justifying people's choices and struggles. In capitalism, the fundamental value of goods is expressed through their quantitative relation with money, which allows them to be exchanged as commodities (Fuchs, 2010). Their representation in monetary units determines both the means and the ends of the productive process and money becomes the primary commodity acquiring exchange-value. Conversely, in the commons economy, exchange serves the circulation of the commons. The commons thus rationalize new types of social relations, along with the institutions that make the accompanying value forms perceptible. 
However, this does not necessarily mean that exchange as a social practice or exchange-value is not relevant to the commons. Polanyi (1957) implied a clear distinction between exchange, markets and a 'market economy', i.e. an economic system controlled, regulated and directed by markets alone. The practice of exchange alone does neither presuppose nor determine a market system as the central locus of value in society. Polanyi viewed markets as merely one of the available forms of resource allocation, along with redistribution and reciprocity. While all the various forms can operate simultaneously, it is when a bulk of human livelihood becames dependent on markets that compels the shift to the market economy.

As already argued, CBPP is socially embedded and oriented towards the creation of use-value. It does not rely on individual motives to gain from barter and trade to allocate resources; sharing freely is considered virtuous. However, our argument is not that we don't have exchange-value in a commons economy, but that exchange-value is not necessarily the value of capitalist commodities. Not all exchange of value is capitalist exchange-value.

There is of course no consistent definition of value in different societies and times. Value as a term alone has no concrete meaning, but it is to be interpreted within a broader social whole (Graeber, 2001). In capitalism, value is mostly related to things, that is, commodities, and is expressed in their exchange for one another based on a nominal representation as money. In the realm of $\mathrm{P} 2 \mathrm{P}$, value is attributed to contributions as a shared effort among peers, and is reflected in the shared significance of those contributions as recognized by those peers.

Hence, value for us is self-determined by communities as contributions. The labour theory of value indeed rules capitalism, yet it co-exists with various forms of value in non-capitalist modes. Therefore, the aim is not a shift from one monolithic value regime to another one, excluding all previous activities. Instead, we make the case for value sovereignty, that is enabling communities and societies to self-determine value for themselves and develop accounting practices to allow this recognition to take place.

In a transition period, there is value competition: a dominant form of value operates under the capitalist logic, and a new social logic of value is emerging in seed forms. Additionally, there is the environmental underpinning of value, integrating a critical recognition of both ecological and social value. Positive and negative externalities have to be re-integrated in our economic system. Hence, recognition of different forms of value is necessary.

\subsubsection{The Ecosystem}

Through CBPP we observe the emergence of a new ecosystem consisting of three institutions: the productive community; the commons-oriented entrepreneurial coalition(s); and the for-benefit association. Our description cannot be all-inclusive because each ecosystem is unique. Moreover, it cannot be 


\begin{tabular}{|l|l|l|l|l|l|}
\hline $\begin{array}{l}\text { Productive } \\
\text { community }\end{array}$ & Linux & Mozilla & GNU & Wikipedia & Wordpress \\
\hline $\begin{array}{l}\text { Entrepreneurial } \\
\text { coalition }\end{array}$ & $\begin{array}{l}\text { e.g. Linux } \\
\text { Professional } \\
\text { Institute, } \\
\text { Canonical }\end{array}$ & $\begin{array}{l}\text { e.g. Mozilla } \\
\text { corporation }\end{array}$ & $\begin{array}{l}\text { e.g. Red Hat, } \\
\text { Endless, } \\
\text { SUSE }\end{array}$ & $\begin{array}{l}\text { e.g. Wikia } \\
\text { company }\end{array}$ & $\begin{array}{l}\text { e.g. } \\
\text { Automatic } \\
\text { company }\end{array}$ \\
\hline For-benefit \\
association & $\begin{array}{l}\text { Linux } \\
\text { Foundation }\end{array}$ & $\begin{array}{l}\text { Mozilla } \\
\text { Foundation }\end{array}$ & $\begin{array}{l}\text { Free } \\
\text { Software } \\
\text { Foundation }\end{array}$ & $\begin{array}{l}\text { Wikimedia } \\
\text { Foundation }\end{array}$ & $\begin{array}{l}\text { Wordpress } \\
\text { Foundation }\end{array}$ \\
\hline
\end{tabular}

Table 1: CBPP Ecosystems.

definite since we are dealing with a rapidly evolving mode of production. The aim is to offer a birds-eye-view of the expanding universe of CBPP. The following table includes just five of the eldest and well-known CBPP ecosystems:

The productive community consists of all the contributors to a project, and how they coordinate their work. The members of this institution may be paid or may volunteer their contributions because of some interest in the use-value of this production. However, all of them produce the shareable resource.

The second institution is the commons-oriented entrepreneurial coalition, which attempts to create either profits or livelihoods by creating added value for the market, based on shared resources. The participating enterprises can pay contributors. The digital commons themselves are most often outside the market because they are not scarce.

What is crucially important in the relations between the entrepreneurs, the community and the commons on which they depend, is whether their relationship is generative or extractive. Of course, extraction/generation are polarities, and every entity is expected to present a mixture. Nevertheless, this dichotomy infers a break between entrepreneurship and capitalism: one can be an entrepreneur without (or with less) capital, while capital accumulation and the profit motive are no longer imperative. Entrepreneurship in our times can be seen as an expression of the desire for autonomy contrasted with the repression of inhibited salaried work. There is an emerging class of autonomous and precarious workers, often involved in auto-entrepreneurship, which are potential allies, not enemies of the commons.

Entrepreneurship, like many notions, has changed vastly in meaning over time. Today the dominant vision of the entrepreneur is someone who is independent and takes all the risk to play the capitalist lottery. In contrast, if one wants a salary, she needs to obey. So, if one is a worker, she has a contract of subordination. The notion of autonomous workers is associated with the freedom to decide and interact with the market and the commons as one wishes in a permissionless manner.

The roots of the term 'entrepreneurship' in economics are found in Cantillon (2010). Etymologically it derives from the French word 'entreprendre', which 
translates to 'undertake', i.e. to set about/attempt; to assume responsibility or obligation. Therefore, in economics entrepreneurship is associated with various individual and collective functions entailing these properties (Tsaliki, 2006), including coordination and organization of (existing) knowledge and capabilities (Say, 1803) and the bearing of uncertainty (Knight, 1921). German Historical scholars (von Schmoller, 1989; 1901; Weber, 1920, Sombart, 1909) have attributed an institutional dimension to the term that became interwoven with the capitalist spirit (Ebner, 2005).

Schumpeter (1934) exaggerated this view by portraying entrepreneurship as an almost mythical function beyond the confines of the capitalist political economy. For him, the spirit of the entrepreneur would manifest itself in any particular social and institutional setting, in the assumption of a leading position, associated with dynamic change and novelty. Schumpeter often criticized Marx for not having a theory of entrepreneurship, since in Marxian thought the entrepreneur is indistinguishable from the capitalist, as the owner of the means of production.

However, Marx's concern was not the function of the entrepreneur, but the source of his reward for fulfilling this role, i.e., the profit. The remuneration of the entrepreneur and thus the rationale for his very existence is rooted in social relations of production that allow for the appropriation of surplus value from unpaid labour. Especially in the 'digital economy', the Schumpeterian quasi-heroic entrepreneur has been disfigured into a false narrative that on the surface celebrates economic freedom, openness and individual excellence, but which merely serves as a smokescreen for precarity and (self-)exploitation.

From a different perspective, an alternative narrative has been developed by commons-based initiatives, spurring a series of entrepreneurial activities, in which the pursuit of economic profit is not the primary motivation, when present at all. Conversely, these entrepreneurs explicitly aim to secure a livelihood and the sustainability of their contribution to a social mission, that they hold as meaningful in itself. Simultaneously, they contribute to the commons (e.g. by sharing knowledge and free software) and create the conditions for more commoners to emancipate themselves and earn their livelihood through their contributions.

Commons-oriented entrepreneurial coalitions can thus be viewed as transitional livelihood organizations. Livelihood is understood as the human capacity to reproduce oneself and acquire the means of life. It varies among different people and different contexts, but it is not necessarily restricted to subsistence. It is also connected to the 'good life' or often referred as 'thrivability'.

This notion of entrepreneurship arguably goes beyond the Marxian critique by introducing a break between the profit motive and the entrepreneurial function. It is the antipode of those neo-liberal convictions viewing entrepreneurship as some sort of 'excellent' quality, with which certain privileged people are born. Leadership in commons-oriented initiatives is a function and a responsibility that can be assumed ad hoc and permissionlessly by those most 
capable and motivated in a given situation. Novelty and change are normative, and they are connected to the circulation of the commons and the empowerment of commoners. Commons-based entrepreneurial coalitions thus serve to transcend the elements of freedom, autonomy, and creativity associated with entrepreneurship, by placing them in a contributory context.

Of particular interest is John Wood's (1990) proposal to change the language from 'entrepreneur' to 'entredonneur', which hints at this distinction between extractive and generative entrepreneurship mentioned above. This dichotomy signifies a shift from a logic of 'how can I put myself in between and extract a surplus' to 'how can I build a livelihood around my contributions and share it fairly while recognizing natural limits in the process'. In the same direction, Marjorie Kelly (2012) introduces non-capitalist/generative enterprises, which again comes back to the distinction between markets and capitalism. We can have collectively owned market agents that have social and environmental goals and use their surplus for these goals, rather than accumulation.

To demonstrate the difference between extractive and generative, think of industrial agriculture and permaculture. In the former, the soil becomes more impoverished and less healthy, while in the latter case the soil becomes more productive and healthier.

Extractive entrepreneurs seek to maximize their profits, and generally do not sufficiently reinvest in the maintenance of productive communities. Like Facebook, they do not share any profits with the co-creating communities on which they depend for their value creation and realization. Like Uber or Airbnb, they tax exchanges but do not directly contribute to the creation of transport or hospitality infrastructures. So, the problem is that though they develop useful services that reuse unused resources, they do this in an extractive manner. They may facilitate these services, but they also create competitive mentalities: participants of their systems often construct new material infrastructures, e.g. new buildings to rent or cabs to hire, in their effort to maximize profits. Moreover, extractive enterprises may free ride on a whole set of social or public infrastructures (e.g. roads as in the case of Uber).

On the other hand, generative entrepreneurs create added value around these communities. Seed-forms of commons-oriented entrepreneurial coalitions create added value on top of the commons that they co-produce and upon which they are co-dependent. In the best of cases, the community of entrepreneurs coincides with the productive community. The contributors build their vehicles to create livelihoods while producing the commons. They reinvest the surplus in the well-being of themselves and the overall commons system they co-produce.

The third institution is the for-benefit association that can also be called the infrastructural organization. Many CBPP ecosystems not only consist of productive communities and entrepreneurial coalitions, but also have independent governance institutions that support the infrastructure of cooperation and, thus, empower the capacity for CBPP. They enable cooperation to take place autonomously and do not command and control the CBPP process itself. Behind 
any commons project, one always finds some infrastructural organization, as commoning cannot exist without infrastructure. For example, the Wikimedia Foundation, as the for-benefit association of Wikipedia, does not coerce the production of Wikipedia producers. Likewise, the free and open-source software foundations that often manage the infrastructure and networks of the projects.

By way of contrast, for-benefit associations differ significantly from both for-profit corporations and traditional non-profits. For-benefit associations are separated from the commons and the productive community. They are not directly involved in the production and do not command its processes. They instead enable and safeguard the basis for the production to take place. Furthermore, for-benefit associations are not profit-oriented, but promote sustainability and welfare in the system as a whole and are usually democratically governed.

Similarly, traditional non-governmental and nonprofits organizations operate in a world of perceived scarcity. They identify problems, search for resources, and allocate those resources in a directive manner to the solving of the issues they have identified. This approach arguably offers a mirror image to the for-profit models of operating.

For-benefit associations operate for abundance. They recognize problems and issues but believe that there are enough contributors that desire to assist in solving these issues. Hence, they maintain an infrastructure of cooperation that allows contributive communities and entrepreneurial coalitions to engage in CBPP processes vital for solving these issues. Not only do they protect these commons through licenses, but may also help manage conflicts between participants and stakeholders, fundraise, and assist in the general capacity building necessary for the commons in particular fields of activity (for example, through education or certification).

\subsection{Four Short Case Studies ${ }^{5}$}

In addition to the well-documented ecosystems of free and open-source software projects (see indicatively Dafermos, 2012; Harhoff and Lakhani, 2016; Mateos-Garcia and Steinmueller, 2008; Scacchi et al., 2006; Benkler, 2006; von Hippel, 2016), the cases of Enspiral, Sensorica, WikiHouse, and Farm Hack offer new perspectives on the rich tapestry of the increasing number of CBPP ecosystems.

They fit within the parameters of our description, like many free and opensource software projects, Wikipedia and an increasing number of open design projects that build new post-capitalist ecosystems of value creation. The following ecosystems are interrelated through their digital commons (the output of one project can be the input of another) and, thus, CBPP can be seen as a grand ecosystem consisted of diverse smaller ecosystems (see infographic in Chapter 4). 


\subsubsection{Enspiral}

Enspiral is a network of professionals and companies focused on socially oriented projects, or as often mentioned: 'working on stuff that matters'. The network is based in Wellington, New Zealand and was founded in 2008 by Joshua Vial, who was then a freelance software engineer. The primary motivation behind Enspiral was to enable skilful individuals to commit more time to socially-oriented projects. For this purpose, an initial group of freelancers begun developing a form of collaboration that would create enough resources and flexibility, inspired by free and open-source software.

Since then, Enspiral grew to encompass a broad community of diverse professionals (productive community), including software engineers, trainers, legal and financial experts. These pool their skills and energy to create a commons of knowledge and software. They are self-organized, without central coordination, and share resources to initiate and support projects that contribute to the network's social purpose.

Around these commons, a web of business ventures (entrepreneurial coalitions) offers open-source tools and services that enable communities, like- and including- their own, to address particular challenges related to democratic governance and adaptation to the digital age. For example, Loomio is an opensource platform for participatory decision making that was developed by Enspiral with a group of activists from the local 'Occupy' movement in Wellington. Another one of the first ventures of Enspiral is Rabid, which is a company offering expert services on web development.

The picture is completed with the Enspiral Foundation (for-benefit association), a cooperatively governed nonprofit that facilitates collaboration and supports the network as a whole. The Foundation is the entity with which all the professionals and the companies have a formal relationship. It maintains the network's infrastructure, holds the collective property and guarantees its culture and mission. At the time of this writing, about 300 people are contributing to one or several of over 15 business ventures linked to the Enspiral Foundation.

Enspiral ventures generate revenue by offering their software solutions and services to clients. In turn, they distribute this revenue back to contributors and a part of it (usually 20 per cent) is contributed to the Foundation. Almost half of these funds cover the operational costs of the Foundation, while the rest is invested through collaborative funding in projects proposed by the community. Digital solutions developed by the network again support these processes. For instance, a back-end platform called 'my.enspiral' facilitates the distribution of revenue, while a collaborative budgeting tool, 'co-budget', is used for the investment of the Foundation funds.

Enspiral's culture is dedicated to the creation of value for the society rather than for shareholders. It is statutorily oriented towards the common good and is proactively developing the conditions to serve this purpose. New projects can be initiated by anyone from within or outside the network. Multi-stakeholder 
teams organize around exciting ideas and iterate potential solutions. The network's companies and professionals offer expertise in all relevant fields, including financial support, either by using the Foundation's funds (via co-budget) or by leveraging external funding. Enspiral thus aims to engage resources from the broader spectrum of the economy to the creation of social value.

One of the core practices that illustrate this approach on value is 'capped returns.' The general idea is to introduce an upper limit (a 'cap') on the total returns that investors may receive on the equity of a business. For this, the shares issued by a company are coupled by a matching call option that requires the repurchase of the shares at an agreed-upon price. Once the company has redeemed all shares, it is then free to reinvest all future profits into its social mission. Through this mechanism, external and potentially extractive capital is 'subsumed' and disciplined to become 'cooperative capital.'

\subsubsection{Sensorica ${ }^{7}$}

Sensorica is a collaborative network dedicated to the design and deployment of sensors and sense-making systems. It was officially launched in 2011 in Montreal, Canada, inspired by free and open-source projects and the forms of collaboration entailed. The vision of Sensorica is to empower P2P development and the provision of products and services through a business model and proper infrastructure that would make it economically sustainable.

Sensorica offers an open platform for interaction among individuals, with any skills or expertise (e.g. engineers, researchers, developers or lawyers), as well as organizations from the business and public sector and civil society. It is partially a commons-based community and partially an entrepreneurial entity. On the one hand, the individuals and organizations (productive community) pool resources and organize around projects that produce open hardware technological solutions. Those are generally driven by a diverse set of motivations, where financial compensation is not prominent or included at all.

On the other hand, a group of independent business entities (entrepreneurial coalitions), often launched by the community, introduce innovations into the market. All revenue is distributed back to the network and in particular to the people that have been involved. For this, Sensorica has developed a system that facilitates value accounting and resource management in the network, which is called Network Resource Planning-Contribution Accounting System (NRPCAS). This system records and determines every member's input in every project and redistributes revenues in proportion to each contribution. It simultaneously tracks all activities in the network with the relevant resources that are either used or generated by a project, as a project's output can be another project's input.

All the agents participating in the network are affiliated with a nonprofit organization (for-benefit association), namely the Canadian Academy for the 
Knowledge Economy (CAKE), which manages the shared infrastructure and resources. It is a custodian holding all assets and liabilities of the network, based on a 'non-dominium' agreement. 'Non-dominium' reflects the fact that no agent or combination of agents may have dominant control over the shared resources. It illustrates the dynamic and highly adaptable structure of Sensorica that strives to combine open, large-scale collaboration with a fair distribution of the co-created value.

Projects in Sensorica get initiated either internally or externally. In the former case, the network participants, individuals or organizations, broadcast their ideas to the community. When enough people get on board, a collaborative process of design and planning begins where they contribute under various roles. If all goes well, the VAS-CAS is set-up for this project, and it moves to the development stage where everyone starts logging in his or her contributions. In the latter case, external parties contact Sensorica and initiate joint projects outsourcing innovation processes to the network. Other than that, the network still operates similarly in both cases.

For instance, one of the most popular Sensorica projects is called 'Mosquito', which entails the design and production of a force/displacement sensor device with numerous applications in science and biotechnology. The project, according to the publicly available data on Sensorica's NRP-CAS, has been launched in 2012, coordinated by 15 people in various roles, from design, research, and development and experimentations, to marketing, strategy, documentation and accounting processes. In 2013 two Sensorica affiliates launched Tactus Scientific Inc., a company that successfully introduced the Mosquito Scientific Instrument System as a product in the market. The device has been first tested in research in cardiovascular diseases in collaboration with the Montreal Heart Institute. In its next phase, the Mosquito technology has been applied in other domains, such as wearables (e.g. smart sports equipment, assistive technology for disabled) and robotics (e.g. haptics).

Similarly, in 2015 Sensorica has been contacted by a Montreal-based company to assist in the development of an Internet-of-Things solution for the heavy industry. The final product would be a mesh network of sensors gathering data to analyze the life expectancy of products and predict failures. The company has agreed to follow a business model that is compatible with Sensorica's mission and values concerning the openness of the outputs. The company thus has financed CAKE, the network's custodian, which in turn has distributed funds to the people participating in the project to develop the product released under open-hardware license.

Income can be generated in Sensorica through market operations or government grants. The NRP-CAS allows revenue to flow back to all contributors, not just those directly connected to the sources of income, either market or government partners. The system allows the identification and evaluation of the different qualities of contributions, through a combination of self-logging and peer review. It thus succeeds in avoiding rent-seeking behaviour, not just by 
external forces, but also by privileged internal agents, which attempt to exploit the common value for their individual gain. On the one hand, the techno-social infrastructure of Sensorica supports the network's operations and its contributors. On the other, it reinforces a specific state of affairs that represents a collective sense of fairness within and beyond the network.

The organizational model of Sensorica has been identified as an 'Open Value Network' (OVN). An OVN has been developed as a generic organizational and business model apt to enhance and support CBPP. It is highly adaptive, fully decentralized and governed through distributed decision-making processes and resource allocation. Inspired by the practices exemplified by free and opensource projects, it supports open participation, with low barriers of entry and is designed to empower permissionless individual action through open knowledge and transparent processes.

The OVN model aspires to create a viable structure that harnesses the advantages of open collaboration and sharing, while it addresses the challenges of digital commons projects related to governance and sustainability. Its economic dynamics are based on economies of scope created by large-scale collaboration and customized production. Sensorica with the OVN model benefits from the diversity of inputs and shared resources. It stimulates and harnesses human creativity while reducing time-to-market for innovations. This way Sensorica's business entities exploit this unique potential to become competitive in the market.

Generally, the OVN model, as demonstrated by Sensorica, carries some decisive solutions for commons-oriented projects. It can support their unique forms of collaboration allowing CBPP communities to interface with the market and the public sector; capture, manage and distribute financial rewards to contributors; deal with trust-related issues; retain and protect a formal legal structure and brand, and formulate and execute a business strategy.

\subsubsection{WikiHouse}

WikiHouse is an open-source construction kit initiated by the UK-based studio named 'Architecture 00'. It aims to enable a global community of people to share designs and tools related to all the different parts of house construction. Those parts would then be produced with low-cost materials, like plywood, and assembled using digital fabrication tools, such as 3D printers and CNC machines, even by people with no exceptional skills or training. WikiHouse has been inspired by the developments in digital fabrication and parametric automation, conceived as an opportunity to drastically lower the social thresholds regarding skills, time and cost for people to design and manufacture a house.

A global community of architects, designers, engineers and builders (productive community) contributes to the WikiHouse commons of designs and technologies. Participation is open to anyone interested in using, improving, 
adapting and sharing existing designs and technologies, and develop new ones. The contributors to the community interact through a stack of online tools that allow them to communicate and share designs and experience.

The WikiHouse library is organized to include different house types, available as ready-designed building layouts, and technologies that constitute the sub-components of a house and its utilities. It also includes the tools necessary for the physical manufacturing of the constructions. At the time of this writing, the library includes one main house type, the 'MicroHouse', a CNC routed frame technology called 'WREN' and two simple tools, a mallet and a step-up stool.

The limited number of designs and technologies is due to the complexity entailed in house constructions and the variety of the possible contexts. The MicroHouse type and WREN were initially designed in the UK and are suitable for these conditions. Therefore, further development of static ready-to-produce designs for other house types would be of limited use. WikiHouse also focuses on the development of parametric design tools that may allow for a broader range of possibilities and different house types. Several research and development teams work on new sets of digitally fabricated technological solutions. A set of design principles are guiding this process, which generally prescribes an open, fail-proof and modular design, low-cost and broadly available materials, and user-friendly layouts.

A UK-registered nonprofit, the WikiHouse Foundation (for-benefit association), is the caretaker of the community. Its mission is to bring together companies, organizations, and governments to promote open technologies and common infrastructures for housing and sustainable development. The Foundation provides for the WikiHouse commons by maintaining the infrastructure and through commons-based licenses. It facilitates cooperation in the ecosystem by coordinating interactions among the contributors and raising funds from donations.

Furthermore, the WikiHouse Foundation collaborates with a global network of companies, called 'providers' (entrepreneurial coalitions), which cover all the relevant services across the building supply chain, from architecture, engineering and insurance services, to loans, construction management and delivery of parts. Those usually participate in research and development for WikiHouse and have thus advanced knowledge of its tools and technologies, while some may specialize in local applications of WikiHouse solutions. For instance, WREN is supported by an architectural design studio (Architecture 00) and a structural engineering company (Momentum Engineering), both based in the UK, but also by a New Zealand-based social housing company (Space Craft Ltd), a multinational expert group (Arup Associates) and several individual contributors. Moreover, a structural engineering student group from the Free University of Brussels (ULB) is also working on the hardware, while another architecture team (Architype-Team Architects) is engaged in the parametric development. 
The Foundation does not engage in the design or manufacturing itself. Instead, it ensures compliance with the design principles and sets the criteria for quality assurance, by curating a catalogue of certified solutions and providers. This way, it encourages experimentation, openness, and diversity in community interactions, while maintaining minimum industry standards for the designs and technologies hosted in the WikiHouse public library.

In this perspective, the enabling role of the commons in the WikiHouse ecosystem is twofold. On the one hand, it is socially-oriented with regards to the role of architecture beyond the construction of buildings. It focuses on the development of design solutions that are low-cost, high-performance, sustainable and adaptable. People are thus provided with the tools to reconfigure the public sphere in the area where they live, especially in urban environments. There is a robust socializing element emphasized in the construction of WikiHouse layouts that is reminiscent of pre-industrial vernacular architecture and community-based building.

On the other hand, it introduces a new business strategy for the sector. Apart from high-end, sophisticated construction projects, WikiHouse sees most of the architectural work take place outside the market economy, where everyday people try to solve their problems by themselves. Hence, the challenge for WikiHouse is to provide the tools, the infrastructure, and the institutions to develop architecture in those parts of society. WikiHouse thus strives to expand the availability and relevance of architecture and its related services to the more significant part of the economy, where it is arguably most needed.

In this direction, WikiHouse is in the process of developing a platform that would enable companies to identify new customers for their products and services, coalesced around citizen-driven projects for affordable and sustainable housing. In turn, they would share a part of their revenue for the maintenance and improvement of the shared infrastructure and the building technologies.

\subsubsection{Farm Hack}

Farm Hack is a community of farmers that build and modify their machinery. It was established in 2011, following a gathering organized by several groups of farmer activists in collaboration with engineers from the Massachusetts Institute of Technology, aimed at discussing and producing solutions to various problems related to farming tools. Gradually, a series of events were held across the USA engaging farmers, activists, designers, researchers and engineers in discussion and exchange of ideas, and the design and prototyping of farming tools. Inspired by open-source culture, soon the idea expanded to the rest of the world and eventually a global community (productive community) was established.

The central node of Farm Hack is its digital platform, where solutions developed in the events are documented. The primary function of the platform 
is to host a database of designs, know-how, and ideas shared by the productive community. In addition it serves as a medium of communication and dissemination, while it also facilitates coordination among the members of the community and, to a certain degree, the development of technologies.

Currently, the platform features more than 500 pieces of machinery that have either been collectively created in Farm Hack events or developed by individual members of the community. The platform includes anything from integrated solutions and ready-to-market products to prototypes, fixes and even concept designs or ideas for brainstorming. All artifacts are available under Creative Commons licenses and may be accessed, used, modified, improved and shared by everyone.

A nonprofit (for-benefit association) has been formally established in 2013 to provide Farm Hack with legal status. The primary role of the organization is to monitor, maintain and improve the platform according to the ethos and desires of the community. Further more, it secures funds for its functions and maximizes outreach within and outside the community. The organization has a formal board of directors, in line with legal provisions; however the actual decision-making process is decentralized and meritocratic. Practically any member of the community can be involved, while those most engaged in the Farm Hack activities may have enhanced influence.

Acquiring a legal form has provided the flexibility to strengthen collaboration with other organizations and raise funds from grants. Over time, this has allowed Farm Hack to employ community members on a more permanent basis, thus enabling them to contribute their time and efforts more intensively. However, this cannot be sustained over long periods of time as its non-profit statute does not allow for direct engagement in financial activities. Therefore, a critical challenge for Farm Hack is to create a business ecosystem around the platform that would generate income and improve the overall sustainability of the community and its efforts.

For this reason, the community enables some of its most active contributors to engage into entrepreneurial activities (entrepreneurial coalitions), so that they can continue their contribution to the commons, but also sustain themselves in the process - those are individuals that have invested considerable time and resources in the development and documentation of various tools and have gained substantial experience.

Typically, these contributors commercialize tools that they have contributed to the platform or offer related paid services for individuals or entities that would instead purchase them than directly engage in their development. Farm Hack community members are relatively flexible when it comes to adopting any suitable business model, as long as the fundamental principle of openness is maintained. They may manufacture and sell the tools or components of them, or they may sell partially assembled kits or merely conduct workshops to teach other farmers to build their tools. 
Furthermore, the platform includes a component, called 'Open Shops', envisioned as a space for businesses and organizations sharing Farm Hack's ethics. Ultimately, Open Shops aspires to curate a commercial toolkit that would support different groups and individuals by offering products and services to the broader community. Concurrently, Open Shops connects Farm Hack with other projects working on the same field from all over the world and provides a collaborative space for sharing of skills, knowledge, and designs.

The process of commercialization is challenging for Farm Hack and a significant point of discourse within the community. The creation of sustainable commercial activity is desired and encouraged. It is a means to build economic resilience, by supporting local manufacturing that provides farmers with tools customized to their needs. Hence, commercial activities may be benefiting from the community, but are simultaneously empowering and supporting it.

Interestingly, even though significant improvements have been implemented in the platform over time, most of the coordination and collective development takes place in the physical sphere, for instance at Farm Hack events. The operation of the digital platform as a coordination tool has been not been stressed, while the documentation of processes and technologies are often posing problems within the community. Nevertheless, the platform is continuously updated and improved, based on feedback provided by the community and other sources. Its role concerns both digital interactions, such as the documentation of tools, as well as physical ones, like the provision of templates for the organization of independent events.

In the same direction, several members of the Farm Hack community have developed FarmOS, a web-based open-source software that assists farmers in record keeping, planning, and management of their farm-related work. Similarly to the Farm Hack platform, FarmOS also serves multiple purposes. It can offer different possibilities through the sharing of data and knowledge across the community, but also with third parties, like researchers and expert service providers. Moreover, the open and transparent architecture of FarmOS provides enhanced freedom and control over data sharing by the users in comparison to similar proprietary applications, while the sharing of data is not prerequisite for the use of the software.

\subsection{From Contradictions to an Integrated Economic Reality}

We do not claim that such nascent ecosystems are sovereign in the current socio-political order. Even more, they all come with their challenges and contradictions. For instance, Enspiral, as a business model, owes a large part of its success to the distinct talent and skills of its members that allows them to be very competitive in their respective fields: skills and competencies that they have acquired from their education and occupation in established institutions, 
such as universities, software companies, and financial firms. Its area of expertise is within a niche with a structured market and low capital entry. Therefore, the replicability of its business model is both a matter of some subtlety in application and highly dependent on context.

Similarly, Sensorica and Farm Hack both face significant challenges concerning proper and comprehensive documentation of their processes and outputs, while WikiHouse is still striving to broaden the scope and reliability of its layouts and technologies. Furthermore, all the described projects, especially those entailing any form of localized manufacturing, still substantially rely on cheap mass-produced raw materials and components, which are only affordable mainly because they are produced and distributed under exploitative conditions. Their respective business models are also yet to be defined, and in most cases, it is the case that only a small number of active and highly dedicated contributors that can safely claim sustainable livelihoods.

Nevertheless, we should not underestimate the importance of such cases in providing solutions to very timely and neglected societal challenges. Most importantly, in doing so, they are gradually building a considerable capacity to support their emerging political economy. From Enspiral's co-budget, to Sensorica's Network Resource Planning, and from WikiHouse's parametric design to Farm Hack's on-demand customized manufacturing, each case offers unique techno-social solutions that crystallize a new socially embedded perception of value. They also define new forms of organization and relation to the means of production and offer an alternative representation of economic reality as a whole.

These can empower commoners to counter situations where capitalists coopt the commons and head towards others in which the commons capture capital and utilize it for the development of the commons. This proposed strategy of reverse co-optation has been called 'transvestment' by Dmytri Kleiner and Baruch Gottlieb (Kleiner, 2010, 2016). Transvestment describes the transfer of value from one modality to another. In our case, this would be from the capitalist market to the commons, using generative market practices wherever and whenever possible. Thus transvestment strategies aim to help commoners become financially sustainable and independent. Transvestment strategies can be identified in all the cases presented above.

Enspiral ventures offer their products and services in the market, like any ordinary enterprise. However, their focus is on the social economy, mobilized in response to societal challenges. Through this process, they create commons (software, infrastructures, knowledge), but also revenue and even profits (some Enspiral ventures are profit-oriented). A significant portion of these finance the operation of the Enspiral Foundation, and the rest is reinvested to new commons-based projects through democratic procedures. When external finance is used, the system of capped returns is applied to redeem control of the projects funded. This ensures that, in the long term, the companies can decide to reinvest their profits in their social mission and new Enspiral projects. 
In addition, Sensorica explicitly separates its production processes, which are commons-based, from its market operations, that are held by independent entities, yet entirely controlled by the productive network. Moreover, the network's contribution-based accounting system links every contribution to the people involved in a project, from its initiation to the marketed product. In turn, this allows the network to harness the commercialization of its products under participatory and democratic processes, by fairly distributing all revenue back to the people that have contributed to the production. Through this process, Sensorica emancipates its contributors by providing livelihood opportunities, which enables them to commit more of their creative energy to commons-based production processes.

WikiHouse attempts to create a new market strategy for architecture and related services, by coalescing various stakeholders around the commons. Instead of focusing on large-scale construction projects, which are typically centrally designed and coordinated, a key faction of expert and competent agents can be employed for the parametric design of solutions for every-day problems of the broader society. Through the pooling of designs, knowledge, and technology from all the involved parties in the construction value system, WikiHouse shifts resources from the creation of capital to the creation of commons. Simultaneously, it provides the means to deem a form of community-based design and construction sustainable, which would otherwise be susceptible to enclosure.

Finally, the Farm Hack community encourages its most active constituents to undertake entrepreneurial activities, so long as the community's fundamental values of openness and non-discrimination are safeguarded. On a first level, this enables some of the main contributors to the Farm Hack commons to become more financially sustainable and potentially commit more of their time to the community. On a second, it increases the impact and availability of Farm Hack commons-based technologies. In a vital economic sector like agriculture, this conditions the movement of people, land, and capital to the commonseconomy. Because technology is not neutral, opaque technologies with high capital input would force these communities to conform to intensive, largescale practices. Conversely, the promotion of commons-based technologies emancipates commoners to build a counter-economy.

These commons-oriented practices consciously strive for a transition to a fairer and more sustainable economy and society. There have been many historical opportunities for such a transition, but capitalism has demonstrated high resilience as an economic system, adaptability as a cultural framework, and brutal force as a political apparatus.

The difference on this occasion is found in the profound techno-social transformations that take place on the micro-economic level. P2P constitutes a generic capacity for human beings to contribute to the creation and maintenance of shared resources while benefiting from them. Early CBPP initiatives illustrate the potential of this capacity that allows people to build new vehicles - and 
transform old ones - to create and distribute value. Those have been developing along with nascent practices and tools that make certain forms of social relationships visible.

Medieval merchants had too developed their own practices and tools to transform the pre-capitalist societies, guided by the generic capacity of people to exchange and barter in markets. It was not the first time in the history of humanity that trade took place, nor that markets existed. It was, however, the transformational dynamic of their tools that made things visible, rather than the humans behind them. The labour theory of value was one of the first systematic approaches that subsumed human 'toil and trouble', in Smith's (1776) terms, under the sway of commodities to exchange for one another.

The nascent theory of value that is being developed by the CBPP practices can conceivably subsume various qualities of things, such as resources, assets, and commodities, under the capacity of human beings to relate to one another in a non-coercive and permissionless manner. It is a critical process that is transforming the CBPP practices from re-active to pro-active. Such groups are shaping their existence within a dominant system, and through transvestment, they transcend its inherent dynamics. This approach is arguably anti-fetishistic, as it reinstates the relations amongst people that have been hidden by relations between things.

Moreover, this nascent value regime already holds the preconditions to recognize and acknowledge different forms of value. With regards to social relations there is the acknowledgment of contribution, and concerning natural resources, there is the recognition of planetary limits. CBPP thus contributes to a biocapacity-based understanding of value, which establishes foundations for integrating social and environmental externalities.

In the current system, we externalize social and environmental factors to maximize exchange-value. A new form of value is one that integrates social, ecological and economic value. We have to work on our capacity to integrate social and ecological value in our decisions about the use and allocation of resources. CBPP inaugurates a move from a redistribution model, where value is created through the market and then distributed, to a predistribution approach, where economic activities are socially and ecologically embedded, which concerns itself with the recognition of natural limits, as well as the fair distribution of rewards. A crucial task is to re-integrate the different forms of value in a new economy.

Nevertheless, we cannot ignore the close interdependence of CBPP initiatives with capitalism in their struggle to gain autonomy. The success of this struggle necessitates the adoption of practices, tools, and narratives that have been historically been synonymous with capitalism. In order to win in the capitalist game one first needs to abide by its rules, even when trying to bend them. Hence the more successful these initiatives become, the higher the danger of reifying and fetishizing capitalism, which never fails to reward its greatest enemies. The increasing interest in the commons already provides the grounds 
for alliances with certain forces that aim to exploit the commons to expand the power of capital and further deepen the divide with class movements (Caffentzis, 2012; De Angelis, 2012).

However, we also cannot overlook the fact that those initiatives have been nurtured within capitalism and aspire to overcome it. The same way that the commons can be exploited to rejuvenate capitalism, CBPP can form coalitions and revitalize radical social movements, including class, gender, ecology, and degrowth or post-growth.

From a Gramscian (1971) perspective, CBPP can be viewed as an effort to advance alternatives to dominant ideas of what is considered 'normal' and legitimate. Commons-based entrepreneurship, for instance, transcends those elements of entrepreneurship that are associated with freedom and autonomy and places them in a contributory perspective. Similarly, for-benefit associations transcend elements traditionally associated with the state in its role as the guarantor of the common good, that are reflected in the quality of benefiting from- and contributing to- the commons.

As these solutions mature and as they are taken-up, replicated and improved by other projects, this new economic reality could subsume and transcend today's tumbling political order. Through the support of the commons and the expansion of P2P as the new common sense, in time they shall reshape and sublate the various contradictions and processes upon which they currently rely, into a synthesized, concrete, commons-centric totality. 


\section{- THENEW ECOSYSTEM •}

\section{OF VALUE CREATION}

Commons-based peer production enables new systems of value creation. Around shared commons of knowledge, code and design we find three institutions: the productive community, the commons-oriented entrepreneurial coalition(s), and the for-benefit association. This ecosystem can be visualized as a plant pollinating a rich environment.

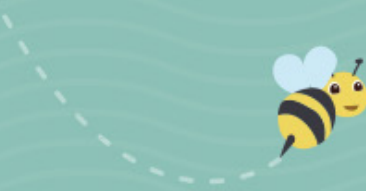

\section{DIGITAL COMMONS}

The flowers and stems of the plant can be thought of as commons, representing nonand even anti-rivalrous resources (the more people who draw from the resource, the more the resource is strengthened). These commons can be expanded upon, re-purposed and modified for specific situations and contexts.

\section{.}
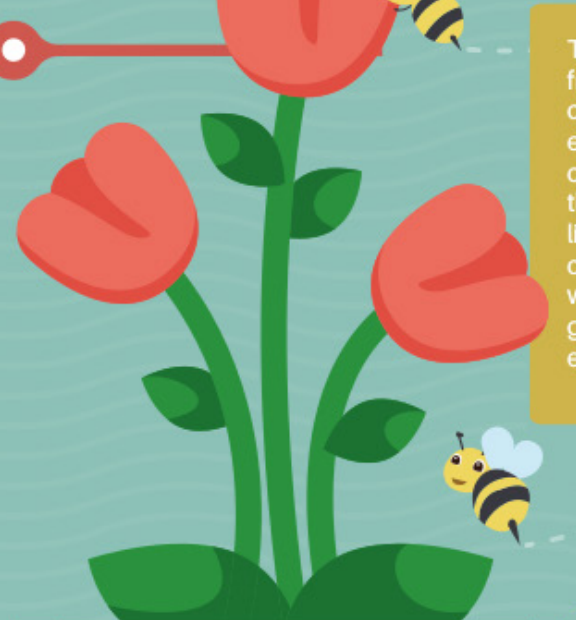

The community of bees, pollinating from digital commons of knowledge coalesce into commons-oriented entrepreneurial coalitions. These create added market value around the common resources to secure livelihoods for the commons-producing communities while enriching the soil through generative (as opposed to extractive) practices.

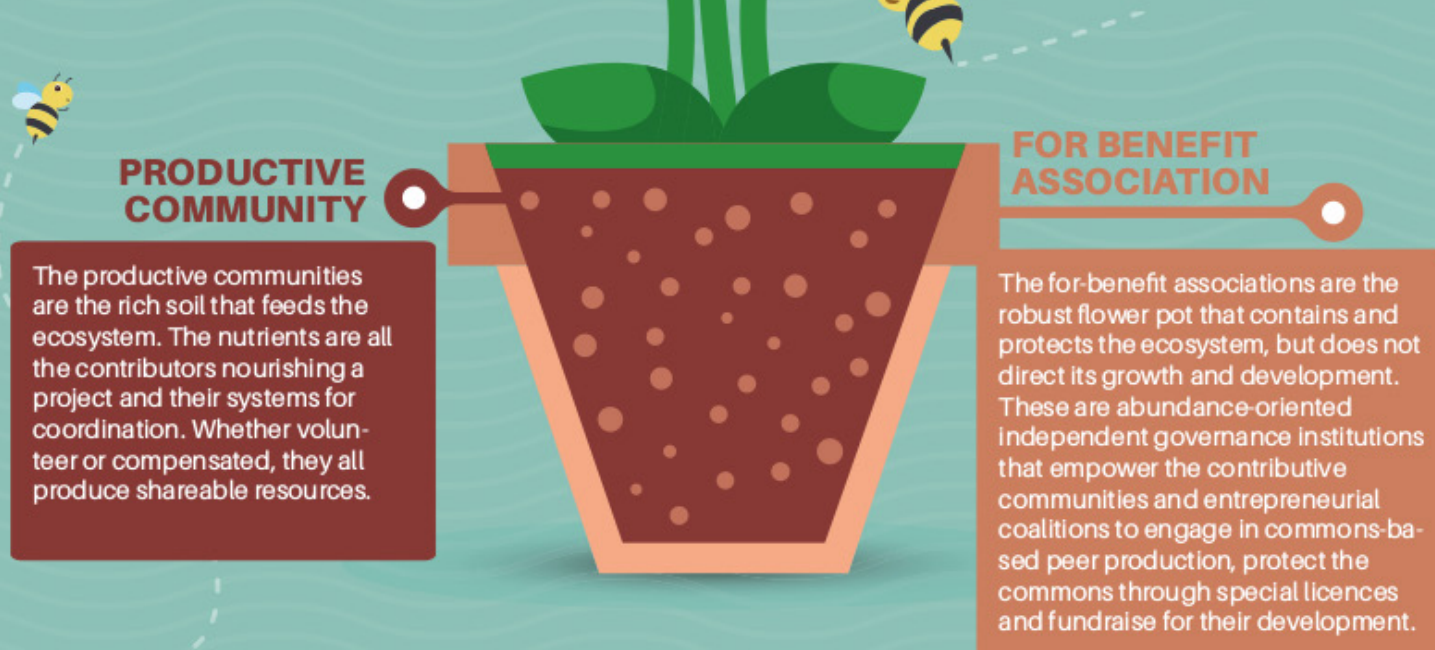

Together, this ecosystem of value creation helps create vibrant free, fair and sustainable economies which are not only based on the Commons, but actively stewards them and protects them for future generations. 


\section{CHAPTER 3}

\section{P2P and New Socio-technological Frameworks}

Technologies should not be seen as neutral, entirely deterministic nor as univocal in their effects. Instead, we should look at technology as 'value(s)-sensitive' responding to the material interests and social imaginaries of those that fund, develop and use them. Technology is thus a terrain of struggle, in which different interests and values strive for supremacy (Feenberg, 2002). The most fruitful approach is to look at the various potentials of new technologies, which can evolve in multiple ways, and how various social groups can take advantage of these potentials. Our vantage point is to consider to what degree the new networking technologies are useful in the context of a transition towards a commons-centric society.

The Internet itself, and its complexity offer an excellent example of various possible evolutionary paths possible since it was initially developed by the military-funded researchers of ARPA, to create a fully distributed structure that would share digital resources among geographically dispersed computers. The Internet was also adapted to their needs by scientific communities who saw it as a means to share knowledge. It was further influenced by commercial interests after the invention of the World Wide Web, and by governments' intent on controlling its mechanisms. However, the Internet was also taken up by the hacker movements and user communities adapting it to their uses. The Internet is therefore neither merely a tool of capital or the state nor merely a tool of liberation.

Internet technology uses are appropriated by social groups, but the critical issue here is that it creates new capacities (mild techno-determinism), and these new capacities may be more important for those that did not have them, than for those who already did. Large companies and governments already had private networks that interconnected them. However, these capacities have been

How to cite this book chapter:

Bauwens, M., Kostakis, V. and Pazaitis, A. 2019. Peer to Peer: The Commons Manifesto. Pp. 33-45. London: University of Westminster Press. DOI: https://doi.org/10.16997/ book33.c. License: CC-BY-NC-ND 4.0 
democratized mainly through the Internet, especially after the advent of the World Wide Web, and this despite the subsequent control of the Internet by dominant players. As with the emergence of the printing press, the Internet democratized a capacity, which may then be contested. The result of these social struggles may not undo the unleashed capacity.

In the case of the Internet, at least three capacities have been created:

1. A capacity for many-to-many communication using all other forms of previous media as these are all integrated and included in a universal digital medium.

2. A capacity for self-organization that is the result of that permissionless communication.

3. A capacity to create and distribute value in new ways, i.e. self-organization can be put to use in the sphere of production.

In this manner, like the invention of the printing press before it, the Internet has created a historical opportunity for reconfiguring production, exchange, and the organization of society at large. The core emancipatory feature of the Internet lies in its capacity to massively scale up many-to-many communication, and therefore, in its capacity to lower the cost of self-organization and create and distribute value in radically new ways.

Despite the various adaptations of the social forces involved, and despite the partial subsumption of Internet infrastructures to the needs of global capital and a new type of capitalist investors (Malcomson, 2016), the fundamental underlying freedom for the capacities mentioned above has not been destroyed (yet). Capital and governments need the capacities of the Internet as much as civil society does.

To understand the subsequent politics of socio-technological design of various P2P applications, we have developed a framework that explains how the encapsulations of these designs lead to different outcomes.

\subsection{Two Generic Models}

We attempt to provide a birds-eye-view of the initiatives that utilize P2P social dynamics and technologies by introducing four quadrants. Each quadrant stands for a specific scenario in which a dominant force determines the design of the particular networks to facilitate specific outcomes. The forces at play want to protect their interests through the control of technological platforms, which encourage specific behaviours but discourage others. In other words, the owners or managers of platforms may design decisions and invisible protocols based on their interests, which in turn influence human behaviour in networks (Kostakis \& Bauwens, 2014).

Here is our summary graphic: 


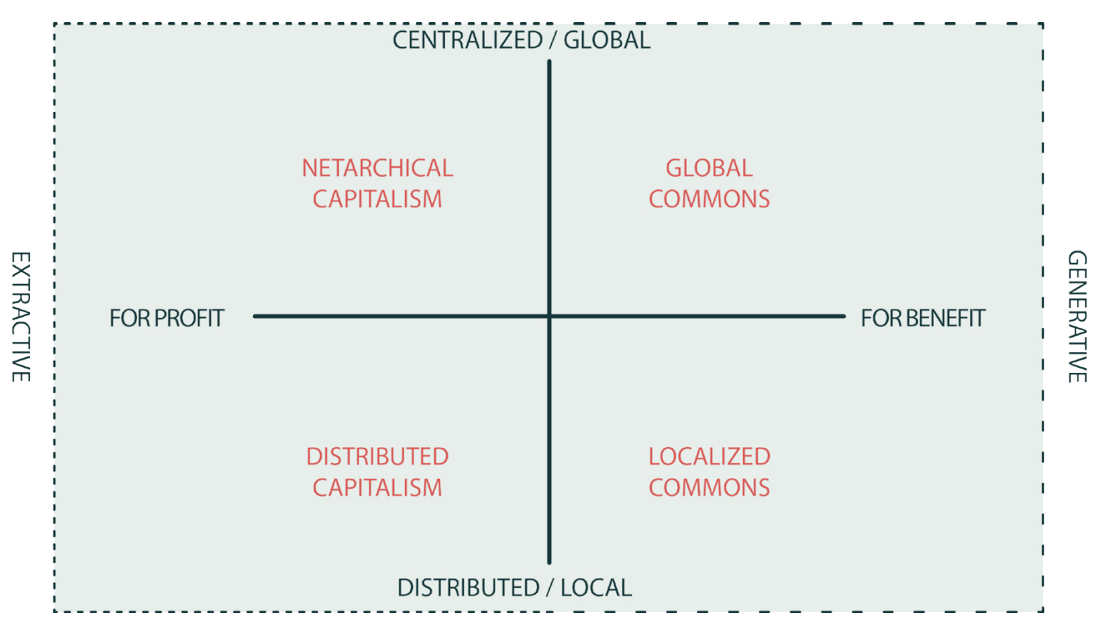

Fig. 1: Four Scenarios.

The vertical axis presents a polarity where the top (up) indicates the centralized control of digital production infrastructure and the bottom (down) for the distributed control of it. The horizontal axis relates on one side (left) to an orientation towards profit maximization versus on the other side (right) an orientation towards the commons. In addition, at the top are the infrastructures with global orientations, and at the bottom initiatives with more local or 'distributed' orientations.

So, the left side can be called 'extractive' because it impoverishes the natural and community resources it uses. The right side is the 'for-benefit' side that aims to create common good value either at the local level or the global level. This latter side we also call 'generative's as it seeks to add value to communities and commons, both social and environmental. One of the key aims of many different contemporary transition movements is precisely this shift from predominantly extractive to generative models.

There is a strong linkage between the terms 'extractive' and 'exploitative': people who respect human beings will probably respect nature. It is a metaphysical attitude expressed both ways; against nature and people. It extends the view of human exploitation to that of a broader extraction from the totality of life. McKenzie Wark (2015) discusses Bogdanov's novel Red Star (1984) indicating a shift from class struggle to the struggle to organize the totality of human effort', where the exploitation between classes is only one of the fetishes to be overcome.

Also, what one may see in the history of the West is that as soon as we obtained social consciousness, we obtained environmental consciousness as well. Therefore, getting rid of the exploitation of humans and the exploitation of nature is, despite the different domains, a related process. As Jason Moore (2014) 
highlights 'the "exploitation of nature" is placed on a more-or-less equal footing with the exploitation of labour power'. It is no coincidence that the same set of relations reveals itself in several works, including Foster $(1999,35)$, Clark and York (2005, 395), Clausen and Clark (2005, 423), Clark and Foster (2009), Clark and Foster (2010, 145), Clark and York (2013, 30), Foster et al. (2010). The suggested duality between extractive and generative models reflects this approach.

User-oriented technological systems generally can be looked at from two layers. The front-end is where user interaction takes place. It allows users to interface with each other and the system itself. The back-end is the technological underpinning that enables the whole process. The platform owners engineer both, but only the former is visible to the users. Hence, a P2P social logic is often enabled by a front-end, which is highly centrally regulated and appropriated on the back-end. An invisible techno-social system is thus formed, which profoundly influences the behaviour of those using the front-end. It sets limits on what is possible concerning human freedom and can 'nudge' behaviour (Thaler and Sunstein, 2009) in desired directions that correspond to the interests of the platform owners and managers.

A genuinely free P2P logic at the front-end is improbable if the back-end is under exclusive control and ownership. It does not mean, however, that users of these systems are powerless to use these capacities for their ends (especially if they are conscious of the limitations of such cognitive capitalist systems).

Following Figure 1, four future scenarios are introduced:

- netarchical capitalism;

- distributed capitalism;

- localized commons;

- global commons.

Each scenario sketches a different politico-economic approach that actuates different future road maps (Miles, 2004). The models of the left are inserted in the general model of contemporary capitalism that has been called 'cognitive capitalism'. The models on the right could be inserted in a context that has been called 'post-capitalist', as the core of the activity is not geared towards profit-maximization.

\subsection{The Extractive Model of Cognitive Capitalism}

Cognitive capitalism concerns a systematic process of privatization and commodification of information, in the form of data, knowledge, design or culture, to maximize profits. In this new chapter in the evolution of capitalism, control over information and networks is the driving force of capital accumulation, 
rather than material production and distribution. (see Boutang, 2012; Bell, 1974; Drucker, 1969; for a critical analysis, see Webster, 2006). ${ }^{10}$

By 'netarchical' we mean the hierarchies within the network that own and control participatory platforms. This version of capitalism is characterized by digital platforms that combine $\mathrm{P} 2 \mathrm{P}$ elements, which allow people to interact with each other directly, but they are controlled and monitored by the platform owners. The full centralized control of the rest of the infrastructure is used to form these exchanges.

This new form of capital directly exploits networked social cooperation that often consists of unpaid activities that can be captured and financialized by proprietary 'network' platforms. It sustains itself from the positive externalities created through human cooperation and the commons. If previous versions of capitalism were hostile to the commons and tried to destroy it, this new version has learned, at least provisionally, to 'tame' the commons. Nevertheless, this also means that it has become parasitic and rent-seeking. Netarchical capitalism is rent-seeking capital that has shifted its control mechanisms to control the whole network itself and functions one step away from real production.

For example, social media platforms like Facebook almost exclusively capture the value of their members' social exchange, by monetizing the data and selling the 'attention' of their users to advertisers. In addition, crowdsourcing models rely on distributed labour, and the 'shared' content contributes to firms' profit generation (for an overview on the critique of crowdsourcing models and precarious digital labour, see the collective book edited by Scholz, 2012). In netarchical models, such as that of Uber, Airbnb, Kickstarter and TaskRabbit there is no community nor the creation of commons; rather individual workers compete for their own livelihood.

In CBPP, productive communities consciously create commons, whereas in the so-called 'sharing economy' there are distributed market (P2P) exchanges taking place over private platforms, whose owners extract a toll from the exchanges. The process is controlled by the owners of the platforms, who extract value (rents or fees) from these processes. The 'sharing' concept here is no more than a marketing ploy.

Furthermore, the bottom-left quadrant, which includes examples like Bitcoin and some of the emerging initiatives based on Bitcoin's distributed ledger called 'blockchain', can be characterized as 'distributed capitalism'. These more distributed developments embrace the idea that 'everyone can become an independent capitalist or trader', and they purport to offer individual autonomy from both big business and the state. In this model, the aspects of autonomy and large-scale participation are celebrated and supported by P2P infrastructures, though individual profit-maximization is still the primary motive. The design of Bitcoin is quite exemplary in that context, as its deflationary design means that early buyers or producers of the virtual coin, can sell them to latecomers 
at a premium, without the necessity of productive work. Bitcoin is similarly extractive towards nature because of its enormous appetite for energy.

More generally, each system that is geared towards competition for scarce resources, will favour winners over losers and, over time, lead to the same oligarchy as netarchical capitalism. Distributed capitalism is ideologically different and is based on a different techno-social paradigm, but the unequal distribution of influence within networks lead to the same place as where netarchical capital started from. This is already true for both the ownership of Bitcoin mining capacity and the ownership of the coins themselves. Generally speaking, such projects are driven by an underlying vision that society is just a sum of autonomous individuals, who create contracts with each other. There is no real society and no collectivity in these visions. Lastly, the projects related to this vision of distributed capitalism (also called 'anarcho-capitalism') lack any counter-measures that can prevent the creation of inequality and oligarchy (Boehm, 2001).

Moreover, many forms of the left quadrants are hybrid and should not be considered 'wholly negative', since they still rationalize P2P sociality, thus conditioning autonomous forms of production and exchange for an increasing number of users. Paradoxically, capitalism itself strengthens non-capitalist and post-capitalist forms of self-organization and value creation. Examples are how the popular forces of resistance and even revolution self-organized during the Arab Spring, but also various CBPP communities have made inventive use of netarchical platforms and distributed systems to organize themselves and their projects. For example, a community-supported fishery in Ostend, Belgium uses Facebook to connect fishers and their clients. Hence, netarchical platforms invest in $\mathrm{P} 2 \mathrm{P}$ infrastructures and effectuate the material conditions, where the struggle for more autonomous and inclusive forms of network society may take place.

Another example from the software domain, is the case of coalitions between IBM and various commons-based projects. Being a profit-driven corporation, IBM exploits the use-value produced through CBPP. But, simultaneously, the IBM involvement has enhanced the sustainability of many CBPP projects, by stimulating opportunities for paid work and the creation of more and better outputs. Likewise, Bitcoin may be pushing towards distributed capitalism, but has signalled an essential milestone for some post-capitalist aspirations. It is the first global currency based on 'social sovereignty', which signifies alternative paths for 'post-Westphalian' monetary systems that are able to scale and coexist. Blockchain technology, associated with Bitcoin as a distributed database, eliminates the need for a trusted third party. The transparent and distributed nature of the blockchain theoretically could help small and large communities to reach consensus and implement novel forms of self-governance. These potentialities introduce various opportunities and challenges worth enough to investigate and experiment, despite their enduring weaknesses of blockchain-based applications, such as their high energy usage and thus environmental cost. 


\subsection{The Generative Model of Commons-based Peer Production}

Let us now move to the right quadrants which include several promising social movements, and CBPP projects. If the left side showed predominantly extractive, rent-seeking behaviour vis a vis $\mathrm{P} 2 \mathrm{P}$ exchanges, then the right side shows a positive engagement with the commons and communities, that is, a generative relationship.

In both the bottom and top right quadrants, the 'civic' element predominates, either in the form of a local community or in the form of a global open design community that mutualizes its knowledge. Both use digital platforms, but the difference lies in how they instrumentalize the digital commons that they use.

In the localized commons model, the global digital commons are used to strengthen and organize the local. In the global commons model, networks are used to directly organize at the global level, to deploy activities directly at the global level, and to project power at that level. For example, the priority of the Transition Town movement (localized commons quadrant) is towards local transitioning, and their use of global digital commons is at the service of their local goals. Conversely, the goal of Wikipedia (global commons quadrant) is to create a global and universal knowledge resource, just as GNU/Linux aims to create a global alternative to proprietary operating systems.

The vein of our critique of localized commons initiatives is twofold (Kostakis et al., 2015). First, many localization communities (e.g. several ecovillages) produce a digital commons (e.g. novel permaculture techniques) while working to meet their needs. However, because of their local focus, they have loose connections with each other; they do not produce a global commons, and thus they fail to contribute to the formation of a global counter-power. Many global issues cannot be solved at the local level, and hostile global power dynamics can thwart many local solutions. For example, industrial fishing fleets operating outside of the national nautical zones can easily thwart a local fisheries commons.

Localization is part of the answer, and it is necessary, but not sufficient. Such initiatives could deploy their efforts at translocalization and transnationalization. For example, they could federate both at the local and transnational level around their domain of activity, such as provisioning systems (e.g. food or shelter). Some cities could function as 'partner cities' enabling the deployment of these local systems while they create transnational coalitions themselves, and support global open design communities that mutualize the development of shared infrastructure.

Our approach is in no way hostile to localized commons initiatives. We have to co-construct the new generative mode of production and allocation at all levels. Localized projects can interconnect at all levels, including the local territorial level, and local structures can create transnational infrastructures (such as a global coalition of cities). Our argument is instead that these local initiatives vitally and structurally need global complements to be effective. However, 
we have also a broader argument, in which the local is considered a vital dimension of a commons-centric society.

In line with degrowth and localization narratives, we are living the endgame of neoliberal material globalization based on cheap energy, labour, and transport, which necessitates the relocalization of production. The value-creation communities of the global commons approach are based locally and simultaneously connected globally. New and substantially more community-oriented forms of socio-economic organization emerge. There is arguably no contradiction between open design collaboration on a global level, and production/ manufacturing on a local level. Even more, a potential convergence may strengthen localized reterritorialization through global networks of enterprises. These will be based on global digital commons, of software, knowledge, and design, but operate according to relocalized implementations

To distinguish this approach from both localized communities and global neoliberal material networks, we could call it 'cosmolocalism' (Ramos et al., 2017; Kostakis and Ramos, 2017). This idea comes partly from the discourse on cosmopolitanism which asserts that all human beings belong to a single community, based on a shared morality and a shared future. Cosmolocalism captures the potentials of the global digital commons in conjunction with the capacity for more localized manufacturing. The shared morality comes through the commons, meaning, through co-creating and co-managing shared resources.

The dominant economic system treats physical resources as if they were infinite and then locks up intellectual resources as if they were finite. However, the reality is quite the contrary. We live in a world where physical resources are limited, while non-material resources are digitally reproducible and therefore can be shared at a low cost. Moving electrons around the world has a smaller ecological footprint than moving coal, iron, plastic and other materials.

At a local level, the challenge is to develop economic systems that can draw from local supply chains: what is light (non-rivalrous; e.g. knowledge) becomes global and what is heavy (rival; e.g. manufacturing equipment) remains local. We can thus design global and manufacture local (Kostakis et al., 2016; 2017). Decentralized open resources for designs can be used for a wide variety of things, medicines, furniture, prosthetic devices, farm tools, machinery and so on. For example, the WikiHouse project produces designs for houses; the LibreSpace community that built the first open-source satellite in orbit; the Farm Hack and L'Atelier Paysan communities that produces designs for small-scale agricultural machines; the OpenBionics project that produces designs for prosthetics; the AbilityMate that produces ankle-foot orthoses; the RepRap community creates designs for $3 \mathrm{D}$ printers.

Such projects do not necessarily need a physical basis as community members are dispersed all over the world. Global design communities and local production communities could thus create commons-oriented entrepreneurial coalitions: participatory business ecosystems that work for a community and 
its commons. The participating entities constitute sovereign means for the commoners to create livelihoods, whilst maintaining global commons. This approach may move beyond the threats of social regression, through a vision of a more frugal abundance for the whole of humanity. It maintains a maximum amount of wellbeing services and infrastructures but with a lower load on natural resources and the environment.

A limitation of this new model is that the problems of its two main pillars, information and communication as well as local manufacturing technologies, are not yet directly addressed. These issues may pertain to resource extraction, exploitative labour, energy use, material flows or the digital divide (see the work of Christian Fuchs for an integrative approach on the issue from a social sciences perspective: Fuchs, 2008; Fuchs and Horak, 2008; Fuchs, 2017). Our claims for the sustainability potential of commons-based products and practices rest on thin empirical foundations. However, some favourable dynamics cannot be neglected (Kostakis, Roos and Bauwens, 2016; Kostakis et al. 2017; Piques et al. 2017).

CBPP communities are not motivated to follow a planned obsolescence approach to design and engineering. Also, local manufacturing technologies (from 3D printers and laser cutters to drills, low-tech and crafts) offer possibilities for on-demand manufacturing resulting in less transportation of the raw materials. While the potential of such models is still debatable regarding scale, when customization and scope are needed they can be instrumental. Moreover, CBPP communities tend to mutualize their productive resources (for example, shared manufacturing infrastructure in makers-spaces) and thus benefit in tandem.

WikiHouse, Open Source Ecology, Farm Hack, L'Atelier Paysan, RepRap, OpenBionics, AbilityMate are only some empirical cases where the digital commons converge with local manufacturing technologies creating sophisticated products (from houses, tractors and other agricultural machines to prosthetic robotic hands and 3D printers). These communities develop, share and improve the design as a global digital commons, while the actual manufacturing takes place locally through shared infrastructures, often with local conditions in mind.

To escape the predicaments of the current political economy and to move towards ecologically sustainable alternatives (Bollier, 2014b), we envision a transition effectuated by new distributed systems of provisioning and democratic governance. The global commons scenario suggests that we should work on building both global and local political and social infrastructures.

Of course, CBPP cannot instantly substitute all production processes or that centralized infrastructures (such as water supply) are useless. CBPP is a proto-mode of production and, thus, currently unable to perpetuate itself on its own outside capitalism, to a full mode of production. Central to this discussion is, on the one hand, the concept of the 'ethical market' that would include commons-oriented enterprises; and on the other hand, the 'partner state' that 
would enable and empower direct social-value creation by providing support for the necessary infrastructures, and focus on the protection of the commons sphere (Orsi, 2009; Bauwens and Kostakis, 2015; Kostakis, 2011).

It is necessary to tackle the flow of value, which is now 'extracted' by netarchical capital, to create a fully-functioning commons-centric economy. Contributors of global and local communities must create their commons-oriented entities so that the surplus can be used for creating livelihoods, ensuring social reproduction of commoners, and reinvesting in P2P-based production networks. Capital accumulation must be replaced by 'cooperative accumulation' ${ }^{11}$, which is reinvested in the growth of the commons-based productive communities and their entrepreneurial coalitions. This strategy was used successfully to grow cooperative networks such as Mondragon, Spain, but also to create the vibrant cooperative economy of Emilia-Romagna, Italy.

Nevertheless, the aim here is to use cooperativism for strengthening the emergence, expansion and dominance of CBPP. Moreover, it is an illusion that such a development of the commons forces can be done with a hostile state. A successful commons transition strategy requires tackling the issue of political organization and on influencing the form of the state head on. Before proposing a more coherent strategy for a commons transition (Chapter 5), we need to place $\mathrm{P} 2 \mathrm{P}$ within the wider context of the structure of world history (Chapter 4). 


\section{TWO MODELS OF VALUE CREATION AND THELR TECHNOLOGIGAL INFRASTRUGTURES}

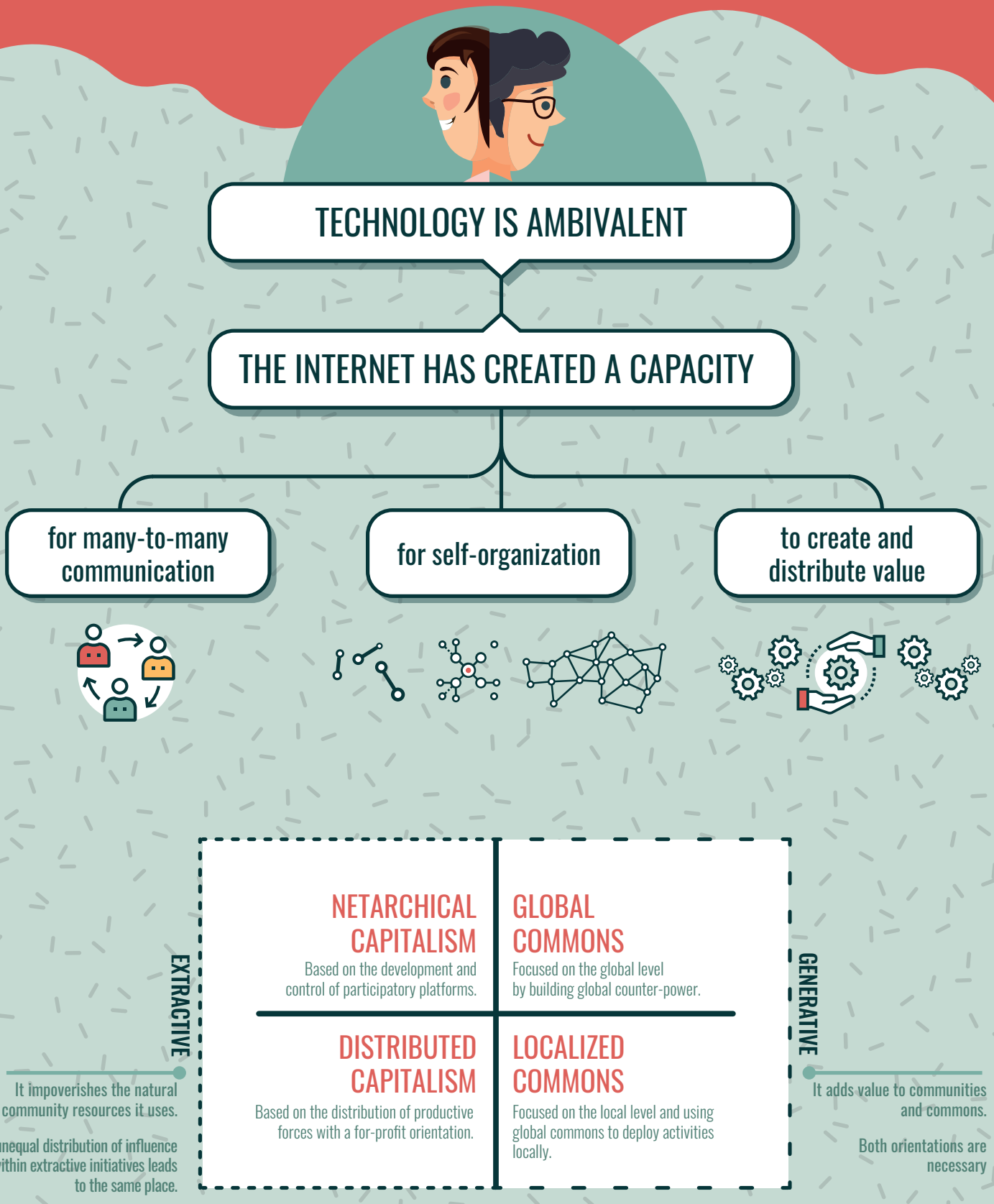




\section{These are the traits of a new mode of production}

Our dominant system exploits natural resources as if they were infinitely abundant. Negative consequences become 'externalities', evading responsible use.

Meanwhile, knowledge - socially productive, naturally abundant, easily reproduced - is locked behind Intellectual Property and paywalls.
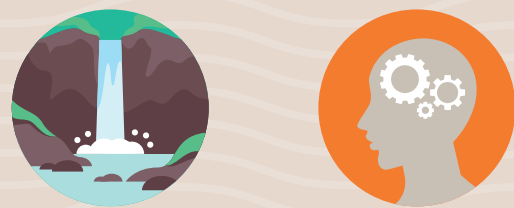

\section{But we can turn this around!}

...by combining digital commons with community-based manufacturing.

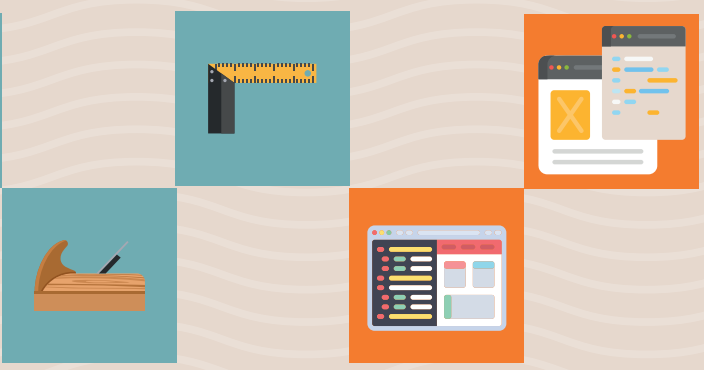

\section{$\rightarrow$ ITS KEY:}

What's 'light' (knowledge) is global, and what's 'heavy' (physical manufacturing) is local.

\section{Three advantages over capitalist forms \\ of industrial production:}

\section{NON-PROFIT}

Communities design the objects they will use. This way, planned obsolescence is halted while resilience is promoted. 


\section{LOCAL}

Customized physical manufacturing happens in community workshops. High transportation costs are reduced while maintenance and spare parts are handled locally.

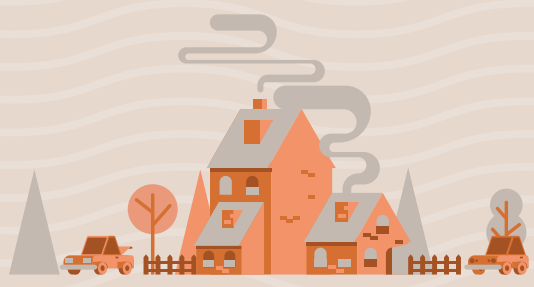

\section{SHARED}

Digital resources like blueprints, collaboration methods and software are shared globally. Material resources like community spaces, tools and machinery are managed locally. Precarious work decreases and power is distributed to create a true 'Sharing Economy' more worthy of the name.

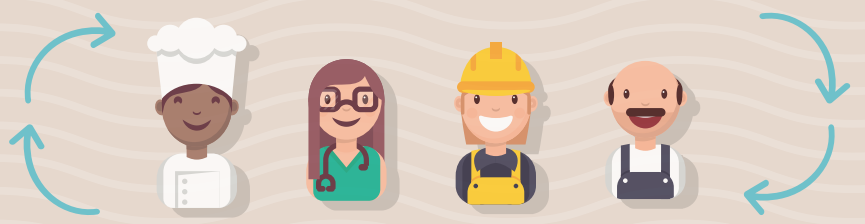

The 'design global, manufacture local' approach can work for

- Housing

- Medicine

- Transportation

- Agriculture

- ...and more!
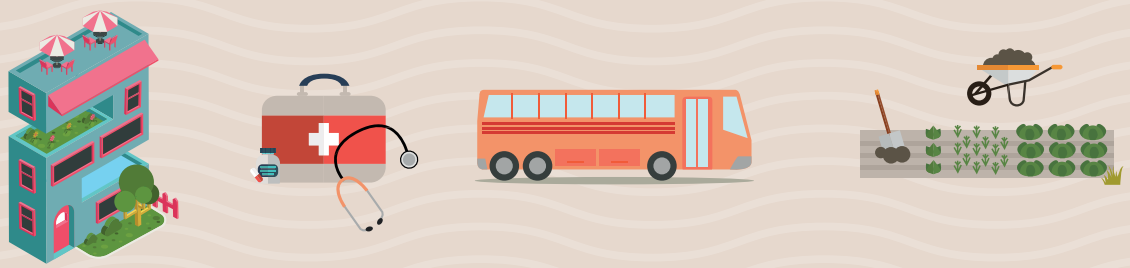

DEMOCRATIZE PRODUCTION, 



\section{CHAPTER 4}

\section{P2P and the Structure of World History}

$\mathrm{P} 2 \mathrm{P}$ is not something new. It has existed since the dawn of humanity and was initially the dominant form of relationship in nomadic hunter-gathering societies. In industrial capitalism (and later in state-socialist systems) the commons and $\mathrm{P} 2 \mathrm{P}$ dynamics were driven to the margins. However, with the affordance of P2P-based technologies, the commons and P2P dynamics can now scale up to a global level and create complex artifacts that transcend the possibilities of both state- and market-based models alone.

\subsection{Four Modes of Exchange}

A basis for our approach is provided by the Japanese philosopher Kojin Karatani $(2008,2014)$, who understands human history through modes of exchange. Karatani proposes that the relationship between humans could be seen in terms of exchange in a broader sense. By 'exchange' he also refers to 'allocation'; hence we use these two terms interchangeably. For example, in primitive societies, collaborating people share the products of their labour. Their relations are reciprocal and can be seen as a mode of exchange. In class societies, some people work for others either by force or for money. These relations can be seen as different modes of exchange.

In his early work, Marx had used the notion of exchange in such a broad sense. In particular, he used the German word 'Verkehr' that stands for intercourse/traffic. In The German Ideology (Marx and Engels, 1846), 'Verkehr implied diverse notions of trade and war between family and tribal communities, and even communication in general, not to mention traffic in a narrow sense' (Karatani, 2008: 572). Marx abandons the concept in The Communist Manifesto in 1848. Karatani (2008) claims that the abandonment was due to Marx's submergence in the study of economics. Marx focused on the study of the capitalist

How to cite this book chapter:

Bauwens, M., Kostakis, V. and Pazaitis, A. 2019. Peer to Peer: The Commons Manifesto. Pp. 47-54. London: University of Westminster Press. DOI: https://doi.org/10.16997/ book33.d. License: CC-BY-NC-ND 4.0 
economy limiting his observation of exchange to one modality, namely, commodity exchange. Thus, the state, the community, and the nation had a secondary role. Karatani suggests a return to the notion of Verkehr to address those matters more comprehensively.

He considers the state and the nation as derived from the modes of exchange rather than exclusively from commodity-exchange: 'In Capital, Marx tried to explain these grandiose and illusive systems from the basic mode of commodity exchange. We can see the state and the nation as historical derivatives of the basic modes of exchange. Neither is a communal fantasy nor ideological image; they have firm and necessary grounds. That is precisely why they cannot be easily dissolved' (Karatani, 2008: 573).

Karatani shows how the state, under absolute monarchy regimes in Europe, strengthened but also subordinated market forces, until these forces, through political and social revolutions, subordinated the state. Markets became strong in Europe because they had existed at the margins of the imperial systems, and did not have to face the unchallenged and robust power of imperial centralization. This gave market forces a unique historic opportunity to first grow in the 'free cities' of medieval Europe.

As the capital-state nexus destroyed previous forms of community, a new form of 'imagined community' (Anderson, 1983) emerged that became the nation. Capitalism is the convergence of the dominant capitalist market logic, the subordinated state logic, and the equally subordinated logic of the nation. These modes of exchange (Table 2) have always existed but in different combinations reflecting different configurations of dominance.

The first mode (Mode A) includes the reciprocity of the gift and is based on the 'community'. The second mode (Mode B) is related to ruling and protection and is based on a state-like apparatus (for purposes of simplicity, we shall call it the 'state'). The third (Mode C) involves commodity exchange, and is based on the 'market'. It corresponds to a subversion of the state form of power modality and imposes its power structures in the name of free exchanges in the marketplace. Therefore, capitalism emerges when the capitalist market becomes dominant and subordinates the 'community' and the 'state' to its own needs. The fourth (Mode D) is the possible mode of 'association', which would transcend the power of the state and the class divisions of the market.

Each modality changes as it becomes constrained by the influence and domination of other modalities. For example, the form of 'community' is the first band (under nomadism) then the tribe, next is the agricultural or territorial community under imperial systems, and finally becomes the nation under the domination of capitalist systems.

In a nutshell, Karatani recognizes four transitions in human history. A first transition occurred when the pooling of resources in nomadic bands was replaced as a dominant modality of exchange by the reciprocity-based gift economies of tribal systems. This allowed a scaling from bands to clans, tribes and inter-tribal systems and therefore, created a world that consisted of a collection 


\begin{tabular}{|l|l|l|l|l|}
\hline \multicolumn{1}{|c|}{\begin{tabular}{|l|l|} 
Types of \\
mode \\
exchange
\end{tabular}} & $\begin{array}{c}\text { Mode A: } \\
\text { Community }\end{array}$ & $\begin{array}{c}\text { Mode B: } \\
\text { State }\end{array}$ & $\begin{array}{c}\text { Mode C: } \\
\text { Market }\end{array}$ & $\begin{array}{c}\text { Mode D: } \\
\text { Association }\end{array}$ \\
\hline Description & $\begin{array}{l}\text { The reciprocity } \\
\text { of the gift (or } \\
\text { 'pooling' } \\
\text { through } \\
\text { commons) }\end{array}$ & $\begin{array}{l}\text { Ruling and } \\
\text { protection (also } \\
\text { called: 'plunder } \\
\text { and } \\
\text { redistribute') }\end{array}$ & $\begin{array}{l}\text { Commodity } \\
\text { exchage } \\
\text { (capitalist } \\
\text { market) }\end{array}$ & $\begin{array}{l}\text { It transcends the } \\
\text { other three (the } \\
\text { return of mode A } \\
\text { at a higher level } \\
\text { of complexity) }\end{array}$ \\
\hline
\end{tabular}

Table 2: Types of Mode Exchange.

of tribal mini-systems. Karatani links this shift to the settling of a nomadic population (sedentarization).

A second transition occurred when reciprocity-based systems of tribes were replaced by state-like systems, based on the logic of 'plunder and redistribute' or 'rule and protect. This allowed scaling at inter-tribal and inter-community levels and, therefore, created a world of world-empires that competed with each other.

A third transition occurred when the capitalist market form replaced these systems as the dominant mode of exchange. A global world-market system was created in which nation-states competed with each other, which Karatani characterizes as a world economy.

Finally, he foresees a new transition towards the 'association', a mode of allocation that will integrate the previous ones but will be dominated by the pooling that was originally dominant in the early nomadic groups. Karatani calls this modality 'associationism'. Associationism (Mode D) is characterized by the recovery of the principles of reciprocity (Mode A), on a higher level, and beyond the state and capitalism (Modes B and C). However, Karatani stresses that associationism does not exist in reality but exists only as a 'regulative idea'.

Karatani's description of the 'association' mode is congruent with our idea that we may be at the threshold of a new type of civilization, based on a new mode of exchange/allocation in addition to a new mode of production. A particular aspect of his argument is that 'association' is not just a return to the reciprocity of the 'community', nor a pure nomadic band structure, but a new structure that transcends all three preceding structures.

Pooling and gift economy dynamics dominated 'community' while 'association', in the case of the digital commons, enables various kinds of pooling. The 'association' is an attempt to recreate a society based on the 'community', but at a higher level of complexity and integration retaining individual freedom.

As discussed below, this new integration strongly assimilates reciprocity mechanisms around the pooling and mutualization of productive knowledge. Before we move on with the pre-figurative transition towards the modality of 'association', it is of particular value to more deeply explore how this integration 
becomes apparent in contemporary community-driven struggles striving for autonomy and collective organization.

\subsection{Towards Associationism}

We can now argue that one of the central goals of the P2P theory is to investigate the transition from social forms based on the domination of the market forces (capitalism), to social forms based on P2P network dynamics. So, P2P theory should be at the service of the forces of transition that work for the emergence, advancement and eventual domination of associationism.

Let us stress a few points made by Karatani. First, all systems are multimodal, and the transitions depend on struggles for dominance among the co-existing modalities. In an existing configuration of systems, transitions occur because a formerly subordinate mode of exchange, through prefigurative changes, achieves dominance in a new configuration. In this scenario, political and social revolutions occur as the result of previous structural changes, not as a prior condition to it. There have to be capitalists or merchants in a feudal system for capitalism to become dominant eventually. By extension, this means that there have to be commoners for the commons to become the core of the next system.

In addition to the physical commons on which humanity still depends, but which have been subordinated and weakened by capitalism, there are new digital commons that are innovative and productive even in the context of a capitalist market and state. This means that integrated production systems, which include digital commoning, often outperform the systems that do not use these methods. This is true both for systems in which capital integrates the commons as well as for systems in which the commons integrates the market. There is a growing band of self-organized commoners, existing within the dominant mode of capital.

The current form of transition, therefore, entails strengthening the autonomy of the commons modality and, hence, strengthening the power of commoners vis a vis other modalities. This multi-modal strategy is at the heart of our approach, and makes it differ from the previous approaches that were (and still are) based on the conquest of state power by classical 'labour movements'.

The strength of capitalism, Karatani argues, is the integration of three modalities in a system that includes capital-nation-state (i.e. an integration of a dominant 'market') but allied with the 'state' and even the 'community' (the national community as the locus of reciprocity and an 'imagined community' that attempts to resurrect the lost 'community'). This is, he says, why capitalism is such a robust system since whenever capital gets out of line and creates imbalances in society, the nation (that is the community of the nation-state) forces the state to discipline the capitalist market.

This is also the source of the insight of Karl Polanyi (1957) about the famous 'double movement' (the periodic capacity of the people to re-discipline 
the imbalances of capitalism, through the state). One of the critical issues today is precisely that the double movement does not seem to work because the state has become a market-state, which is too controlled and subservient to the power of transnational capital.

But, as we explain in Chapter 5, a strategy that solely relies on the nation-state as counter-power to transnational capital is doomed to failure. Of course, until there is a widespread and robust enough network of commons activities, the positioning of the nation-state as counter-power to transnational capital might also be a necessary component of any viable strategy. The good news is that there is an alternative strategy. That alternative strategy is based on strengthening the new prefigurative system and a new integrated set of institutions with a new configuration of the pre-existence modalities under the 'domination' of the commons.

Contemporary politics should no longer be only about the balance in the trinity of capital-nation-state. It should no longer be about anticapitalist struggles that can be seen as either a struggle for a new balance within the old system, for a more significant piece of the pie within the old system, or to create an alternative state-based distribution system. In reality, these are tantamount to a restoration of the Mode B ('state'), which is what the socialist revolutions attempted and failed to achieve in any lasting way. Contemporary politics should be about post-capitalist, commons-oriented construction and struggles. The new configuration could be as follows.

Firstly, the new dominant model will have at its core a neo-nomadic contributory system that all citizens can contribute to. The Internet allows cognitive labour to take place from various physical locations and facilitate the generalized pooling and reproduction of knowledge.

Secondly, this sphere of the commons will be surrounded by productive entities, which will likely use 'reciprocity mechanisms' both internally and externally. We call this the commons-oriented entrepreneurial coalitions that create livelihoods for the commoners and their commons.

Thirdly, in their external mode of operation, these entities discipline the 'market' through the exigencies of reciprocity. This means that they also reintroduce the 'moral or ethical markets' that were dominant before capitalism.

Let us remember Chapter 2 where the micro-economic trinity of CBPP institutions was described. We now argue that it corresponds to the three great spheres of social life: the productive community corresponds to the civil society with its citizen-contributors; the entrepreneurial coalitions, to the economic society of market entities; and the for-benefit association corresponds to the political society of the state.

The for-benefit associations of the CBPP ecosystems are, at the micro-level, a snapshot of 'the state of CBPP', in that they serve the 'common good' of the whole system. They are responsible for the 'field' within which the different players - that is the productive communities and the participating entrepreneurial entities - operate. They take care of the infrastructural needs and the 
common good of the ecosystem. They are also capable of imposing binding rules on the relevant domains. These associations are not merely based on contracts between individuals but are autonomously governed institutions that represent the different stakeholders.

Hence, seen at the macro-level, this allows us to look at the evolution of the state in a commons-centric society as a 'partner state.' The public authorities would empower and facilitate the direct creation of value by civil society at the scale of territory, by creating and sustaining infrastructures for commonsbased contributory systems. Any facilitating and capacity-creating action from the state today could be considered as a prefiguration of a full partner state in the future. Citizen-commoners and their social movements would drive the existing state form into partner state forms that recognize the individual and collective autonomy of citizens, just as the civil rights, suffrage, labour and women's movements forced the state to adapt to new social demands.

As long as we live in an unequal class-based society, a state-based mechanism is arguably needed. The State (capitalized) in the Hegelian notion is the guarantor of the common good. It is an abstraction encapsulating the community as a whole, including its institutions; it is the absolute ends of diverse individuals but also owes its very existence to them. The nation-state is currently in crisis but has been the imagined, yet not unreal, community that has served as the theatre of struggle and transnational movements, such as the internationalist labour movement. Social movements are therefore unlikely to obtain anything outside that frame, while they are often themselves reverting to it.

De Angelis (2017) analyzes both the commons and social movements as enabling environments where individual emancipation takes place. They interrelate insofar the commons provide alternatives, for which the social movements may strive. The process of social revolutions necessitates an alignment of commons with social movements, synchronizing their respective sequences 'to turn the subjects of movements into commoners and make commoners protestors' (De Angelis, 2017: 371). They thus become mutually reinforcing, through the expansion of the commons, which in turn forms a new basis for more powerful movements. CBPP then serves as a driving force for the material recomposition of the commons. It enables the conditions to sustain livelihoods for commoners and the deployment of social force to reconfigure their relations to the current social systems, including the capital and the state.

Therefore, social movements, which emerge from the shift towards CBPP, will exert pressure on the state. If they become majoritarian, a transformation of the state form from the present 'market state' to a 'partner state', which would represent the interests of the commons, is possible. Ideally, as this state and commons-based civil society would create the conditions for a re-emergence of human equality, the state would gradually be 'commonified' (as opposed to privatized) and radically transformed.

Similar to the strategy of transvestment of capital, this is not an 'all or nothing' proposal and could occur at all kinds of scales. However, for real systemic 
change to occur at the macro-level of global society, it would eventually require the reorganization of society under this new configuration. This means that while our strategy is reformist, as it works within the existing configurations, it is also revolutionary in the sense that it is based on the understanding that the current extractive system must at some point transform to a new configuration.

Our approach is related to the theorization of 'revolutionary reforms' by Andre Gorz (1967). A revolutionary reform is acceptable to the existing system but also creates conditions for its transformation. The establishing of a basic income could be an example of this, as it may break the necessity for labour to be commodified, and liberate time and effort towards the construction of selfchosen commons-producing activities.

A historical analogy may be useful here. In her essay on the emergence of guilds in the twelfth century, 'The Silent Revolution' (2008), Tine De Moor describes how the guilds organized labour solidarity, while recognizing, and being recognized by, the existing power structure. At some point, the merchant guilds would evolve to become the new capitalist class that would finally take power in a new configuration.

While the international system of states is failing to address global challenges, and with the idea of a global state looking quite unlikely to emerge - let alone it being also highly undesirable - the nation-state system remains the only viable form of governance able to guarantee rights and protections. A first step would be to complement it with new transnational institutions and networks with a cosmo-local direction that will build upon state power while laying down the foundations to transcend it.

Chapter 5 discusses how commoners could evolve to become the new ruling class in a commons-oriented configuration or in what Karatani calls 'associationism'. 


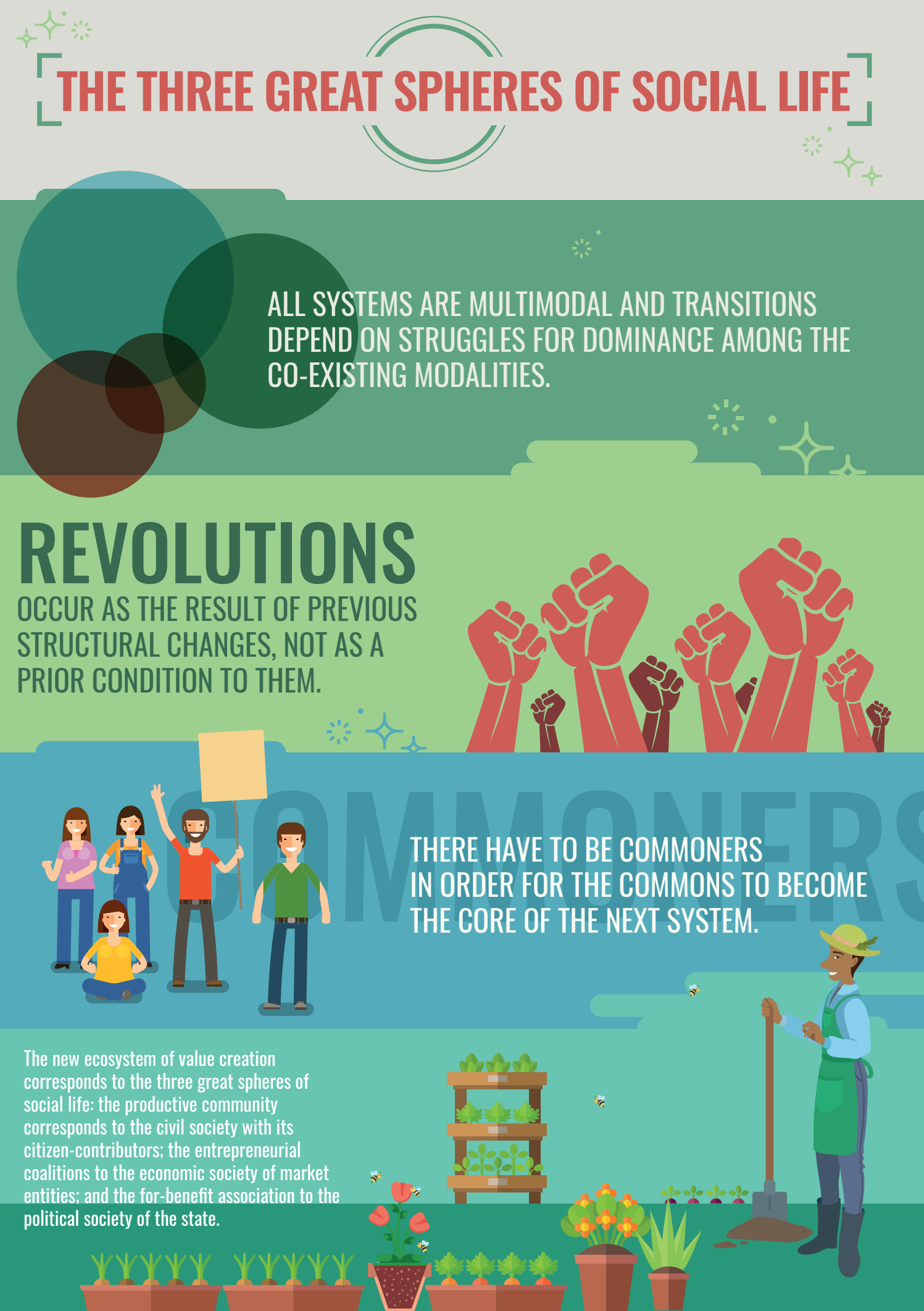




\section{CHAPTER 5}

\section{A Commons Transition Strategy ${ }^{12}$}

How to be an anti-capitalist in the 21 st century? Erik Olin Wright (2015) writes:

Give up the fantasy of smashing capitalism. Capitalism is not smashable, at least if you really want to construct an emancipatory future. You may personally be able to escape capitalism by moving off the grid and minimizing your involvement with the money economy and the market, but this is hardly an attractive option for most people, especially those with children, and certainly has little potential to foster a broader process of social emancipation. If you are concerned about the lives of others, in one way or another you have to deal with capitalist structures and institutions. Taming and eroding capitalism are the only viable options. What you need to do, is participate both in the political movements for taming capitalism through public policies and in socio-economic projects of eroding capitalism through the expansion of emancipatory forms of economic activity.

We mostly agree with Wright's point of view and suggest ways that simultaneously tame and erode capitalism. We, however, do not have the same confidence that the era of violent social and political revolutions is over. Such revolutions are organic events and the result of an unwillingness of elites to accommodate necessary system change.

For us then, eroding capitalism points to the necessity of creating a prefigurative commons-centric economy within existing capitalism. The post-capitalist future requires commoners as the agents of change, and in order to have commoners, the sphere of the commons needs to expand. Taming capitalism predicates no permanent and radical hostility to the state (Kattel, Drechlser and Karo 2018), which has to be 'tamed'. This has been the strategy of all successful social movements to date, and that includes the labour movement, universal

How to cite this book chapter:

Bauwens, M., Kostakis, V. and Pazaitis, A. 2019. Peer to Peer: The Commons Manifesto. Pp. 55-74. London: University of Westminster Press. DOI: https://doi.org/10.16997/ book33.e. License: CC-BY-NC-ND 4.0 
suffrage movements, women's and gay rights movements. This also means finding synergies and convergences among the prefigurative forces that can create the new economy, and finding political expressions for them, so that they can act in alliance with other emancipatory social and political forces.

One of the consequences of a multimodal approach is that allies should be found amongst the forces representing the other modes of production and allocation. This implies uniting the forces which support the commons, that support generative and ethical markets, and which support the development of a partner state.

\subsection{Pooling Resources Wherever Possible}

One of the essential features of P2P technologies is the liberation from the limitations of time and space. Hence, an ever larger number of people is not bound to their territory, which includes territory in the virtual sense (e.g. organization or enterprise). This is now possible both for 'immaterial' and material production. Workers can develop contributory lifestyles and add and withdraw from paid and unpaid projects throughout their lives.

The CBPP communities and their contribution-based technical systems of production can generally be characterized as open contributory systems though they have some filtering membranes in place to guarantee high-quality contributions and contributors. People can freely contribute to one or more commons of their choice. Pooling is, therefore, at the heart of CBPP.

Pooling both 'immaterial' and material resources are a priority. This capacity to pool productive knowledge is now one of the most important characteristics to obtain both 'competitive' and 'cooperative' advantage (depending on the orientation of the productive entity towards profit-maximization or for-benefit generative goals). Pooling - or in other words 'the commons' - should be at the heart of the productive and societal system.

\subsection{Introducing Reciprocity}

The mutual coordination within CBPP that takes place through open signalling can operate for the production of digital commons because these goods are nonrival. But what about material production? Since rival physical goods can be depleted (that includes human labour), and they are in need of regeneration, a different modality of allocation is needed. This is why although we have a 'cybernetic communism' at the heart of the capitalist system in the production of 'immaterial' goods (Barbrook and Cameron, 2015), we need another mechanism for material production. Instead of the practice of the 'communist' principle behind pooling ('from each according to their ability, to each according to need'), we may often need a reciprocity principle: 'to each according to their contribution'. 
We thus propose the model of an 'open cooperative' - an entity that would be legally and statutorily bound to creating commons and shared resources. Open cooperatives would internalize negative externalities; adopt multi-stakeholder governance models; contribute to the creation of digital and physical commons; and be socially and politically organized around global concerns, even if they produce locally (Bauwens and Kostakis, 2016). In short, open cooperatives argue for a synergy between the CBPP movement and elements of the cooperative and solidarity economy movements. The difference with traditional cooperatives is that open cooperatives pool their immaterial resources, creating thus a multifaceted digital commons for other open cooperatives and for-benefit associations. As explained in 5.4, this cooperative advantage could help expand the commons sphere while subordinating capitalism.

Traditional cooperatives have historically served as viable alternatives to the capitalist organization of production. They have proven a distinct capacity in providing employment and security for workers and promote a broader reconfiguration of social structures. However, Rosa Luxemburg's (1899) critique holds for cooperatives using hybrid forms of social production struggling within the capitalist system, which gradually forces them to either adopt competitive and exploitative mentalities or eventually dissolve. Cooperatives often self-enclose around their local or national membership and are less concerned with serving the broader community and thus fail to fulfil their transformative role (Pazaitis et al., 2017b).

In a similar direction, platform cooperatives have been proposed as alternatives to exploitative sharing economy models. They offer a radical redesign of the ownership and control of online platforms, promoting democratic governance, solidarity and social benefit (Scholz and Schneider, 2016). Platform cooperatives create an enabling environment for employees, customers, and users of digital services and contribute positively to the commons. However, platform cooperatives still pose isolated alternatives designed to counter old forms of capitalism, prone to the frailties of traditional cooperatives.

Open cooperatives aim to expand and interconnect to aggregate, support and protect collective knowledge, tools, and infrastructures. They produce locally but organize around global concerns to build a counter-economy that can deem CBPP to be a full and autonomous mode of production. They seek to create new types of vehicles, through which self-organized workers can realize surplus value and emancipate themselves from the confines of the dominant system.

Perhaps a right way to understand these multi-modalities of the new postcorporate entities is to look at the functioning of the medieval guild system. Externally they were selling their goods on the marketplace (but even that was subjected to 'just pricing' practices), but internally they were fraternities and solidarity systems. This offers a historical analogy to understand the double logic of the new entities connected to the commons. In a commons-centric economy, new purposes could be achieved through open participatory systems 
that would connect producers and consumer/user communities, through mutual solidarity, as in the model of community-supported agriculture. We thus propose models that intertwine contributors with various roles, in one solidarity ecosystem. Furthermore, to the degree that these entities can use open contributory accounting systems, parts of the management of material production could be moved towards mechanisms of mutual coordination and pooling, which require a different sort of distributed collaborative planning (e.g. Sensorica).

Physical resources and means of production could also be pooled themselves. Commons-based forms of property could be implemented that are neither state property nor necessarily individual private property. Think about 'commons funds' to which all contributors participate and co-own. These processes would create the linkages between the still scarcity-based distribution of physical resources, which need to be regenerated and therefore require reciprocity; and non-reciprocal general pooling, for resources that need not be regenerated. To the degree that physical resources become more abundant, these resources could move to more abundance-based commonscentric models.

In conclusion: a distinction is made between commons-centric models that are appropriate for rival resources and commons-centric models that are appropriate for non-rivalrous resources. These models should be seen as polarities, with possibilities to move in one or another direction using hybrid combinations. While some communities may want to commonify their physical resources and eventually move to full non-reciprocal sharing modalities, other communities may wish to increase demands for specific reciprocity.

\subsection{From Redistribution to Predistribution}

\subsubsection{The Partner State Approach}

As was explained, the CBPP ecosystem has its productive communities; coalitions of entrepreneurs; and the 'management' or 'governance' institution, that of the for-benefit associations. For instance, the nonprofit foundations of free and open-source communities often manage and enable the infrastructure of cooperation. They defend the use of open licenses, sometimes provide training or certification, but generally, their task is to enable cooperation. Unlike the post-democratic dynamic of polyarchic contributory communities, these for-benefit institutions generally function with formal democratic procedures, such as elections.

In this context, these for-benefit associations operate as mini-states of the CBPP ecosystems. Hence, moving from the observation of the existing practice at the micro-level to the vision of a full social form, we observe that there is room/need for the 'state form': 
1. a productive civil society contributing to the commons;

2. a predominantly generative market that creates added value around the commons;

3. a partner state, whereby public authorities play a sustaining role in the direct creation of value by civil society (i.e. they sustain and promote CBPP).

Something more than a redistributionist welfare state is necessary, which would go beyond accepting the supremacy of capital and disciplining the capitalist market players from the outside. We need a state that would create the conditions for the creative autonomy of its contributing citizens. Predistribution of resources is necessary rather than post-facto redistribution.

The partner state would ideally be the guarantor of civil rights, but also of the contributory equipotentiality of all citizens. It would empower and enable the direct creation of value by civil society at the scale of territory, by creating and sustaining infrastructures for CBPP ecosystems. Without such a territorial function, productive communities would have unequal access to resources and capabilities, leading to a continuing unequal society. In our vision, such a state form should be one that would gradually lose its separateness from civil society, by implementing radical democratic and even rotational procedures and practices.

A partner state approach would not be opposed to the welfare state model, but rather should transcend and include it. It would retain the solidarity functions of the welfare state, but de-bureaucratize the delivery of its services to the citizen. The social logic would move from ownership-centric to citizen-centric. The state should be de-bureaucratized through the commonification of public services and public-commons partnerships.

In the face of rising individualistic political philosophies, such as anarchocapitalism that only sees individuals making contracts with each other, public good institutions are necessary. Society exists and needs its specific forms of expression. The state is one of them. Also, the state imaginary we argue for, synchronized with the unique characteristics of digital technologies, could be that of the partner state.

A partner state approach is seen prefiguratively in some urban practices, such as the Bologna Regulation for the Care and Regeneration of the Urban Commons or the Barcelona en Comú citizen platform.

\subsubsection{The Urban Commons of Barcelona and Bologna}

The urban commons are the locus of convergence between the digital commons of knowledge and culture, and the material reorganization of post-capitalist modes of production and exchange. It is thus not coincidental that such configurations have surfaced on a city-level. Within a globalized economy and with the transnational system of nation-states unable to address contemporary 
challenges, cities provide an alternative transnational governance structure that complements and transcends the current institutions.

The recent emergence of commons-oriented municipal coalitions evinces such a dynamic. In the following sections, we offer a brief description of two paradigmatic cases ${ }^{13}$ of city councils that pose interesting alternatives to the traditional municipal form of government. In contrast to the short cases presented in Chapter 2, the aim here is not to present a generalized set of patterns. Instead, they serve to explore different approaches of cities facilitating types of citizen participation aligned with the commons.

\section{The City of Barcelona}

Barcelona is a momentous case that signifies a new form of radical municipalism directly confronting the current limitations of the nation-state. The city has a great diversity of grassroots initiatives, from the commons-oriented crowdfunding platform of Goteo and the Cooperativa Integral Catalana, to Guifi.net, a free/open telecommunications community network. This rich civic ecosystem has marked Barcelona as a reference point for CBPP.

Barcelona is not a city in reform from the top down; it is a city in a transformation from the bottom up. This is how the Barcelona en Comú (BeC) citizen platform emerged, took power and now governs in the minority in the City of Barcelona. Activist-level praxis matured into a political force attempting to share its hard-won knowledge and experience internationally. The BeC platform has been built step by step, acknowledging every little victory that adds up to something (previously) unimaginable. Moreover, finding the appreciation for the small steps is part of the change.

$\mathrm{BeC}$ is an illustrative case of a citizen platform created by social movements along with political parties to reimagine citizen participation in governance. It was launched in 2014 with an electoral programme collectively drafted by over 5000 people contributing in open assemblies and online procedures. The primary objectives addressed timely political issues, such as austerity, evictions and mass tourism, while particular importance was placed on the improvement of living standards and the urban commons. Moreover, the programme championed openness and democratization of local government institutions and direct citizen participation in local governance, while it explicitly refers to the commons as a central aspect of its political vision.

The $\mathrm{BeC}$ political coalition holds 11 seats out of 41 . Within the small space between simple legislation and doing nothing at all, $\mathrm{BeC}$ attempts to embrace cooperatives and citizen activism despite the many limits and problems at government level. Central to this approach has been the support of the Social and Solidarity Economy (SSE). This effort has been materialized in the Impetus Plan, a set of policies directed towards the development of new SSE 
organizations and the transformation of traditional commercial entities, as well as the improvement of coordination across the sector.

The Impetus Plan includes a dedicated section on the commons, with a policy framework for the Commons Collaborative Economy (CCE), comprising the following layers:

A cross-cutting body inside the city council to coordinate policies around transport, housing, tourism, and labour.

BarCola, a working group involving representatives from the city council and the CCE sector for policy recommendations, assessment and crosssectoral dialogue between the SSE and the commons.

Decidim Barcelona, a hybrid participatory process combining in-person and digital input that has been developed for city residents to collaborate in municipal debate and decision making

Alongside this, in mid-March 2016 Barcelona hosted the Commons Collaborative Economies event (called 'Procomuns'), centred on producing public policy proposals for the commons economy. The event, which drew a vast, diverse crowd from 30 countries, produced a joint statement and a series of policy recommendations targeted toward the Barcelona City Council, the European Commission, and other local governments.

The CCE policy framework for Barcelona has led to a Collaborative Economy Action Plan, with measures spanning from training and outreach to the promotion of circular economy programmes. Simultaneously, $\mathrm{BeC}$ is funding the Ateneus de Fabricació, a network of public FabLabs that strives to provide access to high-tech infrastructures and machinery and assist learning and the development of digital fabrication in every neighbourhood. Other types of interventions include policies for mobility and traffic control targeted at the reduction of pollution and the creation of citizen spaces.

$\mathrm{BeC}$ aspires to overcome national boundaries where possible, through the establishment of translocal coalitions, such as an international committee for cooperation and knowledge exchange with other cities, including Naples and Messina. It is also very active in international forums like the Global Network of Cities, Local and Regional Governments. Furthermore, decidim.barcelona has been used by other cities in Spain, while it is also promoted to cities internationally, exemplifying the potential of shared digital infrastructures in intercity alliances.

\section{The City of Bologna}

Moving about $1000 \mathrm{~km}$ from Barcelona to the east, Bologna is a paradigmatic case for developing new institutional processes for public-commons 
partnerships. It showcases new types of adaptive tools that allow citizens and other actors to get involved in collaborative design processes for the city.

In 2012, the City of Bologna initiated a political process focusing on urban resources and services with the aim to reshape the relationship between citizens and the local administration. Central to these policies has been the role of the Laboratory for the Governance of the City as a Commons (LabGov), which has brought together various stakeholders to develop collaborative projects, policies and regulations for the urban commons.

In February 2014, a regulatory framework titled 'The Bologna Regulation on Civic Collaboration for the Urban Commons' (hereafter 'the Regulation') has been adopted. The Regulation sets a framework for the collective management of public spaces, buildings and other infrastructure, and also considers issues like the improvement of the quality of city life and human flourishing. A vital tool of the Regulation is a collaboration pact that allows the city to establish agreements with residents and other actors, such as NGOs, local entrepreneurs, and institutions.

The Bologna Regulation is based on a change in the Italian constitution allowing engaged citizens to claim urban resources as commons and to declare an interest in their care and management. Typically, after an evaluation procedure, an 'accord' is signed with the city specifying how the city will support initiatives with an appropriate mix of resources and specifying joint publiccommons management. Support may take various forms: from the provision of rules and guidelines for the maintenance of shared resources to the formulation of neighbourhood associations for the management of public spaces, as well as technical and financial assistance.

Since the adoption of the Regulation, 280 pacts for collaborative projects have been registered, from neighbourhood regeneration and social sharing projects to crowdfunding initiatives and digital commons platforms. Moreover, there have been several efforts targeted at disadvantaged communities, such as community-based reuse of infrastructures and resources.

Simultaneously, apart from the Regulation the City of Bologna has put forward other types of commons-oriented public policies. For instance, Incredibol is a successful project promoting creative and cultural activities in the broader region of Emilia-Romagna, which includes the creative use of abandoned or unutilized public assets. Also, Collaborare è Bologna is another project that develops collaborative planning processes for the governance of the urban commons through shared knowledge, technology, and resources.

The next step in the Bologna commons agenda is a program called 'COBologna', which considers the expansion of urban commons design principles to other local public policies. These include areas like collaborative services, ventures and production spaces for the co-creation of solutions to urban problems.

The City vision of Bologna as a collaborative city is bringing together a global network of other cities in the same direction. The successful course of the 
projects in Bologna has encouraged more than 140 other Italian cities to follow.

For instance, Torino is already planning to adopt the Regulation, while Milan, Rome, and Florence have expressed specific interest.

The regulation is radical in giving citizens the direct power to produce policy proposals and transform the city and its infrastructure, as an enabler for this. The key is the reversal of logic: the citizenry initiates and proposes, the city enables and supports. The model of public-commons partnerships reconfigures civic and public collaboration. It envisions a new form of municipal government that views the city as a collaborative social ecosystem, rather than an inventory of administered resources. Nevertheless criticism of the Bologna Regulation is often singling out a top-down approach that differentiates it from the case of Barcelona. However, this again only makes the two cases complementary, rather than mutually exclusive.

\subsubsection{A Coherent Strategy for Urban Commons Transitions}

The cases of urban commons reconfigurations provide useful lessons on how to transit from the current market-state and, respectively market-city institutions, to commons-centric ones. Such a strategy would comprise three phases.

The first phase is characterized by the emergence of commons-based seed forms of systems of provisioning in crucial areas, such as food, shelter, and energy. These provide viable solutions to systemic problems of the dominant political economy. They become stronger as they interconnect with each other, mobilize citizens and integrate within and across different domains. For instance, community-owned energy cooperatives can lead a strategy to promote renewable energy solutions, challenging the traditional activities based on fossil fuels. Similarly, a community-based kitchen can cover the vital needs of disadvantaged members of the society, in contrast to traditional food supply chains. Civic mobilization around such alternatives can create significant pressures for increasing social and eventually, political power.

The second phase centres around the development of the necessary regulatory and institutional frameworks that support these alternatives. Proper institutions and regulations can be crucial for commons-based alternatives so that they can shift from the margin to the centre of the system and be proposed as viable alternatives. For example, in the case of energy cooperatives, policies such as feed-in tariffs incentivize specific forms of energy over others and help alternative models to expand more broadly, by ensuring they are more appealing. Similarly, regulatory measures for profit-oriented ridesharing platforms can support local commons-based alternatives.

Finally, the third phase pertains to the normalization of commons-based practices. With proper institutional support, generative market forms can be developed around commons-based alternatives, allowing them to expand and shape the new logic in their respective systems and territories. 
These three phases are concurrent and tightly interwoven. Also, a critical mass of initiatives needs to be operating before political action can be summoned and relevant institutions can be designed. Likewise, the economic dynamics that these frameworks enable are highly dependent on the existence of a stable and mature commons sphere. Ultimately, this approach is based solely on structural changes that take place within the political economy. An integrated strategy also needs to take particular notice of the relevant cultural and subjective changes that vary in every different context.

\subsection{Subordinating the Capitalist Market}

Under capitalism, the market mechanism is dominant and infects all the other modalities - everything tends to be commodified. Capitalism is an extractive, profit-maximizing relationship. It exploits workers and now extracts profits from the free labour of free and open-source software and open design workers or from communication on social media. It has a similar extractive relation with nature and the environment.

The market, however, would continue to exist in a commons-oriented society. The market would shift from being predominantly extractive to predominantly generative. First, this means that the market will serve the commons. CBPP participants are struggling to create a direct livelihood by merely contributing to the pool of digital commons. They must pass through either the state (payment by the state, for example in public universities and publicly-funded science, or subsidies for culture and non-profits) or the capitalist market. State support could take the form of a basic income, along with other already known models of support.

However, commoners must also create a new type of market entity that would allow them to contribute to the commons. As we explained above, commoners form entrepreneurial coalitions that create products and services for the market and serve as a conduit to generate income for the continued construction of the commons. What role could the capitalist market have in a commons transition?

We argue for commons-based reciprocity licensing, which has been called 'copyfair' as a play on the copyright and copyleft. (For a discussion of reciprocity concerning licensing see Vieira and De Filippi, 2014). Copyfair allows commons-contributing entities to use the commons material for free, but noncontributory for-profit market entities have to pay for a license for the right to commercialize certain commons materials. In this approach, the free sharing of knowledge is preserved (the universal availability of digital commons) but commercialization is made conditional on reciprocity. The Peer Production License, proposed by Kleiner (2010), exemplifies this line of argument.

So, reciprocity is created between the sphere of the capitalist market and the sphere of the commons. This simultaneously allows for the entities participating 
in the ecosystems of commons-oriented entrepreneurial coalitions to pool their immaterial - and even material in the long run- resources and benefit in tandem.

\subsection{Organizing at the Local and Global Level}

Our central political recommendation is that progressive coalitions at urban, regional and nation-state level should develop policies that increase capacity for the autonomy of citizens and the new economic forces aligned around the commons. Merely initiating left-Keynesian state policies will not be sufficient and will probably be met with stiff transnational opposition from the financial oligarchy. These pro-commons policies should be focused not just on local autonomy, but also on the creation of transnational and translocal capacities, interlinking the efforts of their citizens to the global commons-oriented entrepreneurial networks that are in development.

We suggest that progressive coalitions should focus on post-capitalist construction first and foremost. Except in rare locales, current progressive movements are wedded to the old industrial Keynesian models. But as they discover the limits of this strategy, openings towards commons-supportive policies may emerge. What follows from the above analysis is that the current commonsoriented forces must also focus on the creation of translocal and transnational capacities.

So, what could we do? There is a rapid increase in the number of civic and cooperative initiatives outside of the state and corporate world. Most of these initiatives are locally oriented, and that is necessary. We know that today there are movements that operate beyond the local and use global networks to organize themselves. A good example may be the Transition Town movement, and how it uses networks to empower local groups.

Indeed, it has been shown that the city context appears more mature for a commons transition. City administrations can shape the conditions for generative models of production and exchange that increase local autonomy and simultaneously create translocal capacities. Coalitions of cities can support global for-benefit institutions through public-commons partnerships to develop and maintain vital infrastructures and common protocols enabling urban systems of provisioning.

Commons repositories of knowledge, software, and designs can be shared among cities to empower local sharing platforms that commonify urban services, related to systems like food, mobility and lodging. Local adaptations of commons-based platforms, like Fairbnb (Amsterdam) and MuniRide (Ghent), may serve as a field of knowledge exchange and sharing experiences to mutualize physical spaces and services.

However, this is not enough. We propose the creation of translocal and transnational structures that would aim to have global effects and change the power 
balance on the planet. The only way to achieve systemic change at the planetary level is to build counter-power, that is alternative global governance. The transnational capitalist class must feel that its power is curtailed, not just by nationstates that may organize themselves internationally, but by transnational forces representing the global commoners and their livelihood organizations.

We favour commons-oriented entrepreneurial coalitions that strengthen commons and their contributory communities and create an economy for them. These generative, translocal, and transnationally operating coalitions already exist. Amongst the best known are Enspiral (initially based in New Zealand); Sensorica (initially based in Montreal, Canada); Las Indias (mostly based in Spain but with many Hispanic members from Latin America); and Ethos VO (based in the UK). We believe this new type of translocal organization is the seed form of future global coalitions of generative entrepreneurs.

In this context, commons-oriented entrepreneurial coalitions could locally be represented by regional Chambers of Commons, first proposed by David Ronfeldt as a way to emulate the Chamber of Commerce ${ }^{14}$. Moreover, again at the local level, the pro-commons associations could be represented in Assemblies of the Commons. The Assembly of the Commons could help empowering civic power around the commons ${ }^{15}$. It could bring together all those who contribute and maintain common goods and serve as a forum to exchange experiences and bring commonality into diversity. For example, the Assembly of the Commons could organize events around commons topics; support those social and political forces that bring forward an agenda for the commons; promote and engage in public-commons partnerships. It would be fraternally connected to the Chamber of the Commons, as well as to other assemblies. In this way, they all together could operate at a larger scale and form regional, national, transnational federations.

Also, global federations of commons-oriented entrepreneurial coalitions could be created. This initiative would aim at connecting already existing entrepreneurial coalitions so that they can learn from each other, but also at developing a collective voice. We see that as a global equivalent of the proposal for the Chamber of the Commons.

These developments of commons-specific social institutions could emerge in parallel with more traditional political expressions of commons mentalities. We have already seen the emergence of political parties, the Pirate Parties, which are expressions of the file-sharing communities that were repressed through copyright legislation, which led to their politicization. The 15-M movement in Spanish cities gave birth to the en Comú coalition in Barcelona, which raised to power and makes specific references to the commons, e.g. the development of a commons-oriented economy.

In addition to these specific and more direct expressions of commonsoriented political forces, we claim that the acceptance of a commons agenda could be the basis for new progressive coalitions with already existing political forces. With the Pirates reflecting digital culture, the Greens the political 
expression of the natural commons and the new emerging left parties representing a new (post-)industrialism, we foresee the emergence of majoritarian coalitions in which the commons would be a binding element.

We must build 'counter-hegemonic' power at the global level. This continuous meshworking at all levels is what will build the base upon which to create systemic change: the power to change, at the level where the destructive force of global capital and its predation of the planet and its people can be countered.

This has been done before. According to Kojin Karatani (2014), the reason our current market society came about is that Europe was never able to consolidate centralized power, allowing independent cities where merchants could exist and expand their power. This social force became dominant after the fall of absolute monarchs. So market forces had already a long history behind them before social and political revolutions made the market form dominant. Capitalism won because pro-capitalist forces already existed.

However, commoners do exist. We use digital commons and rely on physical commons. Commoners should follow the same multi-modal strategy and prefiguratively build their power and influence at all levels. Of course, just as labourers did, for this we have to develop a consciousness that we are commoners. Anyone participating and co-constructing shared resources without exploiting them is a commoner. It is a question of how people see the 'relative weight' of the commons modality in their lives as well as whether commons become part of their social imaginary of a desired future.

Because the world is multimodal, it does not make sense, and it is impossible, to create a 'totalizing' commons world. We, could however, aim for a commonscentric society where market forces and state functions are 'disciplined' at the service of the commons. Like capital did before us (Karatani, 2014), we must build our strength within a multimodal world.

\subsection{Summary of our Proposals}

Here is a summary of our proposals for a multimodal transvestment strategy as well as for organizing locally and globally.

The first step is to fight against the extractive activities of profit-maximizing entities directed at the commons and its allied economic entities. Commoners should use transvestment strategies that would transfer value from the capitalist market modality to the commons modality. We thus propose that:

- Commoners mutualize digital (e.g. knowledge commons, software, and design) and even physical resources (e.g. shared manufacturing machines). We need pooling wherever it is possible.

- Commoners establish their economic entities and create livelihoods for productive communities. We need open cooperatives. 
- These economic entities use commons-based reciprocity licensing to protect against value capture by capitalist enterprises. We need copyfair.

- Open cooperatives are organized in participatory business ecosystems that generate incomes for their communities. We need commons-oriented entrepreneurial coalitions.

This leads us to the second step that is to build a counter-power at the city, regional and global level. We thus advocate for:

- The creation of local institutions that give voice to commons-oriented enterprises that build commons and create livelihoods for commoners. We need Chambers of the Commons.

- The creation of local or affinity-based associations of citizens and commoners, bringing together all those who contribute, maintain or are interested in common goods, material or immaterial. We need Assemblies of the Commons.

- The creation of a global association that connects the already existing commons-oriented enterprises, so that they can learn from each other and develop a collective voice. We need Commons-oriented Entrepreneurial Associations.

- The creation of global and local coalitions between political parties (e.g. Pirate Parties, Greens, New Left) in which the commons is the binding element. We need a Common(s) Discussion Agenda.

\subsection{A Last Word}

Capitalism has demonstrated a capacity to overcome its challenges. However, it is not an ahistorical system that will magically persist. First and foremost, capitalism has been based on capital accumulation and infinite growth. But it is impossible to imagine perpetual growth in a finite environment: capitalism will not be able to offer a fundamental solution to the ecological crisis that it creates (D’Alisa, Demaria and Kallis 2014).

This book suggests that a commons transition may address the multifaceted crisis the world is facing. In a first period, the commons should be seen as a challenge to capitalism and as a function of struggle and a balancing of forces. Is the surplus value generated by commons extracted or enclosed? Does it take the form of a social compromise? Alternatively, can it be a terrain of struggle, in which the commoners develop their strategies to gain strength within capitalism, to augment the surplus available to their activities and to create social and political power for a subsequent re-arrangement of power, leading to systemic change?

While it is likely that the next wave of capitalism will problematically integrate green and commons-based aspects, it is unlikely to be able to do this in 
the long term, due to its growth fixation and other destructive imperatives. Not knowing this future, which is under construction and subject to power relationships, we can therefore only work with scenarios. However, each of these scenarios includes the necessity to strengthen the autonomy and the place of the commons in a future social order.

Our approach is complementary to the work of Nick Dyer-Witheford (2015) that mostly provides an analysis of classic working-class exploitation within the capitalist system and largely ignores (apart from a few elements) struggle through the construction of seed forms. We do not focus on capitalist exploitation and resistance within the capitalist mode of production but on the construction of post-capitalist seed forms and how to advance them.

On top of that, our approach is also related to both Paul Mason's (2015) and Jeremy Rifkin's (2014) analysis of post-capitalist dynamics. However, both Mason and Rifkin lack much focus on the social and political contradictions of the transition, are strongly techno-deterministic in their orientation, and crucially, don't include any real detail about the transition itself. By contrast, our approach accepts only a mild form of technological determinism and stresses struggle through the construction of alternatives by focusing on realistic institutional design between the commons and the spheres of the market and the state.

Techno-deterministic approaches often celebrate post-scarcity visions of the future. These views reflect a particular understanding of technology that actually intensifies the problems that are sought to be solved through it. New technologies are frequently portrayed only as finished goods, disregarding the economic relations embedded in their development, which conceals the fact that these technologies exist at the expense of other humans and local environments elsewhere.

Similarly, issues of scarcity cannot simply be engineered away by more efficient production methods. What is broadly discussed as the 'Jevons' Paradox' (Alcott, 2005) illustrates that efficiency improvements can lead to an absolute increase in the use of raw materials and energy, due to lower prices per unit and a subsequent increase in demand. On a global scale, such efficiency is best understood as a rearrangement of resource expenditures, where efficiency improvements at one end of the world increase expenditure at the other end.

Acknowledging those multifaceted issues, this book is not based on utopian desires, but on constant analysis of the emerging seed forms and their successes and failures. Through this, a realistic picture emerges of transition strategies that strengthen the commons sphere in a hostile environment.

We thus propose an integrative strategy for a broad societal transition that differs from the classic left narratives of previous centuries. Why could this strategy be effective?

Firstly, it is consistent with the historical record that shows that political revolutions did not precede profound reconfigurations of social power, but completed them. The development of a new movement or class and its practices precedes concluding social revolutions that made their power and modalities 
dominant. There is a convergence of data that supports the prefigurative existence of a growing number of commoners ${ }^{16}$, who could form the basis of a historical subject at the forefront of this transition.

Moreover, essential to this development are the changing cultural expectations of millennial and post-millennial generations, and their requirements for meaningful engagements and work, which are scarcely met by the current regime. The precarization of work under neoliberalism drives the search for alternatives and the cultural force of $\mathrm{P} 2 \mathrm{P}$ self-organizing and corresponding mentalities fuels the growth of commons-oriented networks and communities.

Also, CBPP is a model that could create a context of genuinely sustainable production. It is almost impossible to imagine a shift to sustainable circular economy practices under the current proprietary regime. The thermodynamic efficiencies needed for sustainable production could be found in the regular applications of principles inherent in the commons-centric economy ${ }^{17}$.

Finally, the crises of the left itself, which are now relegated to the management of the crisis of neoliberalism itself, points to the vital need of renewing the strategic thinking of the forces that aim for human emancipation and a sustainable life-world.

We believe that a strategy for a multi-modal commons-centric transition offers a positive way out of the current crisis, and a way to respond to the new demands of the commons-influenced generations. The commoners are already here; so are the commons and the prefigurative forms of a new value regime. 


\section{PROPOSALS FOR A COMMONS TRANSITION}

The first step is to fight against the extractive activities of profit-maximizing entities towards the commons and its allied economic entities. Commoners should use transvestment strategies that would transfer value from the capitalist market modality to the commons modality.
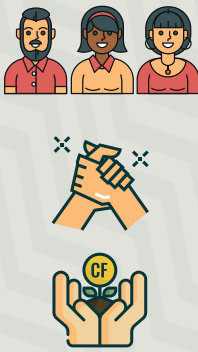

Q 0 0.

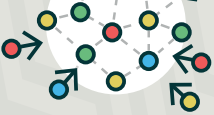

\section{WE NEED POOLING WHEREVER IT IS POSSIBLE.}

WE NEED OPEN COOPERATIVES.

WE NEED COPYFAIR.

WE NEED COMMONS-ORIENTED ENTREPRENEURIAL COALITIONS.

This leads us to the second step that is to build a counter-power at city, regional and global levels. New institutions are needed.
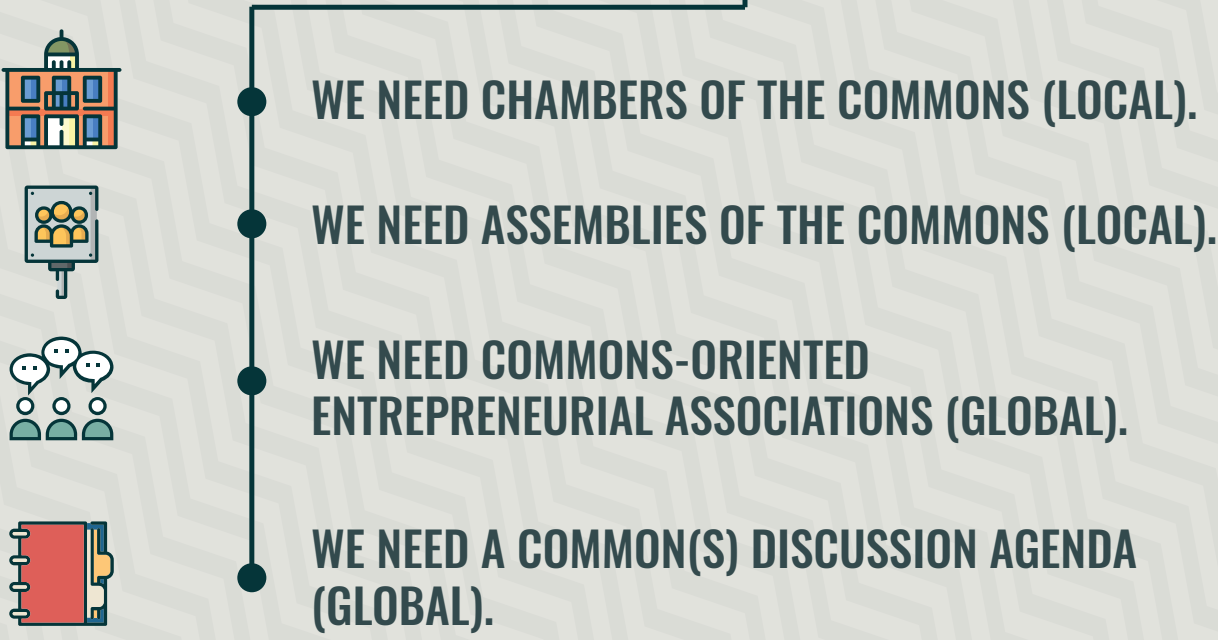


\section{OPEN COOPERATIVISM}

\section{a strategy for generative economies}

Centralized network data platforms form a powerful new 'digital feudalism', threatening the gains of the labor movement and accelerating precarity by influencing deregulation.

To counter this, Open Cooperativism combines Commons/P2P approaches with the cooperative movement, creating agile, resilient economic entities that co-create commons and provide livelihoods.

\section{4}

\section{PATTERNS OF OPEN COOPS:}

FOCUS ON THE COMMON GOOD:

Production is guided by social and environmental values.
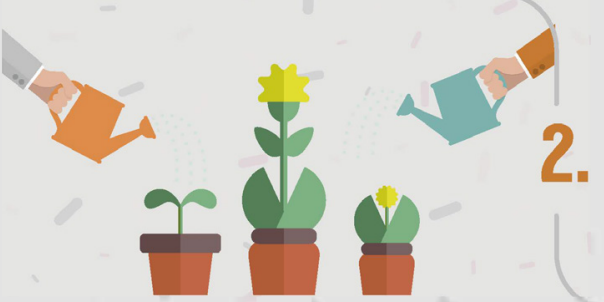

\section{MULTI-CONSTITUENT:}

ACTIVELY CREATING COMMONS:

3. Open Coops co-create and care for digital (code, design, documentation) and physical (infrastructure, deliberation spaces, machinery, etc.) commons.
All contributors affected by the Open Coop's value chain share ownership and control of its structure.

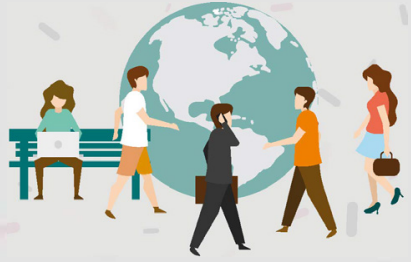

structure. 
WAYS OPEN COOPS CAN REIMAGINE OUR ECONOMIES:

\section{OPEN ABUNDANCE:}

Closed business models are based on artificial scarcity. Open Coops recognise the natural abundance found in digitally shareable knowledge and shares it transnationally.

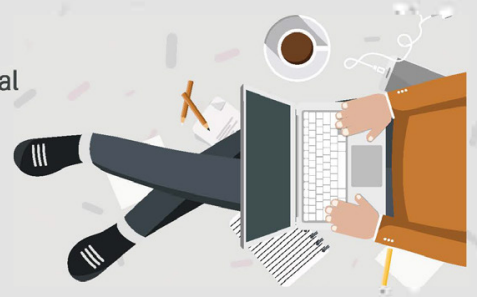

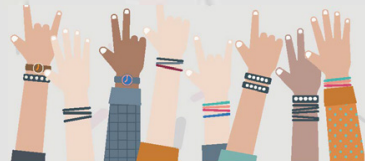

\section{DIVERSE CONTRIBUTIONS:}

Instead of enforcing the division of labour or specialization, Open Coops provide the tools for dynamic and flexible participation.

\section{FAIR DISTRIBUTION:}

3. CopyFair licensing strengthens the commons economy through full sharing economic solidarity within the Commons sphere.
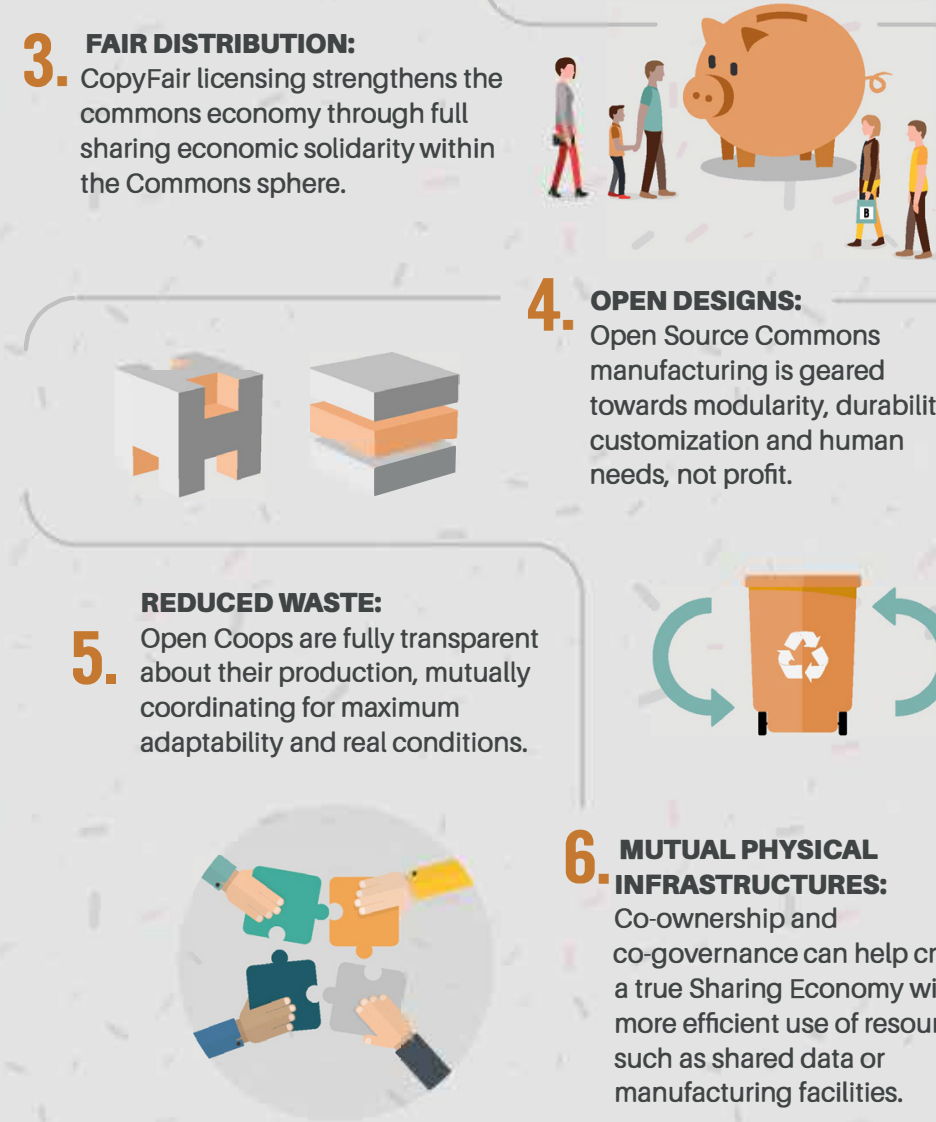

4. OPEN DESIGNS:

Open Source Commons manufacturing is geared towards modularity, durability, customization and human needs, not profit.

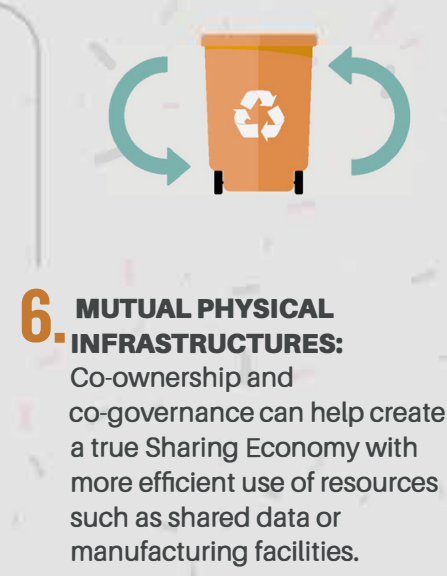

Open cooperativism, combined with distributed 'Design Global-Manufacture Local' production can free commoners to create fulfilling, generative economies instead of remaining on the treadmill of working in an extractive, destructive system. 



\section{Acknowledgments}

This manuscript could not be something else than the product of commonsbased peer production. Michel Bauwens, Vasilis Kostakis, and Alex Pazaitis are the main authors; however, this book would not have been realized without the contribution of many scholars, activists, colleagues, and friends.

We are immensely grateful to anonymous reviewers, Patrick Barrett, Yochai Benkler, Tiberius Brastaviceanu, Kevin Carson, William Charlton, Primavera De Filippi, the Degrowth reading group at the Autonomous University of Barcelona, Wolfgang Drechsler, Aline Duriez-Jablonka, Christian Fuchs, Chris Giotitsas, Neal Gorenflo, Baruch Gottlieb, Simon Grant, Joe Guinan, Ted Howard, Rainer Kattel, Alexandros Kioupkiolis, Nicolas Krausz, Andrew Lockett, John Milios, Vasilis Niaros, Vasilis Ntouros, Alekos Pantazis, George Papanikolaou, Christina Priavolou, Thanasis Priftis, ROAR magazine's editors, Andreas Roos, Nathan Schneider, Gus Speth, Felix Stadler, Margaret Stout, Henry Tam, Stacco Troncoso, Ann Marie Utratel, Jaap van Till, Elena Martinez Vicente and Erik Olin Wright.

Thanasis Papakonstantinou's verses from 'San Michele' were translated into English by Konstantina Tzouma, with thanks to both and for permission to use. All errors remain the main authors' sole responsibility. 


\section{Funding}

The authors would like to thank La Fondation Charles Léopold Mayer pour le Progrès de l'Homme for all the facilities provided. The original manuscript was remotely written by Michel Bauwens and Vasilis Kostakis during a four-month retreat of the former in Madison, Wisconsin, thanks to funding via the Havens Center and the Link Foundation. Vasilis Kostakis and Alex Pazaitis also acknowledge financial support from IUT (19-13) and B52 grants of the Estonian Ministry of Education and Research.

\section{List of diagrams and image credits}

'What the Commons and P2P Are': Infographic 1 was first published in M. Bauwens, V. Kostakis, S. Troncoso and A. Utratel, Commons Transition and Peer-to-Peer: A Primer. Amsterdam: Transnational Institute, pp.8-9 (2017). Design: Elena Martínez Vincente. CC-BY-SA.

'CBPP Ecosystems': Table 1 was first published in Bauwens, M., Kostakis, V., Troncoso, S., and Utratel, A. (2017). Commons Transition and Peer-to-Peer: A Primer. Amsterdam: Transnational Institute (p.13).

'The New Ecosytem of Value Creation': Infographic 2 was first published in Bauwens, M., Kostakis, V., Troncoso, S., and Utratel, A. (2017). Commons Transition and Peer-to-Peer: A Primer. Amsterdam: Transnational Institute (p.16).

'Two Models of Value Creation and Their Technological Infrastructure': Infographic 3a was designed by Elena Martinez Vicente. Text and concept by Vasilis Kostakis and Michel Bauwens.

'Cosmolocalism: Design Global, Manufacture Local': Infographic 3b was designed by Elena Martinez Vicente. Text and concept by Stacco Troncoso, Vasilis Kostakis and Michel Bauwens.

'Types of Mode Exchange': Table 2 was designed by Elena Martinez Vicente. Based on Karatani, K. (2014). The Structure of World History: From Modes of Production to Modes of Exchange. Durham and London: Duke University Press (p. 9). Adapted by Michel Bauwens.

'The Three Great Spheres of Social Life': Infographic 4 was designed by Elena Martinez Vicente. Text and concept by Vasilis Kostakis.

'Proposals for a Commons Transition': Infographic 5a was designed by Elena Martinez Vicente. Text and concept by Vasilis Kostakis.

'Open Cooperativism: A Strategy of Generative Economics': Infographic 5b was designed by Elena Martinez Vicente. Text and concept by Michel Bauwens, Stacco Troncoso, and Vasilis Kostakis. 


\section{References}

All websites were checked on 17 July 2018.

Agrawal, A. and Ostrom, E. 2001. 'Collective Action, Property Rights, and Decentralization in Resource Use in India and Nepal. Politics and Society, 294: 485-514.

Alcott, B. 2005. 'Jevons' Paradox'. Ecological Economics, 54(1): 9-21.

Anderson, B. 1983. Imagined Communities: Reflections on the Origin and Spread of Nationalism. London: Verso.

Aristotle, (trans.) Ross, W. D., and (ed.) Brown, L. 2009. The Nicomachean Ethics. Oxford: Oxford University Press.

Arvidsson, A., Bauwens, M., and Peitersen, N. 2008. 'The Crisis of Value and the Ethical Economy'. Journal of Futures Studies, 12(4): 9-20.

Arvidsson, A., and Peitersen, N. 2013. The Ethical Economy: Rebuilding Value after the Crisis. New York: Columbia University Press.

Baldwin, J.W. 1959. The Medieval Theories of the Just Price: Romanists, Canonists, and Theologians in the 12th and 13th Centuries. Philadelphia, PA: American Philosophical Society.

Barbrook, R,. and Cameron, A. 2015. The Internet Revolution: From Dot-Com Capitalism to Cybernetic Communism. Amsterdam: Institute of Network Cultures.

Bauwens, M., and Kostakis, V. 2014. 'From the Communism of Capital to Capital for the Commons: Towards an Open Co-operativism. triple C: Communication, Capitalism and Critique, 12(1):356-361. 
Bauwens, M., and Kostakis, V. 2015. 'Towards a New Reconfiguration Among the State, Civil Society and the Market'. Journal of Peer Production, 7, 1-6. Retrieved from: http://peerproduction.net/issues/issue-7-policies-for-thecommons/peer-reviewed-papers/towards-a-new-reconfiguration-amongthe-state-civil-society-and-the-market/.

Bauwens, M., and Kostakis, V. 2016. 'Why Platform Co-ops Should Be Open Co-ops'. In T. Scholz and N. Schneider (Eds), Ours to Hack and to Own: The Rise of Platform Cooperativism, a New Vision for the Future of Work and a Fairer Internet, pp. 163-166. New York: OR Books.

Bauwens, M., and Niaros, V. 2017a. Value in the Commons Economy: Developments in Open and Contributory Value Accounting. Berlin: Heinrich Böll Foundation.

Bauwens, M., and Niaros, V. 2017b. Changing Societies Through Urban Commons Transitions. Berlin: Heinrich Böll Foundation.

Bauwens, M., and Onzia, Y. 2017. Commons Transitie Plan voor de Stad Gent. In Opdracht van de Stad Gent. Retrieved from:_https://tinyurl.com/ybyj5qd4.

Bell, D. 1976. The Coming of Post-Industrial Society. New York: Basic Books.

Benkler, Y. 2002. 'Coase's Penguin, or Linux and the Nature of the Firm'. Yale Law Journal, 112: 369-446.

Benkler, Y. 2006. The Wealth of Networks: How Social Production Transforms Markets and Freedom. New Haven, CT: Yale University Press.

Benkler, Y. 2014. 'Between Spanish Huertas and the Open Road: A Tale of Two Commons?'. In B. Frischmann, M. Madison, and K. Strandburg (Eds.), Governing Knowledge Commons, pp. 69-98. New York: Oxford University Press.

Bollier, D. 2014a. Think Like a Commoner: A Short Introduction to the Life of the Commons. Gabriola Island, Canada: New Society Publishers.

Bollier, D. 2014b. 'The Commons as a Template for Transformation'. Great Transition Initiative. Retrieved from: http://www.greattransition.org/document/the-commons-as-a-template-for-transformation

Bollier, D., and Helfrich, S. 2015. Patterns of Commoning. Amherst, MA: Off the Commons Books.

Boehm, C. 2001. Hierarchy in the Forest: The Evolution of Egalitarian Behavior. Cambridge, MA: Harvard University Press.

Bogdanov, A. 1984. Red Star: The First Bolshevik Utopia. Bloomington, IN: Indiana University Press.

Boutang, Y. M. 2012. Cognitive Capitalism. Cambridge: Polity Press.

Caffentzis, G. 2012. 'A Tale of Two Conferences: Globalization, the Crisis of Neoliberalism and the Question of the Commons. Borderlands, 11(2). Retrieved from: http://www.borderlands.net.au/vol11no2_2012/caffentzis_ globalization.htm.

Cantillon, R. 2010. 'An Essay on Economic Theory' - An English translation of Richard Cantillon's Essai sur la Nature du Commerce en Général. Auburn, AL: Ludwig von Mises Institute. 
Clark, B. and York, R. 2005. 'Carbon Metabolism: Global Capitalism, Climate Change, and the Biospheric Rift'. Theory and Society, 34(4): 391- 428.

Clark, B., and Foster, J. B. 2009. 'Ecological Imperialism and the Global Metabolic Rift: Unequal Exchange and the Guano/Nitrates Trade'. International Journal of Comparative Sociology, 50(3-4), 311-334.

Clark, B. and Foster, J. B. 2010. 'Marx's Ecology in the 21st Century'. World Review of Political Economy, 1(1): 142-156.

Clausen, R., and Clark, B. 2005. 'The Metabolic Rift and Marine Ecology: An Analysis of the Ocean Crisis Within Capitalist Production'. Organization and Environment, 18(4), 422-444.

Creative Commons. 2017. The 'State of the Commons' report for 2015 can be accessed here in several languages: https://stateof.creativecommons. org/2015/.

D'Alisa, G., Demaria, F., and Kallis, G. 2014. Degrowth: A Vocabulary for a New Era. New York: Routledge.

Dafermos, G. 2012. 'Authority in Peer Production: The Emergence of Governance in the FreeBSD Project'. Journal of Peer Production, 1 (1), 1-12.

Dalakoglou, D. 2017. 'Infrastructural Gap: Commons, State and Anthropology'. City, 20(6), 822-831.

De Angelis, M. 2012. 'Crises, Movements and Commons'. Borderlands, 11(2). Retrieved from: http://www.borderlands.net.au/vol11no2_2012/deangelis_ crises.htm.

De Angelis, M. 2017. Omnia Sunt Communia: On the Commons and the Transformation to Postcapitalism. London: Zed Books.

De Moor, T. 2008. 'The Silent Revolution: A New Perspective on the Emergence of Commons, Guilds, and Other Forms of Corporate Collective Action in Western Europe'. International Review of Social History, 53: 179-212.

De Moor, T. 2013. Homo Cooperans: Institutions for Collective Action and the Compassionate Society. Utrecht: Utrecht University Press.

Dyer-Witheford, N. 2015. Cyber-Proletariat: Global Labour in the Digital Vortex. London: Pluto Press.

Drechsler, W. 2001. 'Good and Bad Government: Ambrogio Lorenzetti’s Frescoes in the Siena Town Hall as Mission Statement for Public Administration Today'. Discussion Papers, No. 20, Local Government and Public Service Reform Initiative. Open Society Institute.

Drucker, P. 1969. The Age of Discontinuity. London: Heinemann.

Ebner, A. 2005. 'Entrepreneurship and Economic Development: From Classical Political Economy to Economic Sociology'. Journal of Economic Studies, 32(3): 256-74.

Eisenstein, E. 1983/2012. The Printing Revolution in Early Modern Europe (2nd edition). New York: Cambridge University Press.

Elliott, M. 2006. 'Stigmergic Collaboration': The Evolution of Group Work' M/C Journal: A Journal of Media and Culture, 9(2). Retrieved from: http://journal. media-culture.org.au/0605/03-elliott.php 
Feenberg, A. 2002. Transforming Technology: A Critical Theory Revisited. Oxford: Oxford University Press.

Federici, S., and Caffentzis, G. 2007. 'Notes on the Edu-Factory and Cognitive Capitalism'. The Commoner, 12, 63-70.

Foster, J. B. 1999. The Vulnerable Planet: A Short Economic History of the Environment. New York: Monthly Review Press.

Foster, J. B., Clark, B., and York, R. 2011. The Ecological Rift: Capitalism's War on the Earth. New York: Monthly Review Press.

Fraysse, O. 2015. 'Is the Concept of Rent Relevant to a Discussion of SurplusValue in the Digital World? 'In Fuchs, C., and Fisher, E. (eds), Reconsidering Value and Labour in the Digital Age, pp. 172-187. Basingstoke: Palgrave Macmillan.

Fuchs, C. 2015. 'The Digital Labour Theory of Value and Karl Marx in the Age of Facebook, YouTube, Twitter, and Weibo' In Fuchs, C., and Fisher, E. (eds), Reconsidering Value and Labour in the Digital Age, pp. 26-41. Basingstoke: Palgrave Macmillan.

Fuchs, C. 2008. 'The Implications of New Information and Communication Technologies for Sustainability'. Environment, Development and Sustainability, 10(3): 291-309.

Fuchs, C., and Horak, E. 2008. 'Africa and the Digital Divide'. Telematics and Informatics, 25(2), 99-116.

Fuchs, C. 2010. 'Labor in Informational Capitalism and on the Internet'. The Information Society, 26 (3), 179-196.

Fuchs, C. 2017. 'Critical Social Theory and Sustainable Development: The Role of Class, Capitalism and Domination in a Dialectical Analysis of Un/ Sustainability'. Sustainable Development, 25(5), 443-458.

Graeber, D. 2001. Toward an Anthropological Theory of Value: The False Coin of Our Own Dreams. Basingstoke: Palgrave Macmillan.

Graeber, D. 2011. Debt: The First 5000 Years. New York: Melville House.

Gramsci, A. 1971. Selections from the Prison Notebooks of Antonio Gramsci. New York: International Publishers.

Hardt, M. and Negri, A. 2011. Commonwealth. Cambridge, MA: Harvard University Press.

Harhoff, D. and Lakhani, K.R. 2016. Revolutionising Innovation: Users, Communities, and Open Innovation. Cambridge, MA: MIT Press.

Heylighen, F. 2016. 'Stigmergy as a Universal Coordination Mechanism I: Definition and Components'. Cognitive Systems Research, 38: 4-13.

Von Hippel, E. 2016. Free Innovation. Cambridge, MA: MIT Press.

Hornborg, A., Clark, B. and Hermele, K. 2012. Ecology and Power: Struggles Over Land and Material Resources in the Past, Present and Future. New York: Routledge.

Karatani, K. 2008. 'Beyond Capital-Nation-State'. Rethinking Marxism: A Journal of Economics, Culture and Society, 20(4): 569-595. 
Karatani, K. 2014. The Structure of World History: From Modes of Production to Modes of Exchange. Durham, NC: Duke University Press.

Kattel, R., Drechsler, W., and Karo, E. 2018. Innovation Bureaucracies: Let's Make the State Entrepreneurial. New Haven, CT: Yale University Press.

Kelly, M. 2012. Owning Our Future: The Emerging Ownership Revolution - Journeys to a Generative Economy. Oakland, CA: Berrett-Koehler Publishers.

Kleiner, D. 2010. The Telekommunist Manifesto. Amsterdam: Institute of Network Cultures.

Kleiner, D. 2016. 'What Economy? Profit Versus Sustainability'. Retrieved from: https://www.youtube.com/watch?v=iGBzhon_vS0andfeature=youtu. beandt $=36 \mathrm{~m} 1 \mathrm{~s}$.

Knight, F. H. 1921. Risk, Uncertainty and Profit. New York: Houghton Mifflin.

Kostakis, V. 2011. 'Commons-based Peer Production and the Neo-Weberian State: Synergies and Inter Dependencies'. Administrative Culture, 12(2), $146-161$.

Kostakis, V., Roos, A., and Bauwens, M. 2016. 'Towards a Political Ecology of the Digital Economy: Socio-environmental Implications of Two Value Models'. Environmental Innovation and Societal Transitions, 18, 82-100.

Kostakis, V., Latoufis, K., Liarokapis, M., and Bauwens, M. 2017. 'The Convergence of Digital Commons with Local Manufacturing from a Degrowth Perspective: Two Illustrative Cases'. Journal of Cleaner Production. Retrieved from: http://www.sciencedirect.com/science/article/ pii/S0959652616314184.

Kostakis, V., and Ramos, J. 2017. 'Design Global, Manufacture Local: A New Industrial Revolution?' The Conversation. Retrieved from https:// theconversation.com/design-global-manufacture-local-a-new-industrialrevolution-82591

Kostakis, V., Niaros, V., Dafermos, G., and Bauwens, M. 2015. 'Design Global, Manufacture Local: Exploring the Contours of an Emerging Productive Model'. Futures, 73, 126-135.

Kostakis, V., and Bauwens, M. 2014. Network Society and Future Scenarios for a Collaborative Economy. Basingstoke: Palgrave Macmillan.

Luxemburg, R. 1899 [1970]. Reform or Revolution. New York: Pathfinder Press.

Malcomson, S. 2016. Splinternet: How Geopolitics and Commerce Are Fragmenting the World Wide Web. New York: OR books.

Marsh, L., and Onof, C. 2007. 'Stigmergic Epistemology, Stigmergic Cognition' Cognitive Systems Research, 9(1-2), 136-149.

Marx, K., and Engels, F. (ed. C. J. Arthur) 1846 [1970]. The German Ideology. London: Lawrence and Wishart.

Mason, P. 2015. PostCapitalism: A Guide to Our Future. London: Allen Lane.

Mateos-Garcia, J., and Steinmueller, E. 2008. 'The Institutions of Open Source Software: Examining the Debian community'. Information Economics and Policy, 20: 333-344. 
Mazzucato, M. 2018. The Value of Everything: Making and Taking in the Global Economy. London: Allen Lane

Mill, J. S. 1848. Principles of Political Economy with some of their Applications to Social Philosophy, 7th edn. (1909), edited by Ashley, J. London: Green.

Miles, I. 2004. 'Scenario Planning'. In UNIDO (ed.) Foresight Methodologies: Training Module 2. (Vol. 159, pp. 67-91), Vienna: UNIDO.

Moktan, R.M., Norbu, L., and Choden, K. 2016. 'Can Community Forestry Contribute to Household Income and Sustainable Forestry Practices in Rural Area? A Case Study from Tshapey and Zariphensum in Bhutan'. Forest Policy and Economics, 62: 149-157.

Moore, J. W., 2014. 'Beyond the "Exploitation of Nature"? A World-Ecological Alternative'. Retrieved from https://jasonwmoore.wordpress.com/2014/04/25/ beyond-the-exploitation-of-nature-a-world-ecological-alternative/

O'Dwyer, R. 2013. 'Spectre of the Commons: Spectrum Regulation in the Communism of Capital'. Ephemera: Theory, Politics and Organization, 13(3): 497-526.

Orsi, C. 2009. 'Knowledge-Based Society, Peer Production and the Common Good'. Capital and Class, 33, 31-51.

Ostrom, E. 1990. Governing the Commons: The Evolution of Institutions for Collective Action. Cambridge: Cambridge University Press.

P2P Foundation 2016. Cosmo-Localization. Retrieved from: https://wiki. p2pfoundation.net/Cosmo-Localization

Pazaitis, A., De Filippi, P. and Kostakis, V. 2017a. 'Blockchain and Value Systems in the Sharing Economy: The Illustrative Case of Backfeed'. Technological Forecasting and Social Change, 125, 105-115.

Pazaitis, A., Kostakis, V., and Bauwens, M. 2017b. 'Digital Economy and the Rise of Open Cooperativism: Case of the Enspiral Network'. Transfer: European Review of Labour and Research, 23(2), 177-192.

Piques, C., Rizos, X., and Bauwens, M., 2017. Peer to Peer and the Commons: A Path Towards Transition. A Matter, Energy and Thermodynamic Perspective. Amsterdam: P2P Foundation.

Polanyi, K. 1957. The Great Transformation: The Political and Economic Origins of our Time. Boston: Beacon Press.

Ramos, J., Bauwens, M., and Kostakis, V. 2017. 'P2P and Planetary Futures'. In D. Banerji and M. Paranjape, (Eds.), Critical Posthumanism and Planetary Futures. Zurich: Springer.

Reinert, E.S., and Reinert, S.A. 2011. 'Mercantilism and Economic Development: Schumpeterian Dynamics, Institution Building, and International Benchmarking. OIKOS, 10(1): 8-37.

Ricardo, D. 1821. On the Principles of Political Economy and Taxation, $3^{\text {rd }}$ edn. (1951), Cambridge: Cambridge University Press.

Rifkin, J. 2014. The Zero Marginal Cost Society: The Internet of Things, the Collaborative Commons, and the Eclipse of Capitalism. New York: Palgrave Macmillan. 
Rigi, J. 2015. 'The Demise of the Marxian Law of Value? A Critique of Michael Hardt and Antonio Negri'. In Fuchs, C. and Fisher, E. (eds), Reconsidering Value and Labour in the Digital Age, pp. 188-206. Basingstoke: Palgrave Macmillan.

Rogers, T. and Szamosszegi A. 2011. Fair Use in the U.S. Economy: Economic Contribution of Industries Relying on Fair Use. Washington DC: Computer and Communications Industry Association.

Say J.B. 1803. Treatise on Political Economy. New York: C. Princep.

Scacchi, W., Feller, J., Fitzgerald, B., Hissam, S., and Lakhani, K. 2006. 'Understanding Free/Open Source Software Development Processes'. Software Process: Improvement and Practice, 11: 95-105.

Schmoller, G. 1901, Grundriß der Allgemeinen Volkswirtschaftslehre, Vol 1. Leipzig: Duncker und Humblot.

Schumpeter, J.A. 1934. The Theory of Economic Development: An Inquiry into Profits, Capital, Credit, Interest, and the Business Cycle. Cambridge, MA: Harvard University Press.

Scholz, T. (ed.) 2012. Digital Labor: The Internet as Playground and Factory. New York: Routledge.

Scholz, T., and Schneider, N. 2016. Ours to Hack and to Own: The Rise of Platform Cooperativism, a New Vision for the Future of Work and a Fairer Internet. New York: OR Books.

Schor, J., and Fitzmaurice, C. 2015. 'Collaborating and Connecting: The Emergence of a Sharing Economy' In L. Reisch, and J. Thogersen (Eds.), Handbook on Research on Sustainable Consumption (pp. 410-425). Cheltenham: Edward Elgar.

Sewall, H.R. 1901. The Theory of Value before Adam Smith. New York: Macmillan. Retrieved from: https://archive.org/details/valuebeadamsmith00sewarich.

Sombart, W. 1902. Der Moderne Kapitalismus, Bd. 1: Die Genesis des Kapitalismus. Leipzig: Duncker and Humblot.

Sombart, W. 1909. 'Der kapitalistische unternehmer'. In: Archiv für Sozialwissenschaft und Sozialpolitik, Vol. XXV, pp. 689-758.

Smith, A. 1776. An Inquiry into the Nature and Causes of the Wealth of Nations, edited by Cannan, E., London: Methuen [1790/1904].

Tapscott, D., and Williams, A. 2006. Wikinomics: How Mass Collaboration Changes Everything. New York: Portfolio.

Thaler, R., and Sunstein, C. 2009. Nudge: Improving Decisions About Health, Wealth and Happiness. New York: Penguin.

Thompson, E.P. 1971. 'The Moral Economy of the English Crowd in the Eighteenth Century'. Past and Present, 50(1), 76-136.

Toffin, G. 2005. From Kin to Caste: The Role of Guthis in Newar Society and Culture. The Mahesh Chandra Regmi Lecture, 2005. Nepal: Social Science Baha.

Tsaliki, P. 2006. 'Marx on Entrepreneurship: A Note'. International Review of Economics, 53: 592-602. 
Vial, J. 2016. Hacking Capitalism with Capped Returns. In: Joshua Vial (Blog). Retrieved from: http://joshuavial.com/capped-returns.

Vieira. S., and De Filippi, P. 2014. 'Between Copyleft and Copyfarleft: Advance Reciprocity for the Commons'. Journal of Peer Production. Retrieved from:

http://peerproduction.net/issues/issue-4-value-and-currency/invitedcomments/between-copyleft-and-copyfarleft-advance-reciprocity-forthe-commons.

Wark, M. 2015. Molecular Red: Theory for the Anthropocene. London: Verso.

Weber, M. 1920. 'Die protestantische Ethik und der Geist des Kapitalismus'. In Weber, M. (Ed.) Archiv für Sozialwissenschaft und Sozialpolitik, Vol. XXXXI: 1-110. J.C.B. Mohr: Tübingen.

Webster, F. 2006. Theories of the Information Society. New York: Routledge.

Wood, J. 1990. 'COMMENT: The Socially Responsible Designer'. Design Magazine, July.

Wright, E.O. 2015. How to Be an Anticapitalist Today. Jacobin. Retrieved from: https://www.jacobinmag.com/2015/12/erik-olin-wright-real-utopiasanticapitalism-democracy/.

\section{The Authors}

Michel Bauwens is the Founder of the P2P Foundation and works in collaboration with a global group of researchers in the exploration of commonsbased peer production, governance, and property.

Vasilis Kostakis is the Professor of P2P Governance at Tallinn University of Technology and Faculty Associate at Harvard University. He is the founder of the P2P Lab and core member of the P2P Foundation.

Alex Pazaitis is a core member of the P2P Lab and a Junior Research Fellow at the Ragnar Nurkse Department of Innovation and Governance, Tallinn University of Technology. 


\section{Endnotes}

1 'Freedom' is probably one of the most highly contested words in philosophical thought. The conventional understanding of freedom is mostly connected with individual agency and action, especially in the liberal tradition. Particularly in economic affairs, 'free', as in 'free trade', characterizes transactions with little or no influence by state institutions. Interestingly, within Hegelian thought, the state is the sphere of the only genuine freedom, including individual freedom (Drechsler, 2001). In the context of this book, freedom refers to the globalization of the capacity for P2P connections through networked infrastructures. It reflects the material possibility for many-to-many communications on a global scale and the ability for people (peers) to connect, communicate, organize and engage in shared value creation, with little to no restrictions regarding location and time.

${ }^{2}$ Being self-proclaimed as a manifesto, concepts and explored phenomena are presented as they have been expressed through the pioneering social practice of $\mathrm{P} 2 \mathrm{P}$ and commons-oriented projects, and as they have been documented and interpreted in our multi-year interaction with them. As such, most of the terms used, including some neologisms, convey the spirit they carry forwards from this interaction. Nevertheless, we strive for a critical and historically-informed approach, acknowledging how social and political struggles are reflected in ideas expressed through words. Especially in times of dynamic reconfigurations, concepts often break away from their 
accustomed substance, the latter being itself an object of political struggle. Our focus then is on the substance, and particularly on the way it is conceived in common sense. Except for a few neologisms (e.g. 'transvestment'), which are potent for what they are, our primary concern is not conceptual clarity and accuracy, but the intensification of this endeavour to create a new meaning for words that can mobilize, inspire and engage.

${ }^{3}$ Bollier's definition encapsulates both Elinor Ostrom's (1990) and Yochai Benkler's (2006) definitions. He thus offers a more inclusive understanding of the commons.

${ }^{4}$ At the time of this writing, not much work has been published about the 'transvestment' concept. More information can be found at http://wiki.p2pfoundation.net/Transvestment. Moreover, in early 2019 we will engage in a thorough study and discussion of the concept that will be included in the aforementioned wiki entry.

${ }^{5}$ Our point of view is primarily West-centric, as the most broadly documented cases are from the global North, though this does not necessarily mean that $\mathrm{P} 2 \mathrm{P}$ is solely a western phenomenon. There are several examples of commoning documented in Bollier and Helfrich (2015) across different cultures and times. Also, many interesting cases of $\mathrm{P} 2 \mathrm{P}$ practices are encountered in developing countries, which are rooted in local traditional culture, such as community forestry practices in Bhutan (Moktan, Norbu and Choden 2016), India and Nepal (Agrawal and Ostrom, 2001) or the Nepali community-based cooperatives 'Ghuti' (Toffin, 2005). Our intention is to further expand this research with more inclusive perspectives, though being westerners ourselves we need to develop an adequate understanding of the local context.

6 This section is based on Pazaitis et al. (2017b).

7 This section is based on Alex Pazaitis's working paper tentatively titled 'Capturing Value from Open Innovation: The Case of Sensorica'.

${ }^{8}$ For an extended treatment of generative forms of ownership and governance, which are contrasted with extractive forms, see Kelly (2012).

9 In addition to 'cognitive capitalism', there are other competing terms such as informational capitalism, communicative capitalism or digital capitalism. It is out of the scope of this book to discuss these terms that describe more or less the same phenomenon. We use the term of 'cognitive capitalism' because it is more often used in the literature.

${ }^{10}$ We should be aware of Federici's and Caffentzis' remark $(2007,70)$ that notions like 'cognitive labor' and 'cognitive capitalism' represent 'a part, though a leading one, of capitalist development and that different forms of knowledge and cognitive work exist that cannot be flattened under one label'.

11 The concept and practice of cooperative accumulation is detailed and discussed by Mike Lewis in an email discussion of September 2013, which is recorded at: https://wiki.p2pfoundation.net/Cooperative_Accumulation. 
${ }^{12}$ In this book we discuss about systemic transitions in the sense of transformations in the political economy. Our focus is thus on the economic and institutional level. We acknowledge the limitations of this approach, which disregards changes that take place on other levels, such as the cultural, cognitive or spiritual one, while some mild techno-determinism is to be recognized. Nevertheless, we attempt to address the central institutions of the economic and political organization alongside the emergence of new technological capabilities to offer a cohesive basis for more in-depth explorations integrating other levels. From a broader perspective, what is new and what is old is highly contested and depends on the level of organization of the society in question. Different institutional configurations distinguish the new from the old and the emerging from the dominant or established. In the Hegelian view of history, a new form of society will encapsulate and sublate the constituents of the previous ones. Likewise, those who envision a new form of society, engage in the political action of transcending the progressive elements of the old order, while creating a new perspective to distil them.

${ }^{13}$ For a detailed overview see Bauwens and Niaros (2017b).

${ }^{14}$ See David Ronfeldt's discussion about the Champer of the Commons here: http://wiki.p2pfoundation.net/Chamber_of_the_Commons.

15 The European Commons Assembly (https://europeancommonsassembly. $\mathrm{eu}$ ) and the Alliance of the Commons in Greece (https://commons.gr/ about_en/) are examples of such an idea. Similar efforts have been taking place in Ghent, Belgium, and in Toulouse, France (http://wiki.p2pfoundation.net/Assembly_of_the_Commons).

16 See De Moor, 2008; 2013; Creative Commons, 2017; Bollier, 2014 a.

17 For a detailed account of the sustainability potential of commons-based peer production see Piques, Rizos and Bauwens (2017) and Kostakis et al. (2017). 



\section{Index}

A

Aristotle 13

B

Benkler, Yochai $\quad 3,4,11,86$

Bollier, David 3, 41, 86

C

Capitalism

capitalist market vii, $28,48,49$, $50,59,64,68$

cognitive vii, 36,86

distributed $36,37,38$

extractive vii, $16,18,21,35,36$, $38,39,53,64,67,86$

industrial 11,47

neoliberal 40

neoliberalism 70

netarchical 37

Capital-oriented organizations and projects
Airbnb 18, 37

Bitcoin 2, 6, 37, 38

Facebook 2, 6, 18, 37, 80

Kickstarter 37

TaskRabbit 37

Uber $6,18,37$

Commons

associationism vii, 49, 50, 53

commoning $3,19,50,86$

commons-based peer

production vii, $6-8,11$,

$12,14,15,16,18,19,23,29$,

$30,31,37,39,41,42,51,52$,

$56-60,64,70,75,76,84,87$

digital $3,7,11,16,19,23,39,40$, $41,49,50,56,57,59,62,64,67$

economy $14,15,61,67$

entrepreneurial coalitions 7,17 , $18-21,24,26,40,42,51,64$, $65,66,68$

for-benefit associations $15,18,19$, $20,21,24,26,51$ 
generative vii, 1, 16, 18, 28, 35, K

$36,39,56,59,63-66,86$

heterarchy vii, 12

Karatani, Kojin $\quad 47-50,53$

P2P production. See commonsbased peer production

peer production. See commonsbased peer production

productive communities 12,15 ,

$16,18-21,23,25,26,37,42$,

$51,58,59,68$

society vii, $2,7,33,40,52,64,67$

stigmergy 12

Commons-oriented organizations and projects

Apache 4, 11

Enspiral $\quad 6,7,19,20,21,27,28$, 66,82

Fairbnb 65

Farm Hack $\quad 6,11,19,25-29,40$, 41

Linux 11, 39, 78

Mozilla 11

MuniRide 65

Open Source Ecology 41

Procomuns 61

RepRab 11, 40, 41

Sensorica $7,19,21-23,28,29,58$, 66, 86

WikiHouse $\quad 6,11,19,23,40,41$

Wikipedia $1,2,4,6,11,12,19,39$

Wordpress 11

Cooperativism

guild 57

open 57,68

platform 57

\section{D}

De Moor, Tine 56

Dyer-Witheford, Nick 69

F

Fuchs, Christian $\quad 13,14,41$

\section{M}

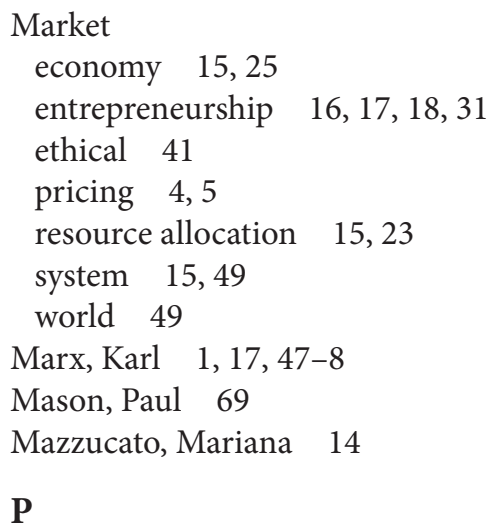

Polanyi, Karl $\quad 15,50-1$

Property

copyfair $\quad 64,68$

GNU General Public License 2

Peer Production License 64

pooling $3,29,48,49,51,56,58,68$

reciprocity licensing $\quad 64,68$

state 58

$\mathbf{R}$

Resilience

community-supported agriculture 58

degrowth 31,40

localization 39, 40

permaculture 18,39

Rifkin, Jeremy 69

S

State

market 52

partner $41,52,56,58,59$

Schumpeter, Joseph A. 17

Sombart, Werner 14 
T

Technologies

blockchain 37

digital fabrication 23,61

free and open-source software 1 , $2,6,12,19,20,64$

P2P vii, 1, 3, 56

Technology

information and communication 3

V

Value

added value $7,16,18,59$ creation vii, $1,7,8,11,12,14,18$, $19,42,85$

crisis 14

exchange-value $12-15,30$

extract 37

labour theory of 13-15, 30

surplus value $5,13,14,17,57,69$

transvestment $7,28,30,52,67$, 68,86

use-value $11-13,15,16$

value regime $7,14,15,30,70$

value sovereignty 15

W

Wright, Erik Olin 55 


\section{PEER TO PEER: THE COMMONS MANIFESTO}

$\mathrm{N}$ ot since Marx identified the manufacturing plants of Manchester as the blueprint for the new capitalist society has there been a more profound transformation of the fundamentals of our social life.

As capitalism faces a series of structural crises, a new social, political and economic dynamic is emerging: peer to peer.

What is peer to peer? Why is it essential for building a commons-centric future? How could this happen? These are the questions this book tries to answer. Peer to peer is a type of social relations in human networks, as well as a technological infrastructure that makes the generalization and scaling up of such relations possible. Thus, peer to peer enables a new mode of production and creates the potential for a transition to a commons-oriented economy.

SOCIAL THEORY | POLITICAL ECONOMY | ECONOMIC DEVELOPMENT

\section{THE AUTHORS}

Michel Bauwens is the Founder of the P2P Foundation and works in collaboration with a global group of researchers in the exploration of commons-based peer production, governance, and property.

Vasilis Kostakis is the Professor of P2P Governance at Tallinn University of Technology and Faculty Associate at Harvard University. He is the founder of the P2P Lab and core member of the P2P Foundation.

Alex Pazaitis is a Core Member of the P2P Lab and a Junior Research Fellow at the Ragnar Nurkse Department of Innovation and Governance, Tallinn University of Technology. 